\title{
Diffuse large B-cell Lymphoma and Multiple Myeloma in elderly patients
}

Citation for published version (APA):

van der Poel, MWM. (2018). Diffuse large B-cell Lymphoma and Multiple Myeloma in elderly patients: treatment-decision making and health-related quality of life. [Doctoral Thesis, Maastricht University]. Maastricht University. https://doi.org/10.26481/dis.20180525mp

Document status and date:

Published: 01/01/2018

DOI:

10.26481/dis.20180525mp

Document Version:

Publisher's PDF, also known as Version of record

\section{Please check the document version of this publication:}

- A submitted manuscript is the version of the article upon submission and before peer-review. There can be important differences between the submitted version and the official published version of record.

People interested in the research are advised to contact the author for the final version of the publication, or visit the DOI to the publisher's website.

- The final author version and the galley proof are versions of the publication after peer review.

- The final published version features the final layout of the paper including the volume, issue and page numbers.

Link to publication

\footnotetext{
General rights rights.

- You may freely distribute the URL identifying the publication in the public portal. please follow below link for the End User Agreement:

www.umlib.nl/taverne-license

Take down policy

If you believe that this document breaches copyright please contact us at:

repository@maastrichtuniversity.nl

providing details and we will investigate your claim.
}

Copyright and moral rights for the publications made accessible in the public portal are retained by the authors and/or other copyright owners and it is a condition of accessing publications that users recognise and abide by the legal requirements associated with these

- Users may download and print one copy of any publication from the public portal for the purpose of private study or research.

- You may not further distribute the material or use it for any profit-making activity or commercial gain

If the publication is distributed under the terms of Article $25 \mathrm{fa}$ of the Dutch Copyright Act, indicated by the "Taverne" license above, 


\section{Diffuse Large B-cell Lymphoma and Multiple Myeloma in elderly patients}

Treatment-decision making and health-related

quality of life 
(C) Marjolein van der Poel, Maastricht 2018

\author{
Layout: Tiny Wouters \\ Cover design: van Kira, www.vankira.nl \\ Production: Drukkerij Walters
}

ISBN: 978-90-828526-0-8 


\title{
Diffuse Large B-cell Lymphoma and Multiple Myeloma in elderly patients
}

Treatment-decision making and health-related

\author{
quality of life
}

\section{PROEFSCHRIFT}

ter verkrijging van de graad van doctor aan de Universiteit Maastricht, op gezag van de Rector Magnificus, Prof. dr. Rianne M. Letschert, volgens het besluit van het College van Decanen, in het openbaar te verdedigen op vrijdag 25 mei 2018 om 14.00 uur

door

Marjolein Wilhelmina Maria van der Poel 


\section{Promotores}

Prof. dr. H.C. Schouten

Prof. dr. L.V. van de Poll-Franse, Tilburg University (Tilburg), Nederlands

Kanker Instituut (Amsterdam) Intergraal Kankercentrum Nederland (Utrecht)

\section{Beoordelingscommissie}

Prof. dr. V.C.G. Tjan Heijnen, voorzitter

Prof. dr. J.W. Coebergh, Erasmus MC, Rotterdam

Dr. J.K. Doorduijn, Erasmus MC, Rotterdam

Prof. dr. C.D.A. Stehouwer 


\section{Contents}

$\begin{array}{lll}\text { Chapter } 1 & \text { Introduction } & 7\end{array}$

Chapter 2 Comorbidity and treatment decision-making in elderly 25

NHL patients: a survey among haematologists

Neth J Med 2014;72:165-9

Chapter 3 Factors that influence treatment decision-making in elderly

DLBCL patients: a case vignette study

Ann Hematol 2015;94:1373-9

Chapter 4 The impact of comorbidity on primary treatment with curative intent of elderly patients with diffuse large B-cell lymphoma: a nationwide study in the Netherlands

Chapter 5 Quality of life more impaired in younger than in older diffuse large B-cell lymphoma survivors compared to a normative population: A study from the populationbased PROFILES registry

Ann Hematol. 2014;93:811-9

Chapter 6 Elderly multiple myeloma patients experience less deterioration in health-related quality of life than younger patients compared to a normative population: A study from the population-based PROFILES registry

Ann Hematol 2015;94:651-61

Chapter 7 Summary and general discussion

Nederlandse samenvatting

Valorisation addendum

Dankwoord 

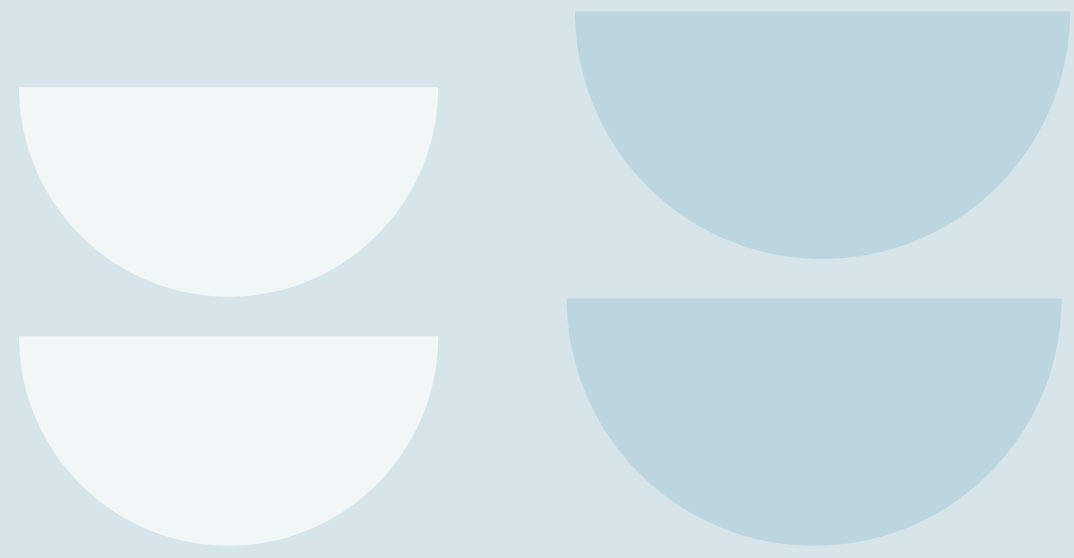


\section{Introduction}





\section{Hematological malignancies in the elderly}

Hematological malignancies comprise a diverse group of blood, bone marrow and lymph node cancers. These malignancies are classified according to the World Health Organisation (WHO) Classification of Tumours of Haematopoietic and Lymphoid Tissue 2017. ${ }^{1}$ According to the WHO, there a 15 categories of hematological malignancies, divided into myeloid and lymphoid neoplasms.

Except for Hodgkin lymphoma and acute lymphoblastic leukemia/lymphoma, the incidence of all hematological malignancies increases with advancing age. ${ }^{2}$ In the Netherlands, among patients aged 60 years and older the incidence of aggressive Non-Hodgkin lymphoma (NHL) and plasmacell neoplasms is the highest of all hematological malignancies. ${ }^{2}$ The most common subtype of aggressive NHL is Diffuse Large B-cell lymphoma (DLBCL) and among plasmacell neoplasms multiple myeloma $(\mathrm{MM})$ is the most frequent.

The care for elderly patients with hematological malignancies is challenging and treatment-decision making can be difficult. Advantaged and disadvantages of different treatment approaches have to be evaluated for each single patient. The focus in this thesis is set on treatment decision-making by hematologists and healthrelated quality of life in elderly patients with DLBCL and multiple myeloma.

\section{Diffuse large B-cell lymphoma in the elderly}

In the Netherlands, in 20121.727 new patients were diagnosed with aggressive $\mathrm{NHL}$ and this number is expected to increase to almost 2.000 patients in the year $2020 .^{3}$ Aggressive NHL especially occurs in elderly patients, with a mean age at diagnosis of 66 years and more than 50\% of patients being older than 64 years at time of diagnosis. ${ }^{4}$ More precisely, between 2007 and 2009, 25\% of all aggressive NHL patients were aged $65-74$ years, $23 \%$ were aged $75-84$ years and $6 \%$ of patients were 85 years or older. ${ }^{5}$ Since the incidence is highest among elderly patients and due to ageing of the population, the absolute number of elderly patients diagnosed with aggressive NHL will increase significantly.

Diffuse large B-cell lymphoma (DLBCL) is the most common subtype of aggressive Non-Hodgkin lymphomas. Standard treatment of DLBCL consists of combination immunochemotherapy with rituximab, cyclophosphamide, doxorubicin, vincristine and prednisone (R-CHOP). Randomised controlled trials (RCTs) demonstrated efficacy of R-CHOP in elderly DLBCL patients, showing increased rates of complete response and improved event-free survival (EFS) and OS with R-CHOP compared to $\mathrm{CHOP}$. $^{6-9}$

Although all these prospective trials do provide evidence for use of R-CHOP in elderly DLBCL patients, they merely included relatively young and fit elderly patients. The 
literature regarding frail elderly patients or very elderly patients is limited and there is a gap in knowledge on optimal treatment for these patient categories.

Although, based on results of RCTs, use of R-CHOP is advocated as standard treatment for elderly patients with $D L B C L$, in routine clinical practice elderly patients are frequently not treated with standard immunochemotherapy. ${ }^{10-15}$ Population-based studies demonstrated that only $33-70 \%$ of elderly lymphoma patients received this immunochemotherapy schedule. ${ }^{12,14,16}$ This reflects a reluctance to use intensive chemotherapy in this particular patient population. There is a fear for treatmentrelated complications as a result of poor performance status, comorbidity, polypharmacy, impaired nutritional status and impaired bone marrow reserves. ${ }^{10,12-15,17,18}$ Other motives for withholding therapy are refusal by patient or family. ${ }^{12,14}$ Moreover, the attitude of physicians towards treatment with chemotherapy in elderly patients is of concern, since high age in itself without a poor performance status is stated as a reason for suboptimal treatment. ${ }^{12-15}$ If the attitude towards treatment with chemotherapy in elderly patients changes and more attention is given to this patient category, more patients are treated with standard therapies. ${ }^{17}$ Population-based studies demonstrated not only that R-CHOP is withheld in a significant percentage of patients, but also that attenuated R-CHOP schedules are often administered. Elderly patients frequently received dose reductions from the first cycle and/or an incomplete number of cycles. ${ }^{12,14,16}$ The main arguments for incomplete chemotherapy were complications of treatment, patient decision, progressive disease and decline in performance status. ${ }^{12,16}$ The incidence of chemotherapy related toxicity was high, with up to $85 \%$ of patients experiencing toxicity. ${ }^{14,16,19}$ However, patients that were able to complete chemotherapy did have improved complete remission rates and survival compared to those with incomplete of suboptimal chemotherapy or those with palliative radiotherapy or supportive care. $^{10-12,14,16,18,19}$ The results of all these population-based studies emphasize the importance of complete R-CHOP treatment, also in the very elderly, with respect to survival. There is a clear decrease in survival with suboptimal treatment including fewer cycles of R-CHOP or other chemotherapy regimens than R-CHOP.

Studies showed that overall survival (OS) is improved in recent years for elderly DLBCL patients aged between 80 and 89 years and also for patients aged $>90$ years. ${ }^{20}$ However, the question is whether this improved OS is due to improved DLBCL management or due to general advances in medical care. The relative survival (RS), which can be interpreted as disease-specific survival, however, also appears to have improved in DLBCL patients, although this improvement is more pronounced in younger than in elderly patients. ${ }^{21}$ Indeed, another population-based study observed a significant improvement in RS in patients aged 80-84 years who were diagnosed in 2008-2015, and the application of rituximab accounted for the improvement. ${ }^{22}$ However, among patients aged $\geq 85$ years no improvement in RS was observed between patients diagnosed in 2008-2015 versus patients diagnosed in 1989-2002. 
Therefore, despite the introduction of new treatment modalities such as rituximab, outcome of elderly DLBCL patients is disappointing. In part, this might be explained by different biological characteristics between younger and older adults. In DLBCL the percentage of patients presenting with the activated B-cell like (ABC) subtype increases with age, and this subtype is associated with a poorer prognosis compared to the germinal center B-cell like (GBC) subtype DLBCL. ${ }^{23,24}$ Another explanation for the poorer survival in elderly DLBCL patients is the lower application of standard immunochemotherapy. Attempts to improve survival may focus on overcoming the poorer prognosis associated with the ABC subtype of DLBCL. Indeed, studies focused on improving survival in the elderly by intensifying treatment, for example with doseintensified R-CHOP or lenalidomide maintenance after R-CHOP. ${ }^{9,25}$ However, did not lead to improved OS and therefore, it remains questionable whether intensification of treatment is the way to go in the elderly, since this also introduces additional toxicity. Instead of focusing in treatment intensification, for which only fit elderly patients qualify, another important focus is selecting those elderly patients in whom the benefits of treatment outweigh the disadvantages of treatment.

\section{Multiple myeloma in the elderly}

More than $60 \%$ of patients diagnosed with multiple myeloma (MM) are 65 years or older and the mean age at diagnosis is 69 years. ${ }^{4}$ In the Netherlands, $31 \%$ of patients diagnosed with a plasma cell dyscrasia between 2007 and 2009 were 65-74 years old, $25 \%$ of patients were $75-84$ years old and $6 \%$ of patients was older than 84 . $^{5}$ Since the incidence of $\mathrm{MM}$ increases steadily with age, and due to ageing of the population, hematologists will increasingly be confronted with elderly patients with MM.

Treatment of multiple myeloma in younger, fit patients differs from treatment in elderly and unfit patients. Currently, the standard treatment for fit patients aged 65-70 years or younger is high dose chemotherapy followed by autologous stem cell transplantation. This improves progression-free and overall survival. ${ }^{26,27}$

There are a few studies showing that autologous stem cell transplant is also feasible in patients older than 65-70 years of age. ${ }^{28-31}$ However, in these studies a small number of fit elderly patients was included, with good performance status and no serious comorbidity and this highly selected population is not representative of the general population of elderly MM patients.

For patients aged older than 65-70 years high dose chemotherapy followed by autologous stem cell transplantation is considered to be unfeasible due to treatmentrelated toxicity. In this patient category treatment with melphalan and prednisone (MP) in combination with bortezomib (VMP) or the combination of lenalidomide with dexamethasone is considered standard treatment for newly diagnosed patients. VMP 
demonstrated to have a superior time to progression, overall response rate and overall survival compared to MP. ${ }^{32,33}$ The combination of lenalidomide and dexamethasone prolonged progression-free survival and overall survival compared to the combination of melphalan, prednisolone and dexamethasone. ${ }^{34}$ Also in population-based registries, the use of novel agents showed an improvement in survival in elderly patients ineligible for high dose chemotherapy and autologous stem cell transplant. 35,36

Although treatment with VMP or lenalidomide with dexamethasone is efficacious, discontinuation of therapy due to treatment-related toxicity is a serious risk in elderly patients. To prevent this, the Dutch Myeloma Working Group recommends dose adjustments for prednisone, melphalan, bortezomib and lenalidomide for patients older than 75 years and for those with comorbidity. The dose adjustments for bortezomib are based on prospective, but non-randomised trials. ${ }^{37,38}$ The dose adjustments for prednisone, melphalan and lenalidomide are based on expert opinion. $^{39-41}$

\section{Treatment decision-making and the role of comprehensive geriatric assessment}

The management of elderly patients with a hematological malignancy is complex. Treatment-decision making is difficult and for each individual the advantages and disadvantages of treatment should be weighed against each other. This complexity has several causes. First, elderly patients are in general underrepresented in clinical trials, due to direct age-based exclusion as well as due to other restrictive inclusion criteria. ${ }^{42,43}$ As a consequence, there is relatively little scientific evidence about the treatment of elderly patients with a hematological malignancy. Second, elderly patients comprise a highly heterogeneous group of variable fitness, from the very frail to the remarkably fit. The prevalence of comorbid conditions in elderly patients is high and increases with advancing age to respectively $75 \%$ and $72 \%$ (excluding hypertension) in patients diagnosed with aggressive $\mathrm{NHL}$ and plasmacell neoplasms aged 75 years and older. ${ }^{44}$ In this age category, especially cardiovascular diseases (prevalence 31-52\%), hypertension (prevalence 29-42\%) and prior malignancies (prevalence 13-21\%) are frequent and to a lesser extend pulmonary diseases (prevalence 7-17\%) and diabetes mellitus (prevalence 12-17\%). In addition, there is a varying degree of performance status and cognitive disorders. Therefore, treatment decisions cannot be made based solely on chronological age. The challenge is therefore to select those elderly patients in whom the benefits of an oncological treatment outweigh the disadvantages and the risk-to-benefit ratio of treatment will depend on multiple factors, among others performance status and comorbidity. In 
this context, in recent years there has been a growing interest in the role of the comprehensive geriatric assessment (CGA).

CGA is a multidimensional method to evaluate somatic, functional, mental and social parameters in the elderly. Also nutritional status and polypharmacy are frequently examined. The goal is to identify problems and to develop a plan for intervention based on the identified problems. ${ }^{45,46}$

Especially in the field of oncology trials analysing the role of CGA in treatmentdecision making have been performed. It appears that use of CGA results in the detection of more previously unknown problems than the physicians' judgment. ${ }^{47,48}$ Furthermore, the frequently used Karnofsky -and Eastern Cooperative Oncology Group (ECOG) performance scores do not always correspond with the actual functional status of the patient. Especially if there is a good performance score, frequently disorders are detected by CGA. ${ }^{49}$ Several studies observed that the results of CGA influenced the oncological treatment of patients. This included decisions to treat with more intensive as well as less intensive chemotherapy schedules. ${ }^{50-52}$ However, relatively small numbers of patients were included with different types of malignancies. Furthermore, it is not clear whether the decisions based on CGA influenced the prognosis with regard to treatment tolerability, survival or quality of life, since these trials were not designed as randomised interventional studies. At last, multiple studies observed an association between varying domains of CGA and treatment toxicity and survival. ${ }^{53-59}$ However, also these trials oftentimes included small numbers of patients and the exact method of CGA differed between the several trials.

Several trials focused specifically on the role of CGA in patients with aggressive B-cell lymphoma. It was observed that in elderly DLBCL patients identified by CGA as unfit or frail, outcome was not improved by treatment with curative intent versus palliative treatment. ${ }^{48,60,61}$ This was explained by lymphoma refractoriness and poor treatment tolerance. In two prospective studies, elderly DLBCL patients received tailored treatment, with patients receiving $\mathrm{R}-\mathrm{CHOP}$ modulated in dose and drugs according to CGA. $^{62,63}$ No major differences in grade 3 or 4 toxicities were observed between fit, unfit or frails patients. Interestingly, the CR rates and relapse rates were similar for fit, unfit and frail patients despite different treatment regimens. However, OS was better in fit patients than in unfit and frail patients. These studies advocate the use of adjusted therapy for unfit and frail patients. However, this could not be confirmed in a retrospective analysis, in which unfit DLBCL patients treated with anthracycline-based chemotherapy had a significantly better OS than unfit patients receiving palliative treatment. ${ }^{64}$ In addition, in a trial among patients older than 64 years outcome of frail elderly patients with DLBCL was evaluated. ${ }^{65}$ All patients underwent comprehensive geriatric assessment (CGA) and frail patients were assigned to treatment according to their physician's discretion. Compared to fit patients, frail patients had a poorer outcome even if there were treated with rituximab and anthracyclines-based 
immunochemotherapy. However, frail patients not treated with a rituximabcontaining regimen had a poorer outcome compared to frail patients that received rituximab.

Data on CGA in MM patients are sparse. The International Myeloma Working Group (IMWG) score consists of age, Activities of Daily Living (ADL), Instrumental Activities of Daily Living (IADL) and Charlson Comorbidity Index (CCI). ${ }^{66}$ This score was validated to split MM patients three groups with different OS and PFS, namely fit, intermediate-fit and frail patients. Also the revised Myeloma Comorbidity Index (R-MCI), which includes renal-, lung-, Karnofsky Performance Status-impairment, frailty, age and unfavourable cytogenetics, allowed identification of fit, intermediate-fit and frail MM patients. ${ }^{67}$ However, for both the IMWG- and the R-MCl score no prospective randomised trials have been performed in which treatment was modified according to this one of these scores.

In conclusion, a patient's health status is better determined by CGA than by clinical judgment, performance status or chronological age. ${ }^{68}$ However, its role is not clearly defined and there are no prospective interventional randomised trials that have proved the role of CGA in treatment-decision making. At the moment there is insufficient evidence for its routine use and therefore it has no role in daily clinical practice. This implies that there are no tools to guide treatment decision-making and therefore hematologists make treatment decisions by their clinical judgement of the patient's general health status.

\section{Randomised controlled trials, population-based studies and patient reported outcomes}

\section{Randomised controlled trials}

Randomised controlled trials (RCTs) are the gold standard to evaluate the efficacy of novel therapies and treatment guidelines are developed based on the results of RCTs. However, they do require patients to meet strict in -and exclusion criteria, and as a result in most RCTs the included patient population is highly selected. Treatment of elderly patients with hematological malignancies is mainly based on results of RCTs that included younger or fit elderly patients. Elderly patients are poorly represented in RCTs, due to age-based exclusion or due to strict in -and exclusion criteria, the latter leading to inclusion of fit and relatively young elderly patients. ${ }^{42,43}$ Therefore, the patient population included in RCTs is often not representative of the elderly patient population seen in routine clinical practice and consequently the results of RCTs are not generalizable. 


\section{Population-based studies}

Unlike RCTs, population-based observational studies are not restricted to strict in and exclusion criteria. Therefore, population-based registries offer an opportunity to study whether the results as observed in RCTs are applicable to the unselected patient population as seen in routine clinical practice. Also the incidence and survival of malignancies can be evaluated as well as guideline adherence. An important advantage of population-based studies is, that patient populations that are underrepresented in RCTs can be evaluated. Therefore, these studies are of particular interest in elderly patients.

\section{Patient-reported outcomes}

Most studies use traditional endpoints such as progression-free, disease-free and overall survival as primary and secondary outcome measures. Although evaluation of treatment efficacy with regards to these outcome measures is of importance, in recent years there is an increasing interest in evaluating patient-reported outcomes (PROs) as endpoints in clinical trials. A PRO is an outcome of a patient's health status, which is directly reported by the patient. Through measurement of PROs the impact of a disease or its treatment on those aspects of the patient's heath status only known to the patient itself can be evaluated. PRO measurement focuses on the patient perspective with regard to the effectiveness of a treatment. Examples of PRO measurements are symptoms (i.e. pain), functioning (i.e. carrying out activities of daily living) or health-related quality of life (HRQOL).

\section{Health-related quality of life}

HRQOL is increasingly considered as relevant outcome parameter in addition to traditional outcome measures. ${ }^{69}$ The purpose of measuring HRQOL is to quantify the impact of a medical condition and its treatment on the quality of life of a patient. It is a multidimensional concept that includes constructs or scales of physical and mental health as reported by the patient. ${ }^{70}$ Especially in the elderly this is of growing interest, since the balance between benefits and risks of a specific treatment is delicate. This balance is influenced by multiple factors, such as the goal of treatment (curative versus palliative) and expected side effects of treatment. In patients with hematological malignancies, HRQOL can be negatively affected by the disease itself or by the treatment.

In patients with DLBCL, the goal of treatment is curative. HRQOL in DLBCL can be influenced by lymphoma-related symptoms, such as rapidly enlarging lymph nodes or systemic B-symptoms (i.e., fever, weight loss or drenching night sweats). On the other hand, a major concern in the treatment of elderly DLBCL patients is that poorer treatment tolerability may lead to treatment-related toxicity. This in turn can also 
cause deterioration of HRQOL. Although patients and hematologists are willing to accept a certain degree of toxicity, concern about deterioration in HRQOL as a result of side effects might be a reason to withhold standard immunochemotherapy and this may be at the expense of disease-free survival.

In contrast to DLBCL, MM is an incurable disease. Therefore, treatment is palliative, aiming not only at prolonging survival, but also at controlling symptoms. Anemia, bone lesions, hypercalcemia and renal insufficiency can lead to symptoms in patients with $\mathrm{MM}$ and this can negatively influence HRQOL. Therefore, an important goal in MM treatment is preventing deterioration of HRQOL and improving HRQOL. However, treatment often is accompanied by side effects, and these in turn can also negatively impact HRQOL.

\section{Outline and aims of this thesis}

\section{Part I - Treatment-decision making}

The first part of this thesis (chapters 2,3, and 4) focuses on treatment-decision making by hematologists in elderly patients. More insight is gained into determinants that may influence treatment decision-making and the relationship between comorbidity and treatment with curative intent is investigated.

More specifically, chapters $\mathbf{2}$ and $\mathbf{3}$ address the influence of comorbidity, cognitive disorders and functional status on treatment-decision making by hematologists in elderly patients with a hematological malignancy. In addition, we investigated the frequency with which dose reductions in advance are applied and the frequency of refrainment from curative treatment because of expected toxicity. We also gained more insight into the extent with which patients are exclusively treated in clinical trials and the extent to which hematologists feel that treatment in the elderly is difficult due to a lack of scientific evidence.

We aimed to validate the findings as observed in chapter 2 and 3 in Chapter 4. Therefore, we performed a nationwide, population-based study to evaluate the primary treatment in elderly DLBCL patients. In addition, the association between socio-demographic and clinical variables, including comorbid conditions, and treatment with curative treatment as well as completing R-CHOP chemotherapy was evaluated.

\section{Part II - Health-related quality of life}

The second part (chapter $\mathbf{5}$ and $\mathbf{6}$ ) centres on HRQOL. The impact of being diagnosed with and treated for DLBCL or MM on the HRQOL of elderly patients is investigated. 
In Chapter 5 we investigated the impact of DLBCL and its treatment on HRQOL. To assess age-related differences three age categories were distinguished: survivors younger than 60 years, 60-75 years and those older than 75 years. Furthermore, we compared HRQOL of DLBCL survivors with $\mathrm{HRQOL}$ of an age -and sex matched normative population to distinguish between the impact of DLBCL on HRQOL and the impact of ageing itself on HRQOL.

In Chapter 6 the impact of MM and its treatment on HRQOL was examined. Since treatment in general differs between patients younger than 66 years versus patients of 66 years and older we compared HRQOL in patients of two age categories: those of 65 years and younger and those aged older than 65 years. Again, we compared HRQOL of MM patients with HRQOL in an age -and sex matched normative population to investigate the impact of $\mathrm{MM}$ on $\mathrm{HRQOL}$ beyond the natural impact of ageing on HRQOL.

Finally, in Chapter 7 the main findings of the studies presented in this thesis are discussed and the implications for health care and future research are addressed.

\section{Study populations}

For the studies described in Chapter $\mathbf{2}$ and $\mathbf{3}$ a questionnaire was designed comprising questions about various determinants that might play a role in treatment-decision making. Hematologists in the Netherlands were invited to complete the questionnaire on behalf of the Dutch-Belgian Cooperative Trial Group for Hemato-Oncology (HOVON). In addition, case vignettes of elderly DLBCL patients with varying age and extent of comorbidity were presented to the same haematologists.

Chapter 4 utilizes the nationwide population based Netherlands Cancer Registry (NCR) to evaluate the impact of comorbidity on primary treatment with curative intent in elderly DLBCL patients.

The studies described in Chapter 5 and $\mathbf{6}$ were conducted with data from the southern region of the NCR (previously known as Eindhoven Cancer Registry) of the Comprehensive Cancer Organisation Netherlands (IKNL). HRQOL data collection was conducted through PROFILES. CentERdata collected data on HRQOL from a normative population.

\section{The nationwide Netherlands cancer registry}

The Netherlands Cancer Registry (NCR) is maintained and hosted by the Netherlands Comprehensive Cancer Organisation (IKNL). In the NCR, newly diagnosed malignancies in the Netherlands are registered since 1989 and the overall coverage has been estimated to be at least $95 \% .^{71}$ The NCR is notified by the nationwide network and 
registry of histo- and cytopathology in the Netherlands (PALGA), as well as by the national registry of hospital discharges. Patient-, disease- and treatment-related characteristics are collected by trained registrars of the IKNL and are retrieved from the medical records. Since its establishment in 1989, the NCR registered primary treatment in broad categories. For patients diagnosed with a hematological malignancy as from January 1, 2014, more detailed data on diagnosis and treatment are registered in the NCR, such as type of comorbidity, and the exact type of (immuno)chemotherapy and number of treatment cycles. ${ }^{72}$

\section{The Eindhoven cancer registry}

The Southeastern region of the NCR, previously the Eindhoven Cancer Registry (ECR), started in 1955 and is part of the NCR since 1989. Data recorded by the ECR comprise disease characteristics including date of diagnosis, histology, disease stage and primary treatment, and socio-demographic characteristics including date of birth, sex and comorbidities. The ECR now covers an area with 2.4 million inhabitants, being referred to 10 general hospitals at 16 locations, with 6 pathology laboratories and 2 radiotherapy institutes.

\section{PROFILES}

PROFILES (Patient Reported Outcomes Following Initial treatment and Long term Evaluation of Survivorship) is a registry for the study of the physical and psychosocial impact of cancer and its treatment from a dynamic, growing population-based cohort of both short and long-term cancer survivors. ${ }^{70}$ It contains a large web-based component and is linked directly to clinical data from the ECR. HRQOL data of patients were collected through PROFILES.

\section{Normative population}

HRQOL data were also collected from a normative population. The normative population consists of over 2000 households, which are representative of the Dutchspeaking population in the Netherlands (CentERpanel). CentERdata, a research institute at Tilburg University, collected these data. ${ }^{73}$ 


\section{References}

1. Swerdlow SH, Campo E, Harris NL, et al. WHO Classification of Tumours of Haematopoietic and Lymphoid Tissues Lyon: IARC; 2017.

2. Intergraal Kankercentrum Nederland. http://www.cijfersoverkanker.nl. Accessed on January 2018.

3. Kanker in Nederland tot 2020. Trends en Prognoses. Signaliseringscommissie kanker van KWF kankerbestrijding, 2011.

4. Surveillance, Epidemiology, and End Results Program. http://seer.cancer.gov/statfacts/html/ mulmy.html.

5. Wymenga A CJ, Maas H, Schouten H. Handboek Kanker bij ouderen (in Dutch). De Tijdstroom, 2012.

6. Coiffier B, Lepage E, Briere J, et al. CHOP chemotherapy plus rituximab compared with $\mathrm{CHOP}$ alone in elderly patients with diffuse large-B-cell lymphoma. N Engl J Med 2002;346:235-42.

7. Feugier P, Van Hoof A, Sebban C, et al. Long-term results of the R-CHOP study in the treatment of elderly patients with diffuse large B-cell lymphoma: a study by the Groupe d'Etude des Lymphomes de l'Adulte. J Clin Oncol 2005;23:4117-26.

8. Pfreundschuh M, Schubert J, Ziepert M, et al. Six versus eight cycles of bi-weekly CHOP-14 with or without rituximab in elderly patients with aggressive CD20+ B-cell lymphomas: a randomised controlled trial (RICOVER-60). Lancet Oncol 2008;9:105-16.

9. Delarue $\mathrm{R}$, Tilly $\mathrm{H}$, Mounier $\mathrm{N}$, et al. Dose-dense rituximab-CHOP compared with standard rituximabCHOP in elderly patients with diffuse large B-cell lymphoma (the LNH03-6B study): a randomised phase 3 trial. Lancet Oncol 2013;14:525-33.

10. Thieblemont C, Grossoeuvre A, Houot R, et al. Non-Hodgkin's lymphoma in very elderly patients over 80 years. A descriptive analysis of clinical presentation and outcome. Ann Oncol 2008;19:774-9.

11. Diem S, Ess S, Cerny T, Fruh M, Hitz F. Diffuse large B-cell lymphoma in elderly patients: a retrospective analysis. Eur J Intern Med 2014;25:577-82.

12. Varga C, Holcroft C, Kezouh A, et al. Comparison of outcomes among patients aged 80 and over and younger patients with diffuse large B-cell lymphoma: a population based study. Leuk Lymphoma 2014;55:533-7.

13. Peters FP, Lalisang RI, Fickers MM, et al. Treatment of elderly patients with intermediate- and highgrade non-Hodgkin's lymphoma: a retrospective population-based study. Ann Hematol 2001;80: 155-9.

14. van de Schans SA, Wymenga AN, van Spronsen DJ, Schouten HC, Coebergh JW, Janssen-Heijnen ML. Two sides of the medallion: poor treatment tolerance but better survival by standard chemotherapy in elderly patients with advanced-stage diffuse large B-cell lymphoma. Ann Oncol 2012;23:1280-6.

15. Hasselblom S, Stenson M, Werlenius O, et al. Improved outcome for very elderly patients with diffuse large B-cell lymphoma in the immunochemotherapy era. Leuk Lymphoma 2012;53:394-9.

16. Boslooper K, Kibbelaar R, Storm H, et al. Treatment with rituximab, cyclophosphamide, doxorubicin, vincristine and prednisolone is beneficial but toxic in very elderly patients with diffuse large B-cell lymphoma: a population-based cohort study on treatment, toxicity and outcome. Leuk Lymphoma 2014;55:526-32.

17. Peters FP, Fickers MM, Erdkamp FL, Wals J, Wils JA, Schouten HC. The effect of optimal treatment on elderly patients with aggressive non-Hodgkin's lymphoma: more patients treated with unaffected response rates. Ann Hematol 2001;80:406-10.

18. Tien YY, Link BK, Brooks JM, Wright K, Chrischilles E. Treatment of diffuse large B-cell lymphoma in the elderly: regimens without anthracyclines are common and not futile. Leuk Lymphoma 2015;56:65-71.

19. Bairey O, Benjamini O, Blickstein D, Elis A, Ruchlemer R. Non-Hodgkin's lymphoma in patients 80 years of age or older. Ann Oncol 2006;17:928-34.

20. Giri U, Martin GM. Survival outcomes in the very elderly with DLBCL prior to and after the introduction of rituximab: a US populaton-based study. Blood Advances 2017;1:615-8.

21. Issa DE, van de Schans SA, Chamuleau ME, et al. Trends in incidence, treatment and survival of aggressive B-cell lymphoma in the Netherlands 1989-2010. Haematologica 2015;100:525-33. 
22. Dinmohamed AG, Issa DE, van der Poel MWM, et al. Treatment and relative survival in very elderly patients with DLBCL in The Netherlands: a population-based study, 1989 to 2015 Blood Advances 2017;1:1839-41.

23. Rosenwald A, Wright G, Chan WC, et al. The use of molecular profiling to predict survival after chemotherapy for diffuse large-B-cell lymphoma. N Engl J Med 2002;346:1937-47.

24. Mareschal S, Lanic H, Ruminy P, Bastard C, Tilly H, Jardin F. The proportion of activated B-cell like subtype among de novo diffuse large B-cell lymphoma increases with age. Haematologica 2011;96: 1888-90.

25. Thieblemont $\mathrm{C}$, Tilly $\mathrm{H}$, Gomes da Silva M, et al. Lenalidomide Maintenance Compared With Placebo in Responding Elderly Patients With Diffuse Large B-Cell Lymphoma Treated With First-Line Rituximab Plus Cyclophosphamide, Doxorubicin, Vincristine, and Prednisone. J Clin Oncol 2017;35:2473-81.

26. Attal M, Harousseau JL, Stoppa AM, et al. A prospective, randomized trial of autologous bone marrow transplantation and chemotherapy in multiple myeloma. Intergroupe Francais du Myelome. N Engl J Med 1996;335:91-7.

27. Child JA, Morgan GJ, Davies FE, et al. High-dose chemotherapy with hematopoietic stem-cell rescue for multiple myeloma. N Engl J Med 2003;348:1875-83.

28. Qazilbash MH, Saliba RM, Hosing C, et al. Autologous stem cell transplantation is safe and feasible in elderly patients with multiple myeloma. Bone Marrow Transplant 2007;39:279-83.

29. Badros A, Barlogie B, Siegel E, et al. Autologous stem cell transplantation in elderly multiple myeloma patients over the age of 70 years. Br J Haematol 2001;114:600-7.

30. Muta T, Miyamoto T, Fujisaki T, et al. Evaluation of the feasibility and efficacy of autologous stem cell transplantation in elderly patients with multiple myeloma. Intern Med 2013;52:63-70.

31. Garderet L, Beohou E, Caillot D, et al. Upfront autologous stem cell transplantation for newly diagnosed elderly multiple myeloma patients: a prospective multicenter study. Haematologica 2016; 101:1390-7.

32. San Miguel JF, Schlag R, Khuageva NK, et al. Bortezomib plus melphalan and prednisone for initial treatment of multiple myeloma. N Engl J Med 2008;359:906-17.

33. Mateos MV, Richardson PG, Schlag R, et al. Bortezomib plus melphalan and prednisone compared with melphalan and prednisone in previously untreated multiple myeloma: updated follow-up and impact of subsequent therapy in the phase III VISTA trial. J Clin Oncol 2010;28:2259-66.

34. Benboubker L, Dimopoulos MA, Dispenzieri A, et al. Lenalidomide and dexamethasone in transplantineligible patients with myeloma. N Engl J Med 2014;371:906-17.

35. Mey UJ, Leitner C, Driessen C, Cathomas R, Klingbiel D, Hitz F. Improved survival of older patients with multiple myeloma in the era of novel agents. Hematol Oncol 2016;34:217-23.

36. Pulte D, Jansen L, Castro FA, et al. Trends in survival of multiple myeloma patients in Germany and the United States in the first decade of the 21st century. Br J Haematol 2015;171:189-96.

37. Mateos MV, Oriol A, Martinez-Lopez J, et al. Bortezomib, melphalan, and prednisone versus bortezomib, thalidomide, and prednisone as induction therapy followed by maintenance treatment with bortezomib and thalidomide versus bortezomib and prednisone in elderly patients with untreated multiple myeloma: a randomised trial. Lancet Oncol 2010;11:934-41.

38. Bringhen S, Larocca A, Rossi D, et al. Efficacy and safety of once-weekly bortezomib in multiple myeloma patients. Blood 2010;116:4745-53.

39. Engelhardt $M$, Terpos $E$, Kleber $M$, et al. European Myeloma Network recommendations on the evaluation and treatment of newly diagnosed patients with multiple myeloma. Haematologica 2014; 99:232-42.

40. Mehta J, Cavo M, Singhal S. How I treat elderly patients with myeloma. Blood 2010;116:2215-23.

41. Palumbo A, Bringhen S, Ludwig $\mathrm{H}$, et al. Personalized therapy in multiple myeloma according to patient age and vulnerability: a report of the European Myeloma Network (EMN). Blood 2011; 118:4519-29.

42. Talarico L, Chen G, Pazdur R. Enrollment of elderly patients in clinical trials for cancer drug registration: a 7-year experience by the US Food and Drug Administration. J Clin Oncol 2004;22: 4626-31. 
43. Bellera C, Praud D, Petit-Moneger A, McKelvie-Sebileau P, Soubeyran P, Mathoulin-Pelissier S. Barriers to inclusion of older adults in randomised controlled clinical trials on Non-Hodgkin's lymphoma: a systematic review. Cancer Treat Rev 2013;39:812-7.

44. Lowenberg B, Ossenkoppele GJ, Blijlevens NMA, Leebeek FWG, Zweegman S. Klinische epidemiologie van bloed -en lymfeklierkanker in Nederland. Leerboek Hematologie (in Dutch) 2015;Chapter 22: 368-9.

45. Ellis G, Whitehead MA, Robinson D, O'Neill D, Langhorne P. Comprehensive geriatric assessment for older adults admitted to hospital: meta-analysis of randomised controlled trials. BMJ 2011;343: d6553.

46. Extermann M, Hurria A. Comprehensive geriatric assessment for older patients with cancer. J Clin Oncol 2007;25:1824-31.

47. Wedding U, Kodding D, Pientka L, Steinmetz HT, Schmitz S. Physicians' judgement and comprehensive geriatric assessment (CGA) select different patients as fit for chemotherapy. Crit Rev Oncol Hematol 2007;64:1-9.

48. Tucci A, Ferrari S, Bottelli C, Borlenghi E, Drera M, Rossi G. A comprehensive geriatric assessment is more effective than clinical judgment to identify elderly diffuse large cell lymphoma patients who benefit from aggressive therapy. Cancer 2009;115:4547-53.

49. Repetto L, Fratino L, Audisio RA, et al. Comprehensive geriatric assessment adds information to Eastern Cooperative Oncology Group performance status in elderly cancer patients: an Italian Group for Geriatric Oncology Study. J Clin Oncol 2002;20:494-502.

50. Girre V, Falcou MC, Gisselbrecht M, et al. Does a geriatric oncology consultation modify the cancer treatment plan for elderly patients? J Gerontol A Biol Sci Med Sci 2008;63:724-30.

51. Horgan AM, Leighl NB, Coate L, et al. Impact and feasibility of a comprehensive geriatric assessment in the oncology setting: a pilot study. Am J Clin Oncol 2012;35:322-8.

52. Chaibi P, Magne N, Breton S, et al. Influence of geriatric consultation with comprehensive geriatric assessment on final therapeutic decision in elderly cancer patients. Crit Rev Oncol Hematol 2011;79:302-7.

53. Maione P, Perrone F, Gallo C, et al. Pretreatment quality of life and functional status assessment significantly predict survival of elderly patients with advanced non-small-cell lung cancer receiving chemotherapy: a prognostic analysis of the multicenter Italian lung cancer in the elderly study. J Clin Oncol 2005;23:6865-72.

54. Clough-Gorr KM, Stuck AE, Thwin SS, Silliman RA. Older breast cancer survivors: geriatric assessment domains are associated with poor tolerance of treatment adverse effects and predict mortality over 7 years of follow-up. J Clin Oncol 2010;28:380-6.

55. Aaldriks AA, Maartense E, le Cessie S, et al. Predictive value of geriatric assessment for patients older than 70 years, treated with chemotherapy. Crit Rev Oncol Hematol 2011;79:205-12.

56. Wedding U, Rohrig B, Klippstein A, Fricke HJ, Sayer HG, Hoffken K. Impairment in functional status and survival in patients with acute myeloid leukaemia. J Cancer Res Clin Oncol 2006;132:665-71.

57. Aaldriks AA, Giltay EJ, Nortier JW, et al. Prognostic significance of geriatric assessment in combination with laboratory parameters in elderly patients with aggressive non-Hodgkin lymphoma. Leuk Lymphoma 2015;56:927-35.

58. Park S, Hong J, Hwang I, et al. Comprehensive geriatric assessment in elderly patients with newly diagnosed aggressive non-Hodgkin lymphoma treated with multi-agent chemotherapy. J Geriatric Oncol 2015;6:470-8.

59. Winkelmann N, Petersen I, Kiehntopf M, Fricke HJ, Hochhaus A, Wedding U. Results of comprehensive geriatric assessment effect survival in patients with malignant lymphoma. J Cancer Res Clin Oncol 2011;137:733-8.

60. Tucci A, Martelli M, Rigacci L, et al. Comprehensive geriatric assessment is an essential tool to support treatment decisions in elderly patients with diffuse large B-cell lymphoma: a prospective multicenter evaluation in 173 patients by the Lymphoma Italian Foundation (FIL). Leuk Lymphoma 2015;56:921-6.

61. Marchesi F, Cenfra N, Altomare L, et al. A retrospective study on 73 elderly patients (>/=75years) with aggressive B-cell non Hodgkin lymphoma: clinical significance of treatment intensity and comprehensive geriatric assessment. J Geriatric Oncol 2013;4:242-8. 
62. Spina M, Balzarotti M, Uziel L, et al. Modulated chemotherapy according to modified comprehensive geriatric assessment in 100 consecutive elderly patients with diffuse large B-cell lymphoma. Oncologist 2012;17:838-46.

63. Olivieri A, Gini G, Bocci C, et al. Tailored therapy in an unselected population of 91 elderly patients with DLBCL prospectively evaluated using a simplified CGA. Oncologist 2012;17:663-72.

64. Yoshida M, Nakao T, Horiuchi M, et al. Analysis of elderly patients with diffuse large B-cell lymphoma: aggressive therapy is a reasonable approach for 'unfit' patients classified by comprehensive geriatric assessment. Eur J Haematol 2016;96:409-16.

65. Merli F, Luminari S, Rossi G, et al. Outcome of frail elderly patients with diffuse large B-cell lymphoma prospectively identified by Comprehensive Geriatric Assessment: results from a study of the Fondazione Italiana Linfomi. Leuk Lymphoma 2014;55:38-43.

66. Engelhardt M, Dold SM, Ihorst G, et al. Geriatric assessment in multiple myeloma patients: validation of the International Myeloma Working Group (IMWG) score and comparison with other common comorbidity scores. Haematologica 2016;101:1110-9.

67. Engelhardt M, Domm AS, Dold SM, et al. A concise revised Myeloma Comorbidity Index as a valid prognostic instrument in a large cohort of 801 multiple myeloma patients. Haematologica 2017; 102:910-21.

68. Hamaker ME. The value of geriatric assessments in elderly patients with a haematological malignancy (in Dutch). NtvH 2014;11:3-8.

69. Ayanian JZ, Jacobsen PB. Enhancing research on cancer survivors. J Clin Oncol 2006;24:5149-53.

70. van de Poll-Franse LV, Horevoorts N, van Eenbergen M, et al. The Patient Reported Outcomes Following Initial treatment and Long term Evaluation of Survivorship registry: scope, rationale and design of an infrastructure for the study of physical and psychosocial outcomes in cancer survivorship cohorts. Eur J Cancer 2011;47:2188-94.

71. Schouten LJ, Hoppener P, van den Brandt PA, Knottnerus JA, Jager JJ. Completeness of cancer registration in Limburg, The Netherlands. Int J Epidemiol 1993;22:369-76.

72. Dinmohamed AG, Huijgens PC, Brink $M$, et al. Het hemato-oncologieregister van de Nederlandse Kankerregistratie: verleden, heden en toekomst. NTvH 2017;14:55-63.

73. van de Poll-Franse LV, Mols F, Gundy CM, et al. Normative data for the EORTC QLQ-C30 and EORTCsexuality items in the general Dutch population. Eur J Cancer 2011;47:667-75. 


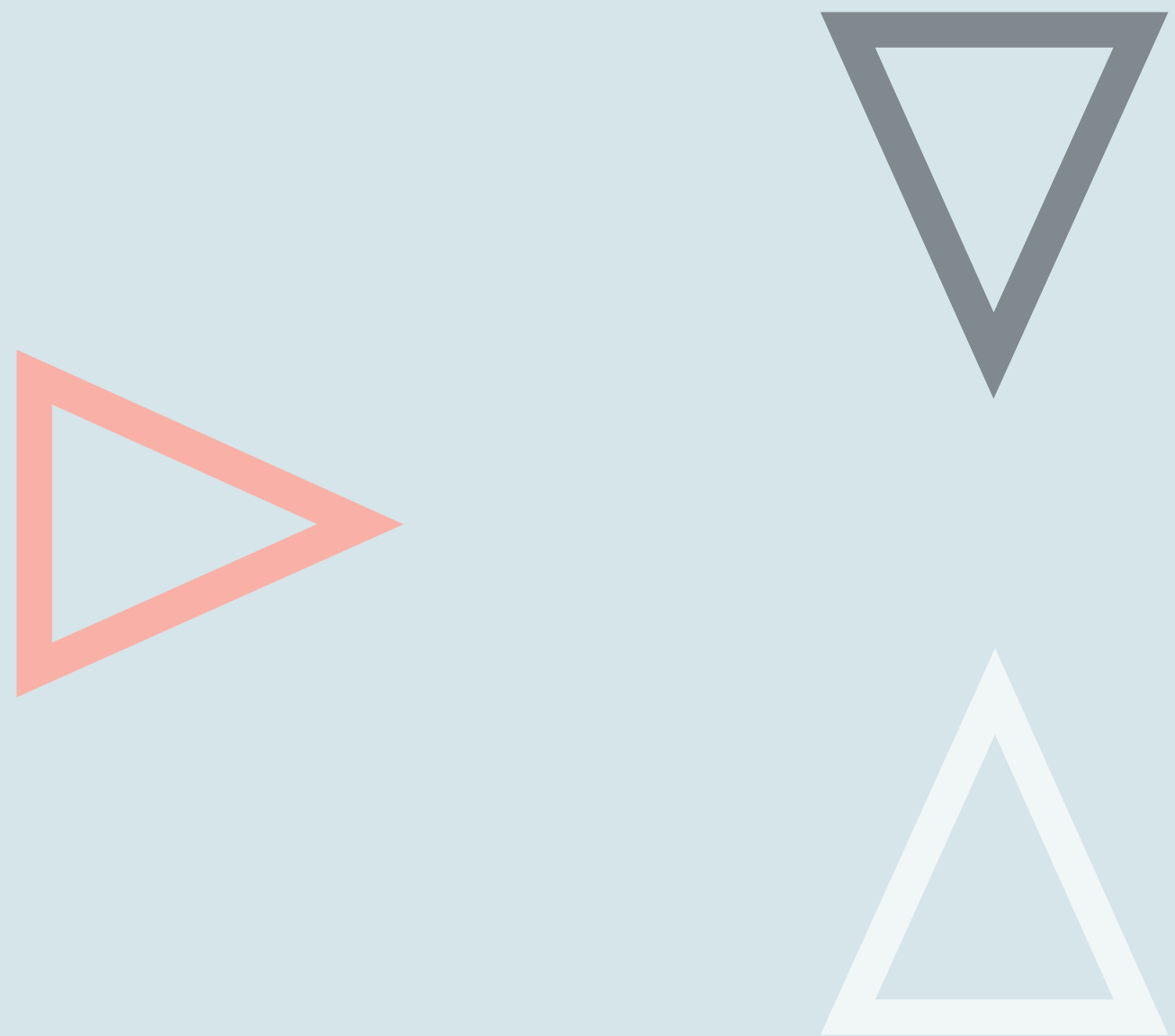


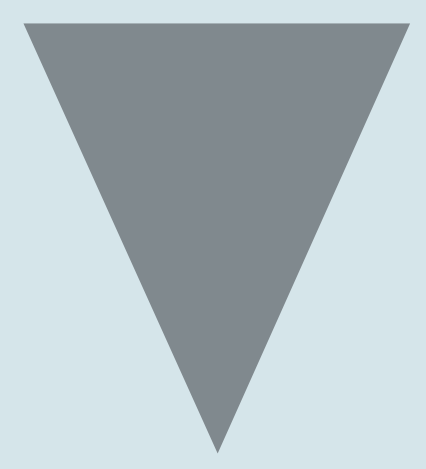

Comorbidity and treatment decision-making in elderly NHL patients: a survey among haematologists 


\section{Abstract}

\section{Background}

Elderly patients with non-Hodgkin lymphoma (NHL) are often not treated with standard immunochemotherapy and this might have a negative impact on their survival. Little is known about the determinants that play a role in treatment decision making of clinicians regarding elderly patients with NHL. The objective of this study was to gain more insight into these determinants.

\section{Methods}

A survey was conducted amongst haematologists in the Netherlands. The survey contained questions about comorbidity, polypharmacy, social setting, nutritional status, depression, mild cognitive impairment, dementia, activities of daily living (ADL) and instrumental activities of daily living (IADL) in relation to treatment decisions in elderly NHL patients.

\section{Results}

Of all comorbidities respondents designated cognitive disorders and cardiovascular comorbidity as the most important factors when assessing whether an older patient with NHL is eligible for curative treatment. Also in decreasing degree of importance ADL, IADL and depressive disorder are frequently included in treatment decision-making. Almost half of the respondents feel that treatment of the elderly is complicated as a result of a lack of scientific evidence.

\section{Conclusion}

Haematologists are aware of coexisting problems in elderly patients and they frequently take comorbidities, cognitive disorders and functional status into consideration in treatment decision-making. Future studies are needed to determine the exact role that these factors should play in the treatment of elderly patients. Furthermore, haematologists feel that treatment of the elderly is complicated and there is a lack of scientific evidence and therefore older adults should be better represented in clinical trials. 


\section{Introduction}

In 2007, 1.572 patients were diagnosed with aggressive non-Hodgkin lymphoma (NHL) in the Netherlands and it is expected that the incidence will increase to almost 1900 patients in the year 2020 due to ageing of the population and increasing incidence with advancing age. ${ }^{1}$ Currently, the median age at diagnosis is 66 years of age. ${ }^{2}$

Diffuse large B-cell lymphoma (DLBCL) is the most common subtype of aggressive NHL. The first choice of treatment for DLBCL is the rituximab, cyclophosphamide, doxorubicin, vincristin and prednisolone (R-CHOP) regimen. This improves complete remission rates and survival, in young as well as in elderly patients. ${ }^{3-12}$ However, treatment of elderly patients with aggressive $\mathrm{NHL}$ can be complicated because of additional factors such as comorbidity and polypharmacy. Furthermore, elderly patients are often under-represented in clinical trials and only relatively fit elderly patients are included. Therefore most evidence is based on a selection of patients. ${ }^{13,14}$ There are only a limited number of population-based studies with unselected elderly DLCBL patients. These also show that R-CHOP is associated with improved survival in comparison with other treatment strategies. ${ }^{9,12,15}$

Nevertheless, elderly NHL patients are often not being treated with standard immunochemotherapy. ${ }^{5-8,10,15}$ Motives for suboptimal treatment are amongst others poor performance status and comorbidity, but also high age in itself is declared by physicians as a reason for refraining from optimal treatment. ${ }^{5-8,15}$

Little is known about the determinants that might play a role in the decision making of clinicians regarding the eligibility of elderly patients with a haematologic malignancy to be treated with curative intent. Therefore, we conducted a survey among haematologists in the Netherlands to gain insight into these determinants. The emphasis was on DLBCL, as this type of aggressive NHL can be treated with curative intent.

\section{Methods}

\section{Data collection}

Haematologists were invited to complete the online questionnaire 'Treatment of the elderly with a haematologic malignancy' on behalf of the Dutch-Belgian Cooperative Trial Group for Haemato-Oncology (HOVON). HOVON is a foundation that focuses on improving and promoting treatment methods for adult patients with malignant haematologic disorders. ${ }^{16}$ Haematologists were invited to participate through e-mail in November 2011. Non-respondents were sent a reminder e-mail within two months. 


\section{Study measures}

The questionnaire contained questions about the importance of various factors that might play a role in the decision making of clinicians regarding treatment with curative intent in elderly patients. There were nine questions regarding comorbidities, polypharmacy, social setting and nutritional status. In addition, there were five items regarding depression, mild cognitive impairment, dementia, activities of daily living $(A D L)$ and instrumental activities of daily living (IADL). The application of chemotherapy dose reductions in advance and refraining of curative treatment in relation to toxicity was assessed. Furthermore, the respondents was asked to what extent they feel that treatment of older adults with haematologic malignancies is complicated because of a lack of scientific research and to what extent respondents exclusively treat elderly patients if they can be included in clinical trials. More detailed information about the survey is provided in Appendix 2.1.

Also the respondents' age and gender were assessed, as well as the type of hospital they work in. In the Netherlands, three types of hospitals can be discerned: university hospitals, tertiary medical teaching hospitals (STZ) and general hospitals. STZ hospitals are large teaching hospitals, where highly specialized care is provided. ${ }^{17}$

\section{Results}

Invitations to complete the questionnaire were sent to 255 haematologists. 94 questionnaires were returned (36.9\% response rate), of which 87 were fully completed and 7 were incomplete (Table 2.1). The mean age of the respondents at the time of survey was 49.6 years. There were more male than female respondents. $29.8 \%$ of the respondents worked at a university hospital, $33.0 \%$ at a STZ hospital and $37.2 \%$ at a general hospital.

Table 2.1 Socio-demographic characteristics of questionnaire respondents.

\begin{tabular}{lc}
\hline & $\begin{array}{c}\text { Respondents } \\
\mathbf{N}=94 \\
\mathbf{N}(\%)\end{array}$ \\
\hline Age at time of survey (mean $\pm \mathrm{SD})(\mathrm{N}=65)$ & $49.6(9.0)$ \\
Gender & $62(66,0)$ \\
Male & $32(34,0)$ \\
Female & \\
Type of hospital & $28(29,8)$ \\
University hospital & $31(33,0)$ \\
Tertiary medical teaching hospital & $35(37.2)$ \\
General hospital & \\
\hline
\end{tabular}


The two comorbidities that respondents designated as the most important when assessing if an elderly patient qualifies for a curative treatment intent (answer categories totally agree and agree combined) were cognitive disorders (99\%) and cardiovascular comorbidity (95.7\%) (Figure 2.1). Subsequently follow pulmonary comorbidity $(88.3 \%)$, nutritional status $(84.1 \%)$, social setting $(79.8 \%)$, kidney disease (70.2\%), mobility disorders (61.7\%), liver disease (57.4\%) and polypharmacy (57.4\%).

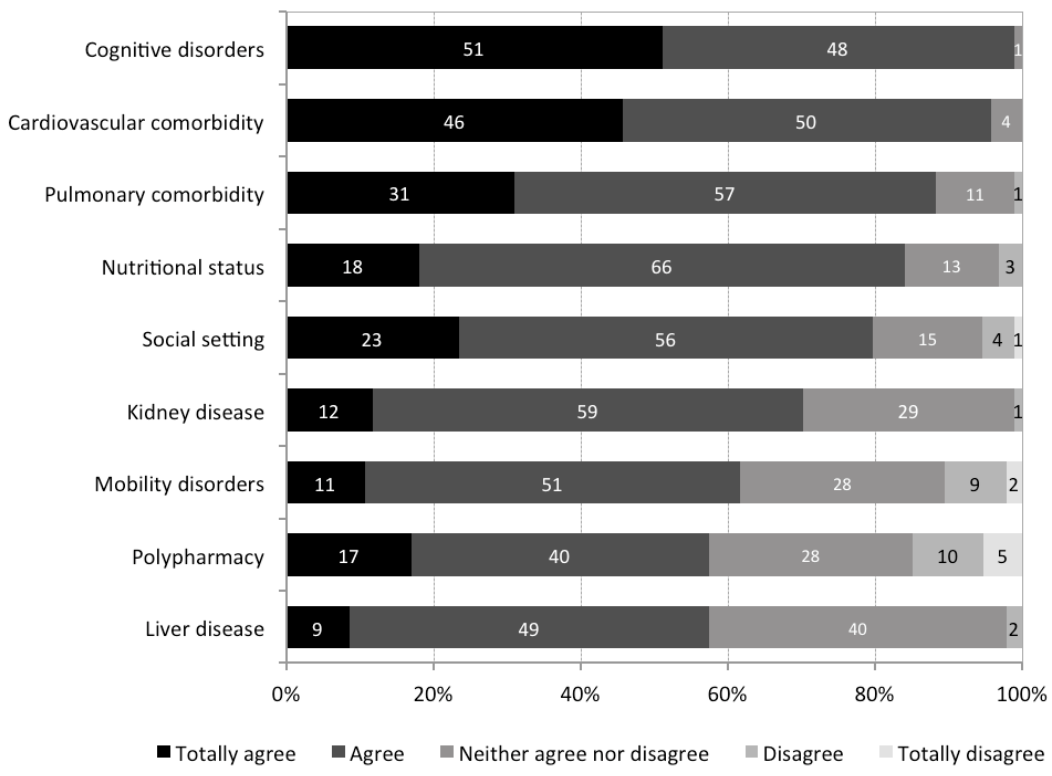

Figure 2.1 Extent to which hematologists agree that various determinants should be included in treatment decision-making in elderly patients with a hematologic malignancy.

Respondents frequently include dementia (89\%, answer categories always and often combined) and ADL (85.7\%) in treatment decision-making in elderly patients with a haematologic malignancy. IADL (69.4\%), depressive disorder (53.2\%) and mild cognitive impairment (41.3\%) are less often taken into account (Figure 2.2 ).

Twenty-three percent of the respondents oftentimes apply dose reductions in elderly patients to avoid estimated toxicity, while only $2.3 \%$ of respondents regularly refrain from treatment with curative intent for toxicity reasons (answer category 'Always' and 'Frequently' combined) (Table 2.2). Of the respondents $45.9 \%$ feel that treatment of the elderly is often hindered because there is too little scientific evidence. A minority of respondents $(10.3 \%)$ only treats elderly patients if they can be included in clinical trials. 


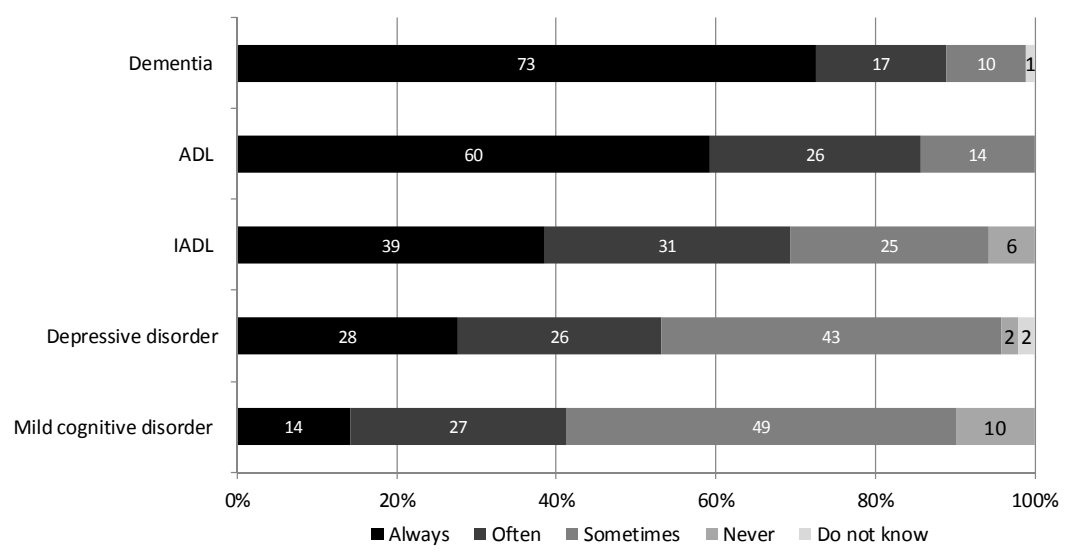

Figure 2.2 Frequencies with which respondents include dementia, ADL, IADL, depressive disorder and mild cognitive impairment in treatment decision-making in elderly patients with a haematologic malignancy.

Table 2.2 Haematologists' responses to questions regarding dose adjustments and toxicity, lack of scientific evidence and treatment in clinical trials in elderly patients with a haematologic malignancy.

\begin{tabular}{lccccc}
\hline & $\begin{array}{c}\text { Always } \\
\mathbf{N}(\%)\end{array}$ & $\begin{array}{c}\text { Frequently } \\
\mathbf{N ~ ( \% )}\end{array}$ & $\begin{array}{c}\text { Sometimes } \\
\mathbf{N}(\%)\end{array}$ & $\begin{array}{c}\text { Never } \\
\mathbf{N}(\%)\end{array}$ & $\begin{array}{c}\text { Do not know } \\
\mathbf{N}(\%)\end{array}$ \\
\hline $\begin{array}{l}\text { I apply dose reductions in advance in elderly } \\
\text { patients because of expected toxicity }\end{array}$ & $4(4,6)$ & $16(18,4)$ & $51(58,6)$ & $16(18,4)$ & $0(0,0)$ \\
$\begin{array}{l}\text { I refrain from curative treatment in elderly } \\
\text { patients because of expected toxicity } \\
\text { I feel treatment decision making in elderly } \\
\text { patients is complicated because there is a }\end{array}$ & $0(0,0)$ & $2(2,3)$ & $69(79,3)$ & $16(18,4)$ & $0(0,0)$ \\
$\begin{array}{l}\text { lack of scientific evidence } \\
\text { I treat elderly patients exclusively in clinical } \\
\text { trials }\end{array}$ & $0(0,0)$ & $93(37,9)$ & $36(41,4)$ & $11(12,6)$ & $0(0,0)$ \\
\hline
\end{tabular}

\section{Discussion}

The aim of the present study was to better understand the determinants that play a role in the decision-making of clinicians regarding treatment with curative intent of elderly patients with aggressive NHL.

Since the incidence of NHL rises with age, comorbidity is common in this patient population and the prevalence of comorbidity ranges from $35 \%$ to $79 \%$ in elderly $\mathrm{NHL}$ patients. ${ }^{18-22}$ Our study shows that haematologists are aware of this problem and that they frequently take comorbidity into consideration in treatment decisions. 
We observed that, in relation to comorbidity, haematologists found cognitive disorders and cardiovascular comorbidity the most important factors in treatment decision-making. Of the cognitive disorders, in particular dementia is often included in treatment decision-making and to a lesser extent mild cognitive impairment. In addition, respondents stated that they regularly take account of ADL, IADL and depressive disorders.

Several studies demonstrate an interrelationship between the presence of comorbidity and poorer complete remission rates, progression free survival and overall survival. ${ }^{10,18-21,23}$ Nevertheless, it is also observed that in the presence of comorbidity chemotherapy is less frequently applied or that the relative dose intensity is lower. ${ }^{19,20,22}$ This suboptimal therapy could also be an explanation for the poorer survival in the presence of comorbidity rather than comorbidity itself. On the other hand, however, there are also studies showing poorer survival in patients with comorbidity, where no relationship was found between comorbidity and chemotherapy dose reductions. ${ }^{10,21}$ With regard to cardiovascular comorbidity in particular, there are indications that in the presence of this the chance of being treated with chemotherapy is reduced and the risk of toxicity is increased. ${ }^{21}$ At last, in various studies a relation was observed between survival and nutritional status, cognition, frailty, IADL, ADL and depression, but this could not be confirmed in other studies. ${ }^{23-28}$ As a result of these inconsistent study results, the interpretation of coexisting diseases in elderly patients with regard to treatment consequences is complicated and more research in this field is necessary.

Interestingly, respondents state that they regularly take comorbidities, cognitive disorders, the patients' social setting, nutritional status, ADL, IADL and depression into consideration when making treatment decisions. However, in daily clinical practice rarely systematic assessments are carried out to identify problems in these areas, among others because this is time consuming. In general, the physicians' judgment is used to estimate whether there are additional problems, even though it is known that this is not very reliable. Comprehensive assessment results in the detection of a higher number of previously unknown geriatric problems than the physicians' judgment, although it is still not known how to adjust treatment decisions based on comprehensive geriatric assessments. ${ }^{29-33}$

Finally, a large proportion of the respondents feel that treatment of the elderly is difficult, because relatively little scientific research has been done among this population. Indeed, older adults are poorly represented in clinical trials, due to direct age-based exclusion as well as due to restrictive inclusion criteria, selecting for the fittest elderly. ${ }^{13,14}$ Since the majority of all DLBCL patients are elderly patients, it is important that they are better represented in randomized controlled trials so that treatment of this population can be improved.

The current study has some limitations. We did not define the term 'elderly patient', but left this to the interpretation of the respondent. Furthermore, we cannot exclude 
that haematologists with a special interest for elderly patients with NHL have responded. However, there are no direct indications for this.

The strengths of our study are that this is, to the best of our knowledge, the first study investigating the determinants that influence treatment decision-making. In addition, it is a multicenter study including haematologists of university hospitals as well as STZ hospitals and general hospitals and the participation rate of haematologists was high. Therefore we are confident that the results of our study are generalizable.

In conclusion, haematologists are well aware of coexisting problems in elderly patients and comorbidities, cognitive disorders and functional status are frequently included in treatment decisions. There is, however, no convincing evidence of the exact role comorbidity should play in the treatment of elderly NHL patients. Moreover, clinicians feel that treatment is complicated due to a lack of scientific evidence. Therefore, future studies should address this problem and older adults should be better represented in clinical trials, so that evidence based guidelines for the treatment of elderly patients with a haematologic malignancy can be developed. 


\section{References}

1. KWF kankerbestrijding SK. Kanker in Nederland tot 2020. Trends and Prognoses (in Dutch). http://www.kwfkankerbestrijding.nl.September 2011.

2. http://www.seer.cancer.gov. (Accessed August 23, 2013.

3. Coiffier B, Lepage E, Briere J, et al. CHOP chemotherapy plus rituximab compared with $\mathrm{CHOP}$ alone in elderly patients with diffuse large-B-cell lymphoma. N Engl J Med 2002;346:235-42.

4. Feugier P, Van Hoof A, Sebban C, et al. Long-term results of the R-CHOP study in the treatment of elderly patients with diffuse large B-cell lymphoma: a study by the Groupe d'Etude des Lymphomes de l'Adulte. J Clin Oncol2005;23:4117-26.

5. van de Schans SA, Wymenga AN, van Spronsen DJ, Schouten HC, Coebergh JW, Janssen-Heijnen ML. Two sides of the medallion: poor treatment tolerance but better survival by standard chemotherapy in elderly patients with advanced-stage diffuse large B-cell lymphoma. Ann Oncol 2012;23:1280-6.

6. Peters FP, Lalisang RI, Fickers MM, et al. Treatment of elderly patients with intermediate- and highgrade non-Hodgkin's lymphoma: a retrospective population-based study. Ann Hematol 2001;80: 155-9.

7. Thieblemont C, Grossoeuvre A, Houot R, et al. Non-Hodgkin's lymphoma in very elderly patients over 80 years. A descriptive analysis of clinical presentation and outcome. Ann Oncol 2008;19:774-9.

8. Peters FP, Fickers MM, Erdkamp FL, Wals J, Wils JA, Schouten HC. The effect of optimal treatment on elderly patients with aggressive non-Hodgkin's lymphoma: more patients treated with unaffected response rates. Ann Hematol 2001;80:406-10.

9. Lee L, Crump M, Khor S, et al. Impact of rituximab on treatment outcomes of patients with diffuse large b-cell lymphoma: a population-based analysis. Br J Haematol 2012;158:481-8.

10. Lin TL, Kuo MC, Shih LY, et al. The impact of age, Charlson comorbidity index, and performance status on treatment of elderly patients with diffuse large B cell lymphoma. Ann Hematology 2012;91: 1383-91.

11. Griffiths RI, Gleeson ML, Mikhael J, Dreyling MH, Danese MD. Comparative effectiveness and cost of adding rituximab to first-line chemotherapy for elderly patients diagnosed with diffuse large B-cell lymphoma. Cancer 2012;118:6079-88.

12. Boslooper K, Kibbelaar R, Storm H, et al. Treatment with rituximab, cyclophosphamide, doxorubicin, vincristine and prednisolone is beneficial but toxic in very elderly patients with diffuse large B-cell lymphoma: a population-based cohort study on treatment, toxicity and outcome. Leuk Lymphoma. 2014;55:526-32.

13. Talarico L, Chen G, Pazdur R. Enrollment of elderly patients in clinical trials for cancer drug registration: a 7-year experience by the US Food and Drug Administration. J Clin Oncol 2004;22: 4626-31.

14. Bellera C, Praud D, Petit-Moneger A, McKelvie-Sebileau P, Soubeyran P, Mathoulin-Pelissier S. Barriers to inclusion of older adults in randomised controlled clinical trials on Non-Hodgkin's lymphoma: A systematic review. Cancer Treat Rev 2013;39:812-7.

15. Varga C, Holcroft C, Kezouh A, et al. Comparison of outcomes among patients aged 80 and over and younger patients with diffuse large B cell lymphoma: a population based study. Leuk Lymphoma. 2014;55:533-7..

16. http://www.hovon.nl. (Accessed August 22, 2013,

17. http://www.stz.nl. (Accessed August 22, 2013. ,

18. van Spronsen DJ, Janssen-Heijnen ML, Breed WP, Coebergh JW. Prevalence of co-morbidity and its relationship to treatment among unselected patients with Hodgkin's disease and non-Hodgkin's lymphoma, 1993-1996. Ann Hematol 1999;78:315-9.

19. van Spronsen DJ, Janssen-Heijnen ML, Lemmens VE, Peters WG, Coebergh JW. Independent prognostic effect of co-morbidity in lymphoma patients: results of the population-based Eindhoven Cancer Registry. Eur J Cancer 2005;41:1051-7.

20. Kobayashi Y, Miura K, Hojo A, et al. Charlson Comorbidity Index is an independent prognostic factor among elderly patients with diffuse large B-cell lymphoma. J Cancer Res Clin Oncol 2011;137:1079-84. 
21. Janssen-Heijnen ML, van Spronsen DJ, Lemmens VE, Houterman S, Verheij KD, Coebergh JW. A population-based study of severity of comorbidity among patients with non-Hodgkin's lymphoma: prognostic impact independent of International Prognostic Index. Br J Haematol 2005;129:597-606.

22. Janssen-Heijnen ML, Houterman S, Lemmens VE, Louwman MW, Maas HA, Coebergh JW. Prognostic impact of increasing age and co-morbidity in cancer patients: a population-based approach. Crit Rev Oncol Hematol 2005;55:231-40.

23. Winkelmann N, Petersen I, Kiehntopf M, Fricke HJ, Hochhaus A, Wedding U. Results of comprehensive geriatric assessment effect survival in patients with malignant lymphoma. J Cancer Res Clin Oncol 2011;137:733-8.

24. Spina M, Balzarotti M, Uziel L, et al. Modulated chemotherapy according to modified comprehensive geriatric assessment in 100 consecutive elderly patients with diffuse large B-cell lymphoma. Oncologist 2012;17:838-46.

25. Nabhan C, Smith SM, Helenowski I, et al. Analysis of very elderly (>/=80 years) non-hodgkin lymphoma: impact of functional status and co-morbidities on outcome. $\mathrm{Br} \mathrm{J}$ Haematol 2012;156: 196-204.

26. Soubeyran P, Fonck M, Blanc-Bisson C, et al. Predictors of early death risk in older patients treated with first-line chemotherapy for cancer. J Clin Oncol 2012;30:1829-34.

27. Aaldriks AA, Maartense E, le Cessie S, et al. Predictive value of geriatric assessment for patients older than 70 years, treated with chemotherapy. Crit Rev Oncol Hematol 2011;79:205-12.

28. Mols F, Husson O, Roukema JA, van de Poll-Franse LV. Depressive symptoms are a risk factor for allcause mortality: results from a prospective population-based study among 3,080 cancer survivors from the PROFILES registry. J Cancer Surviv 2013;7:484-92.

29. Wedding U, Kodding D, Pientka L, Steinmetz HT, Schmitz S. Physicians' judgement and comprehensive geriatric assessment (CGA) select different patients as fit for chemotherapy. Crit Rev Oncol Hematol 2007;64:1-9.

30. Tucci A, Ferrari S, Bottelli C, Borlenghi E, Drera M, Rossi G. A comprehensive geriatric assessment is more effective than clinical judgment to identify elderly diffuse large cell lymphoma patients who benefit from aggressive therapy. Cancer 2009;115:4547-53.

31. Kenis $C$, Bron $D$, Libert $Y$, et al. Relevance of a systematic geriatric screening and assessment in older patients with cancer: results of a prospective multicentric study. Ann Oncol 2013;24:1306-12.

32. Horgan AM, Leighl NB, Coate L, et al. Impact and feasibility of a comprehensive geriatric assessment in the oncology setting: a pilot study. Am J Clin Oncol 2012;35:322-8.

33. Girre V, Falcou MC, Gisselbrecht M, et al. Does a geriatric oncology consultation modify the cancer treatment plan for elderly patients? J Gerontol A Biol Sci Med Sci 2008;63:724-30. 


\section{Appendix 2.1}

\section{Survey 'Treatment of the elderly with a haematologic malignancy'}

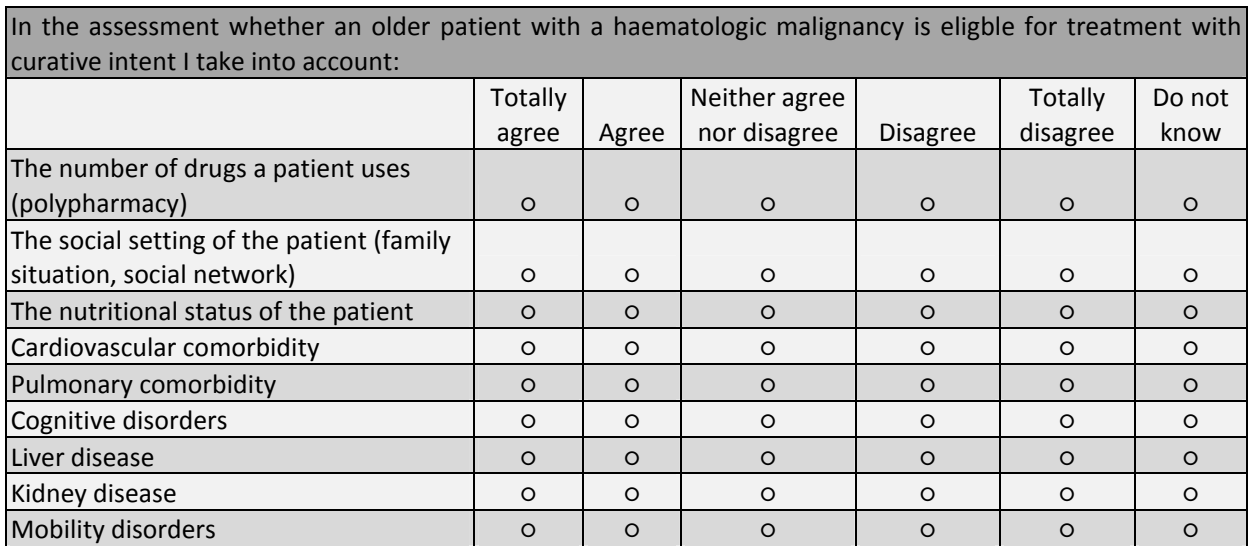

In the assessment whether an older patient with a haematologic malignancy is eligble for treatment with curative intent I take into account:

\begin{tabular}{|l|c|c|c|c|c|}
\hline & Always & Frequently & Sometimes & Never & Do not know \\
\hline Depressive disorder & $\circ$ & $\circ$ & $\circ$ & $\circ$ & 0 \\
\hline Mild cognitive impairment & $\circ$ & $\circ$ & $\circ$ & $\circ$ & $\circ$ \\
\hline Dementia & $\circ$ & $\circ$ & $\circ$ & $\circ$ & $\circ$ \\
\hline Activities of Daily Living & $\circ$ & $\circ$ & $\circ$ & $\circ$ & $\circ$ \\
\hline Instrumental Activities of Daily Living & $\circ$ & $\circ$ & $\circ$ & $\circ$ & $\circ$ \\
\hline
\end{tabular}

\begin{tabular}{|l|c|c|c|c|c|}
\hline \multicolumn{2}{|l|}{ Could you please give your opinion regarding the following statements: } \\
\hline & Always & Frequently & Sometimes & Never & Do not know \\
\hline $\begin{array}{l}\text { I apply dose reductions in advance in } \\
\text { elderly patients because of expected } \\
\text { toxicity }\end{array}$ & 0 & 0 & 0 & 0 & 0 \\
\hline $\begin{array}{l}\text { I refrain from curative treatment in } \\
\text { elderly patients because of expected } \\
\text { toxicity }\end{array}$ & 0 & 0 & 0 & 0 & 0 \\
\hline $\begin{array}{l}\text { I feel treatment decision making in } \\
\text { elderly patients is complicated because } \\
\text { there is a lack of scientific evidence }\end{array}$ & 0 & 0 & 0 & 0 & \\
\hline $\begin{array}{l}\text { I treat elderly patients exclusively in } \\
\text { clinical trials }\end{array}$ & 0 & 0 & 0 & 0 & 0 \\
\hline
\end{tabular}




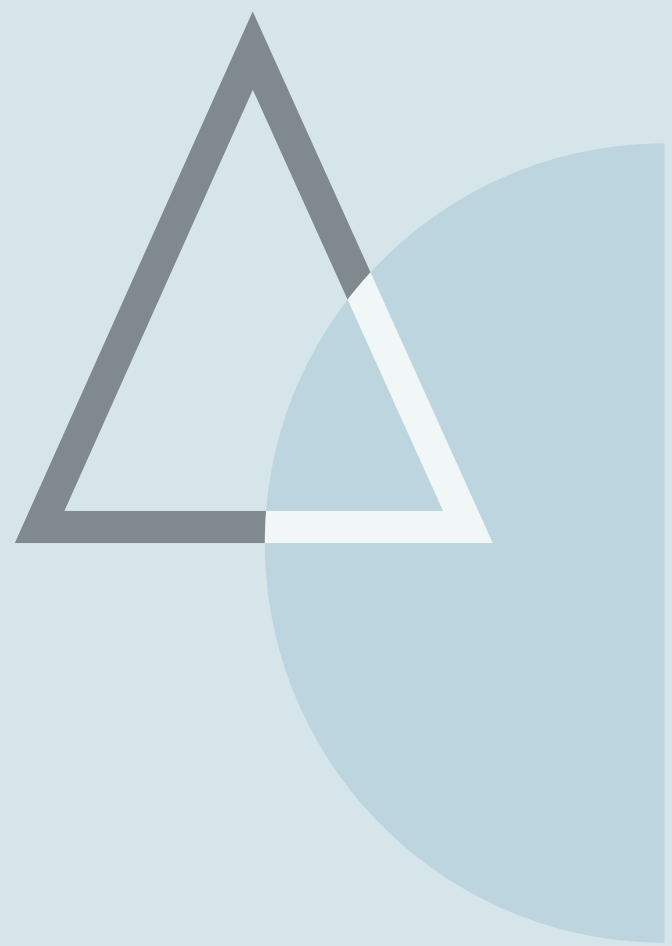




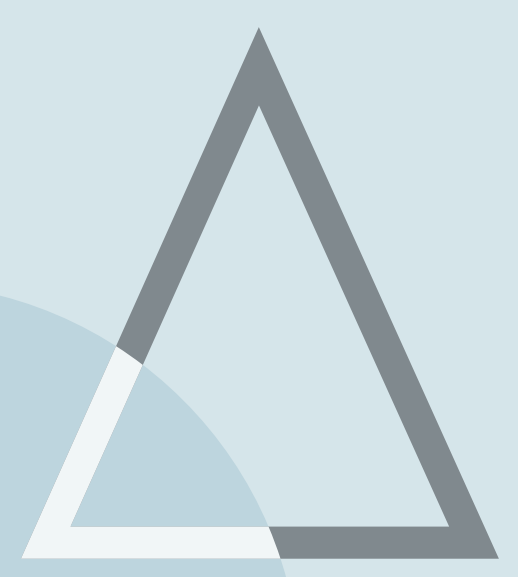

Factors that influence treatment decision-making in elderly DLBCL patients: a case vignette study

Ann Hematol 2015;94:1373-9 


\section{Abstract}

\section{Background}

Elderly patients with diffuse large B-cell lymphoma (DLBCL) are frequently not treated with standard immunochemotherapy and this influences survival negatively. The purpose of this study was to gain more insight into treatment decision-making by hematologists.

\section{Design}

Case vignettes concerning patients with DLBCL were presented to hematologists in the Netherlands. Patient characteristics (age, comorbidity) differed per case. Respondents were asked in each case if they would treat the patient with curative intent by means of full dose chemotherapy or chemotherapy with dose reduction or if they would not treat the patient with curative intent.

\section{Results}

The vast majority of respondents would treat an elderly patient diagnosed with DLBCL without a relevant medical history with full dose chemotherapy irrespective of age. In the presence of comorbidity, lack of social support, cognitive disorders and untreated depression dose reductions in advance are frequently applied or patients are not treated with curative intent. This is most pronounced for patients aged older than 80 years. Respondents working in a university hospital more frequently refrain from full dose chemotherapy with curative intent compared to respondents working in tertiary medical teaching hospitals or general hospitals.

\section{Conclusion}

Patients without a relevant medical history are generally treated with curative intent irrespective of age. Cognitive disorders, comorbidity and depression reduce the chance of being treated with curative intent. This is most prominent in the eldest patient category. 


\section{Introduction}

The incidence of non-Hodgkin lymphoma (NHL) increases with age and currently the mean age at diagnosis is 66 years. ${ }^{1}$ Diffuse large B-cell lymphoma (DLBCL) is the most common type of aggressive NHL. Due to ageing of the population, clinicians will increasingly be confronted with elderly patients diagnosed with DLBCL.

Standard treatment for patients with DLBCL consists of rituximab, cyclophosphamide, doxorubicin, vincristine and prednisolone (R-CHOP). Not only in younger, but also in elderly patients this treatment schedule improves complete remission rates and survival. $^{2-9}$ However, in daily practice elderly patients frequently do not receive standard immunochemotherapy treatment. ${ }^{4,7,9-12}$ Reasons for suboptimal treatment are comorbidity and poor performance status, but also high age alone is adduced as an argument to refrain from standard treatment. ${ }^{4,7,10-12}$

Little is known about the influence of patient characteristics on treatment decisionmaking by clinicians.

In a recent survey among hematologists we observed that comorbidities, cognitive disorders and functional status are frequently taken into consideration in treatment decision-making. ${ }^{13}$ In the second part of this survey, case vignettes of DLBCL patients with varying age and extent of comorbidity were presented to the respondents. By means of case vignettes, more information is gathered about decision-making in the daily clinical practice. Here we present the results of the second part of this survey.

\section{Methods}

\section{Data collection}

Hematologists were invited to complete the online questionnaire 'Treatment of the elderly with a hematologic malignancy' on behalf of the Dutch-Belgian Cooperative Trial Group for Hemato-Oncology (HOVON). HOVON is a foundation that focuses on improving and promoting treatment methods for adult patients with malignant hematologic disorders. ${ }^{14}$ Hematologists were invited to participate through e-mail in November 2011. Non-respondents were sent a reminder e-mail within two months.

\section{Study measures}

The questionnaire consisted of two parts. The first part contained questions about the importance of various factors that play a role in the decision-making of hematologists regarding treatment with curative intent in elderly patients. The results of this part were described previously. ${ }^{13}$ 
In the second part of the questionnaire case vignettes were presented to the respondents. The survey contained a total of 11 case vignettes. All cases concerned patients with $\mathrm{DLBCL}$, however the patient characteristics differed per case. In each case a distinction was made in three age categories: patients older than 60 years, older than 70 years and older than 80 years of age. Furthermore, the extent of comorbidity varied per case, ranging from no comorbidity to serious comorbid conditions. Also the social setting differed in the various cases, from living at home without additional care to living in a nursing home. More detailed information about the case vignettes is provided in Appendix 3.1. The respondents were asked in each case if they would treat the patient with curative intent by means of full dose chemotherapy or chemotherapy with dose reduction or if they would not treat the patient with curative intent.

In addition, the respondents' age and gender were assessed, as well as the type of hospital they work in. In the Netherlands, three types of hospitals can be discriminated: university hospitals, tertiary medical teaching hospitals and general hospitals. Tertiary medical teaching hospitals are large teaching hospitals, where highly specialized care is provided..$^{15}$ In the Netherlands 41 percent of hematologists work in university hospitals, 32 percent in tertiary medical teaching hospitals, 22 percent in general hospitals and in five percent of hematologists it is unknown.

\section{Results}

\section{Respondents' characteristics}

Invitations to complete the questionnaire were sent to 255 hematologists. Eighty-six respondents participated in the second part of the survey $(33,7 \%$ response rate). Eighty-three respondents fully completed the second part of the survey and three incomplete questionnaires were returned.

The mean age of the respondents at time of survey was 49.6 years (Table 3.1). There were more male than female respondents. Of the respondents, $26.7 \%$ worked in a university hospital, $36 \%$ in a tertiary medical teaching hospital and $37.2 \%$ of the respondents worked in a general hospital.

\section{Case vignettes: treatment according to age and comorbidity of patients}

The vast majority of respondents would treat an elderly patient diagnosed with DLBCL without a relevant medical history with full dose chemotherapy irrespective of age (Figure 3.1A). However, the percentage decreased from 100\% in "younger" patients to $83 \%$ in patients over 80 years old. 
Table 3.1 Socio-demographic characteristics of questionnaire respondents.

\begin{tabular}{lc}
\hline & $\begin{array}{c}\text { Respondents } \\
\mathbf{N}=\mathbf{8 6} \\
\mathbf{N}(\%)\end{array}$ \\
\hline $\begin{array}{l}\text { Age at time of survey (mean } \pm \mathrm{SD})(\mathrm{N}=60) \\
\text { Gender }\end{array}$ & $49.6(9.0)$ \\
Male & $56(65.1)$ \\
Female & $30(34.9)$ \\
Type of hospital & \\
University hospital & $23(26.7)$ \\
Tertiary medical teaching hospital & $31(36.0)$ \\
General hospital & $32(37.2)$ \\
\hline
\end{tabular}

In the presence of mild cognitive impairment the percentage of patients that would be treated with full dose chemotherapy decreased in all three age categories, although most patients would still be offered treatment with curative intent (Figure $3.1 \mathrm{~B}$ and $3.1 \mathrm{C}$ ). However, the decrease in treatment with curative intent was more pronounced in elderly patients compared to younger patients.

The majority of respondents would not treat a patient suffering from dementia with full dose chemotherapy, regardless of age category (Figure 3.1D and 3.1E). However, younger patients with dementia living at home with a good support system would generally receive chemotherapy with curative intent, while this was not the case in the oldest group of patients (Figure 3.1D). Regardless of age, a patient suffering from dementia and living in a nursing home would generally not receive treatment with curative intent (Figure 3.1E).

Respondents would not start full dose chemotherapy in patients with an untreated depression in the majority of cases irrespective of age category (Figure 3.1F). In general, if a depression was treated adequately, treatment was not precluded (Figure 3.1G).

Patients with a history of diabetes mellitus type 2, hypertension and myocardial infarction would be treated with curative intent by most of the respondents. However, the number of patients treated with full dose chemotherapy declined if there was no social support system or concomitant mild cognitive impairment (Figure $3.1 \mathrm{H}, 3.1 \mathrm{l}$ and $3.1 \mathrm{~J}$ ). In the event of significant comorbidity, most patients would be treated with curative intent by reduced dose chemotherapy, except for the oldest patient category, which frequently would not be treated with curative intent (Figure $3.1 \mathrm{~K})$. 


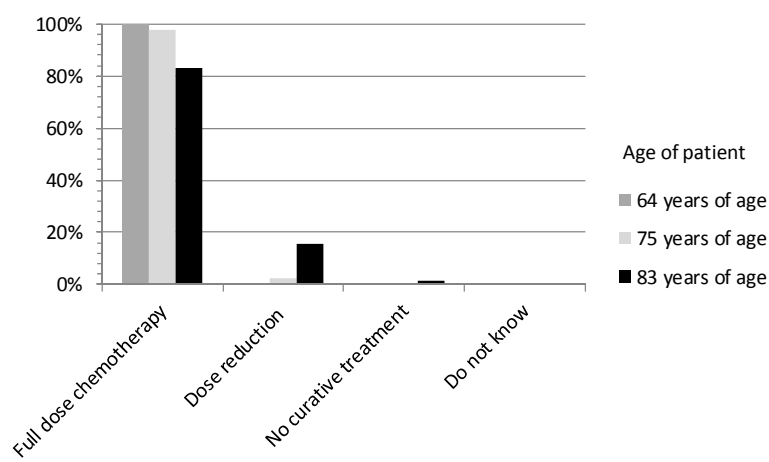

Figure 3.1A Case vignette: The patient has no relevant medical history.

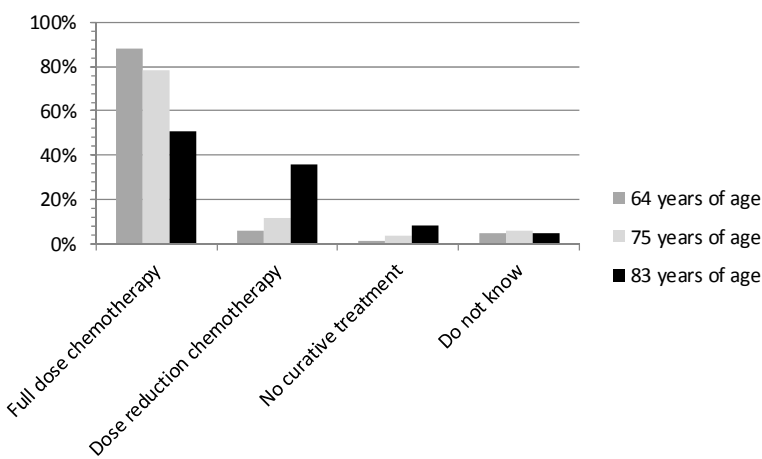

Figure 3.1B Case vignette: The patient is known with mild cognitive impairment and lives at home without additional care.

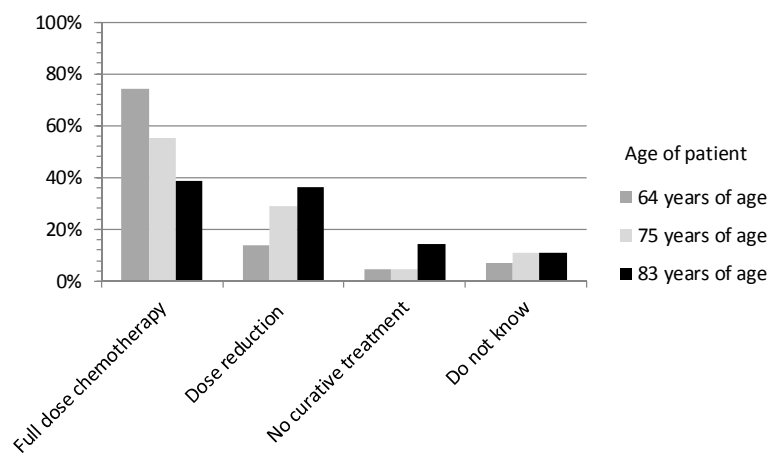

Figure 3.1C Case vignette: The patient is known with mild cognitive impairment and lives at home with additional household care. 


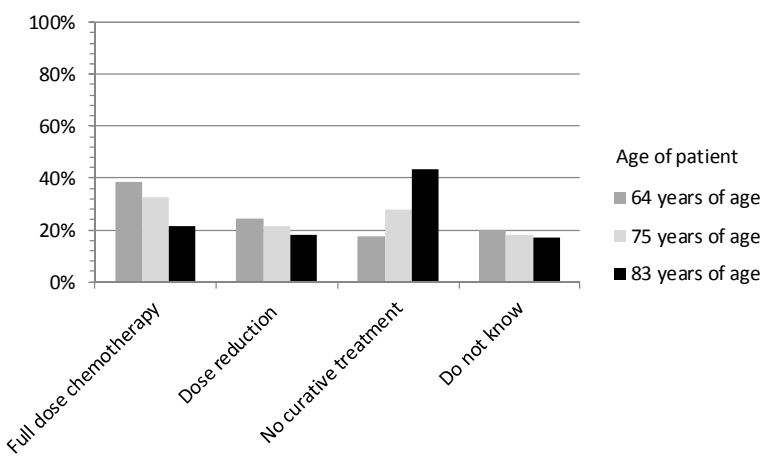

Figure 3.1D Case vignette: The patient has dementia and lives at home with a good health care system.

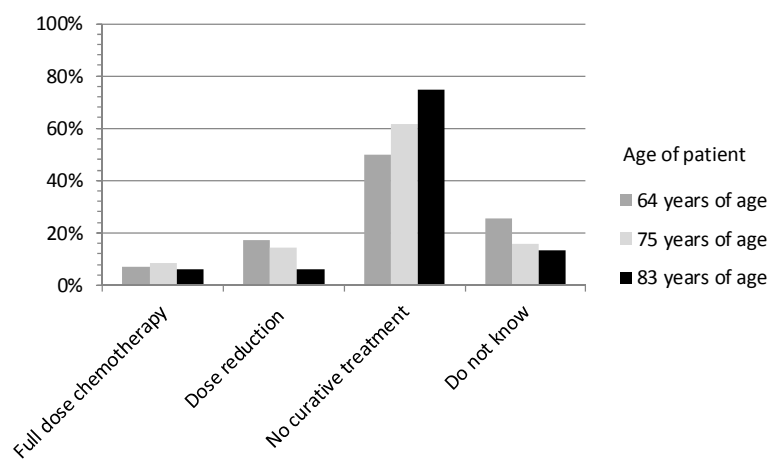

Figure 3.1E Case vignette: The patient has dementia and lives in a nursing home.

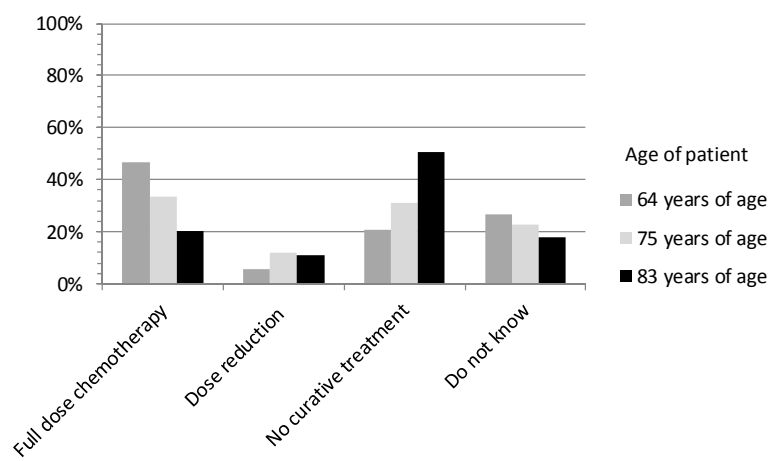

Figure 3.1F Case vignette: The patient has a depression that has not been treated. 


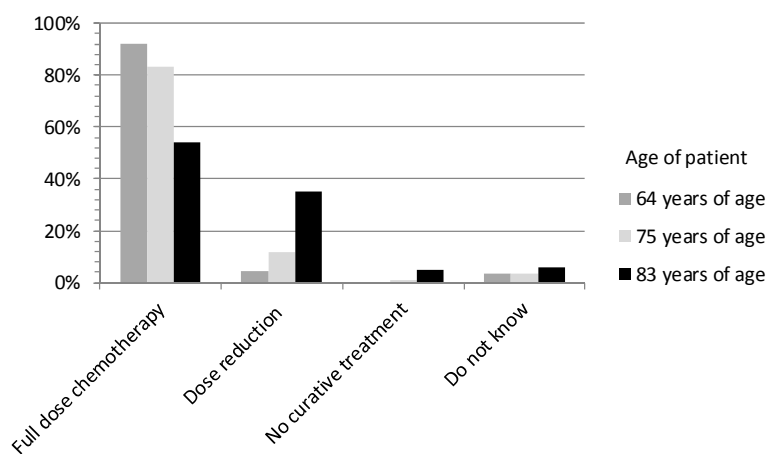

Figure 3.1G Case vignette: The patient has a depression that has been treated adequately with antidepressants.

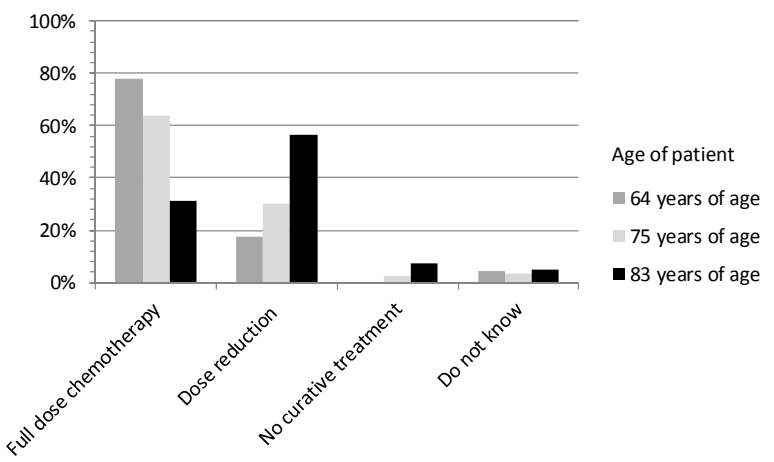

Figure 3.1H Case vignette: The patient is known with diabetes mellitus 2, hypertension and myocardial infarction and lives at home with a good support system.

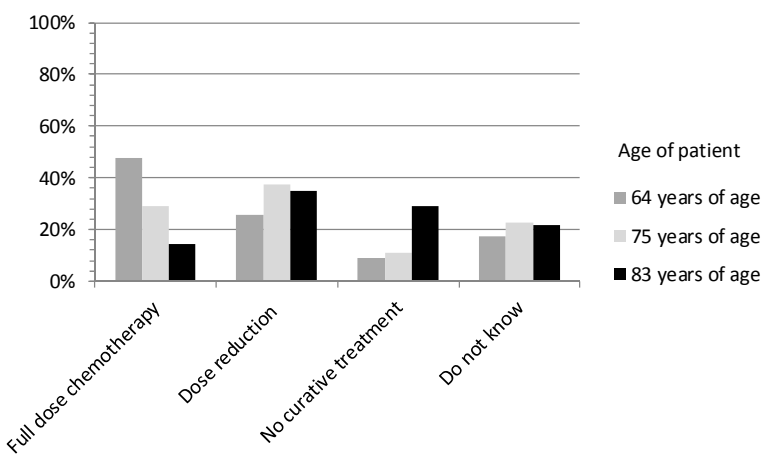

Figure 3.1I Case vignette: The patient is known with diabetes mellitus 2, hypertension and myocardial infarction and lives at home with no support system. 


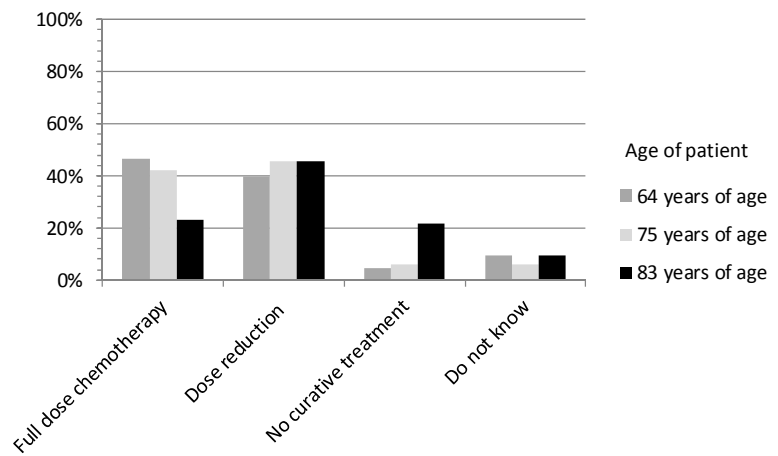

Figure 3.1J Case vignette: The patient has a history of mild cognitive impairment, diabetes mellitus 2, hypertension and myocardial infarction.

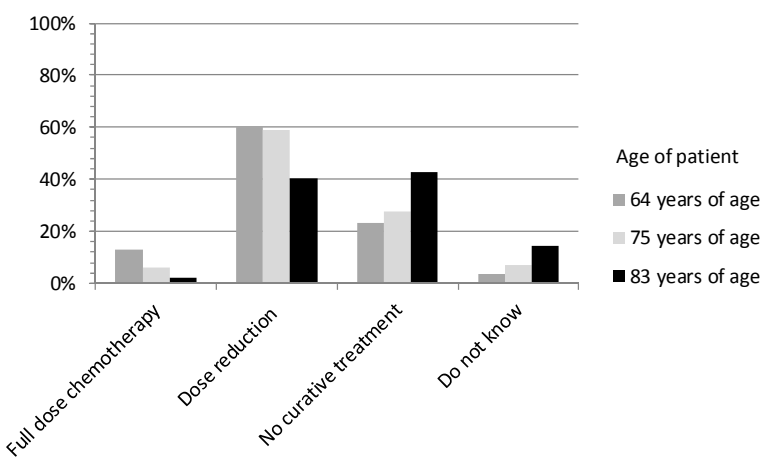

Figure 3.1K Case vignette: The patient has a medical history with hypertension, heart failure NYHA 3 and COPD gold 2.

\section{Case vignettes: treatment according to type of hospital}

Respondents working in a university hospital more frequently refrained from full dose chemotherapy with curative intent in patients of all age categories compared to respondents working in tertiary medical teaching hospitals or general hospitals (Figure $3.2 \mathrm{~A}, 3.2 \mathrm{~B}$ and $3.2 \mathrm{C}$ ). Hematologists in university hospitals more frequently applied dose reductions when treating with curative intent and in the eldest patient category they more frequently did not start treatment with curative intent. No major differences were found between respondents working in tertiary medical teaching hospitals and general hospitals. 


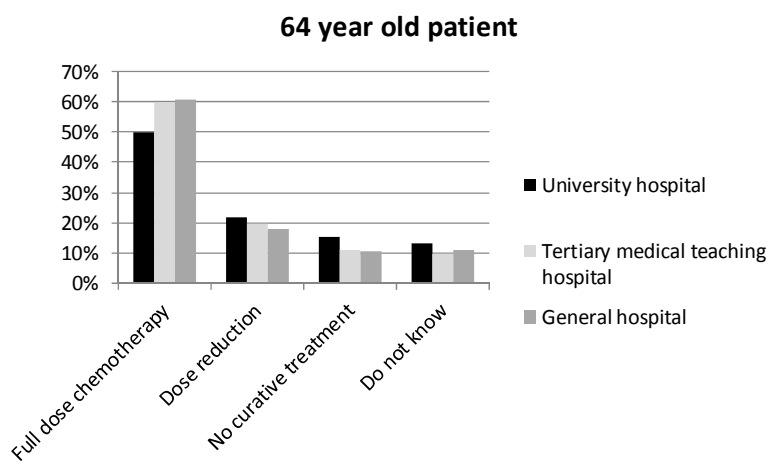

Figure 3.2A Treatment according type of hospital and to age of patient irrespective of comorbidity. Treatment according to type of hospital in case of a 64 year old patient.

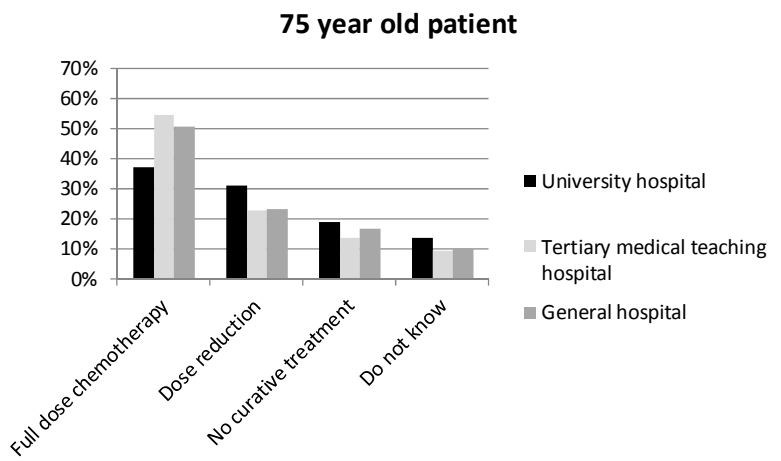

Figure 3.2B Treatment according type of hospital and to age of patient irrespective of comorbidity. Treatment according to type of hospital in case of a 75 year old patient.

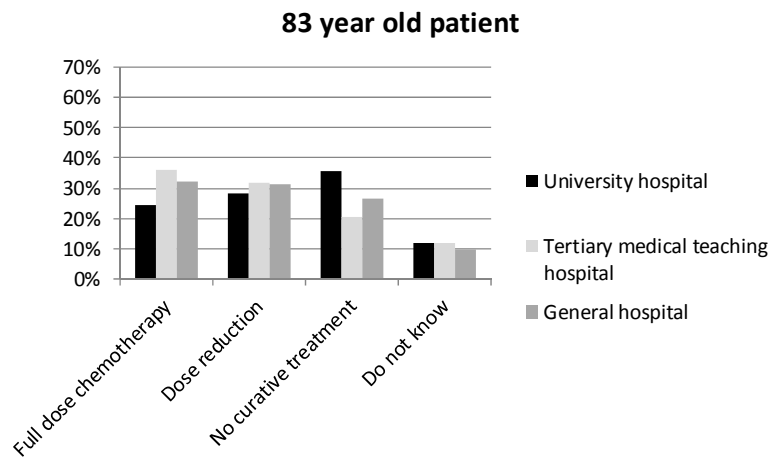

Figure 3.2C Treatment according type of hospital and to age of patient irrespective of comorbidity. Treatment according to type of hospital in case of an 83 year old patient. 


\section{Discussion}

The aim of the present study was to gain more insight into treatment decision-making by hematologists in DLBCL patients of varying age, comorbidity and social support by use of case vignettes.

We observed that almost all respondents would treat DLBCL patients without a relevant medical history with curative intent. In the eldest patient category, intentional dose reductions are frequent. This is in line with the results of previous reports. $^{11,13}$ In a recent study among DLBCL patients older than 75 years, dose reductions occurred in $31 \%$ of patients at start of treatment with $\mathrm{R}-\mathrm{CHOP}$ and age was the most important reason in $27 \%$ of cases. ${ }^{4}$ However in $68 \%$ of patients there was no clear argumentation.

Furthermore, we found that treatment decision-making is to a large extent influenced by the presence of comorbidity. In case of serious comorbidity, respondents frequently applied dose reductions in advance or refrained from treatment with curative intent. This is in line with the results of the first part of this survey in the same respondents and was also observed is previous studies. $5,9,13,16,17$ In elderly patients comorbidity is common and a prevalence of up to $87 \%$ in patients aged older than 80 years is described. ${ }^{10}$ Comorbidity is associated with lower survival in elderly NHL patients. ${ }^{9,11,16-21}$ The impaired outcome in patients with comorbidity can be the result of the direct impact of comorbidity on outcome, but can also be the consequence of less intensive treatment schedules or less treatment tolerability. ${ }^{16,22}$ In addition, the results of this study showed that cognitive impairment has an important influence on treatment decisions. In case of mild cognitive impairment most patients would be treated with curative intent, however there was a marked decrease in this percentage in case of dementia. This was most pronounced for the eldest patients above 80 years of age. It has been shown that dementia is associated with an increased mortality rate in NHL patients., ${ }^{9,23}$

Lastly, we observed that depression, especially when not treated adequately, appeared to affect the treatment regime of DLBCL patients. The prevalence of depression in DLBCL patients is high. ${ }^{24}$ Moreover, a study among cancer survivors observed increased all-cause mortality in patients with depressive symptoms even after adjustment for major clinical predictors. ${ }^{25}$ This might be explained by lower treatment compliance in depressed patients or by a higher incidence of depression in patients with poor performance status. ${ }^{26}$ Expected low treatment adherence or worse coping strategies may be reasons for clinicians to treat patients with a depression with adapted chemotherapy schedules.

Interestingly, respondents working in university hospitals seem to treat elderly patients less often with full dose chemotherapy. This might be the consequence of a referral bias and possibly these respondents have less experience in treating elderly DLBCL patients. 
Respondents declared that comorbidity and cognitive impairment in DLBCL patients largely influences treatment decision-making. In daily clinical practice the extent of comorbidity and cognitive impairment in a patient is in general judged by the physician without performing a systematic assessment, amongst others because the latter is time consuming. Clinical judgment by a physician is however less reliable in detecting geriatric problems compared to a systematic evaluation by comprehensive geriatric assessment (CGA). ${ }^{27-31}$ However, no large prospective randomized controlled trials have been performed investigating the role of CGA in treatment of elderly DLBCL patients and therefore it is not clear how the results of CGA might influence treatment decision-making.

The strengths of our study are that more information is provided about factors that influence treatment decision-making by clinicians, an important topic in cancer treatment. Furthermore, by presenting case vignettes various situations that resemble daily clinical practice could be studied. Moreover, hematologists of university, tertiary medical teaching hospitals and general hospitals participated in the study, making the results generalizable. Possible limitations of our study might be that, even though the response rate was reasonable, especially hematologists with a particular interest in this subject responded. In addition, it cannot be entirely excluded that in clinical practice other treatment decisions are made than that the decisions that were indicated in the cases by respondents. At last, an initial treatment decision is not fixed and it is possible that treatment is for example intensified if treatment tolerability appears to be good.

In conclusion, patients without a relevant medical history are in general treated with curative intent irrespective of age. However in the presence of mild cognitive impairment, dementia, comorbidity or depression dose reductions in advance are frequently applied or patients are not treated with curative intent. This is most prominent in the eldest patient category. 


\section{References}

1. http://www.seer.cancer.gov. (Accessed September 19th, 2014)

2. Coiffier B, Lepage $\mathrm{E}$, Briere J, et al. CHOP chemotherapy plus rituximab compared with $\mathrm{CHOP}$ alone in elderly patients with diffuse large-B-cell lymphoma. N Engl J Med 2002;346:235-42.

3. Feugier P, Van Hoof A, Sebban C, et al. Long-term results of the R-CHOP study in the treatment of elderly patients with diffuse large B-cell lymphoma: a study by the Groupe d'Etude des Lymphomes de l'Adulte. J Clin Oncol 2005;23:4117-26.

4. Boslooper K, Kibbelaar R, Storm H, et al. Treatment with rituximab, cyclophosphamide, doxorubicin, vincristine and prednisolone is beneficial but toxic in very elderly patients with diffuse large B-cell lymphoma: a population-based cohort study on treatment, toxicity and outcome. Leuk Lymphoma 2014;55:526-32.

5. Hasselblom S, Stenson M, Werlenius O, et al. Improved outcome for very elderly patients with diffuse large B-cell lymphoma in the immunochemotherapy era. Leuk Lymphoma 2012;53:394-9.

6. Lee L, Crump M, Khor S, et al. Impact of rituximab on treatment outcomes of patients with diffuse large b-cell lymphoma: a population-based analysis. Br J Haematol 2012;158:481-8.

7. Varga C, Holcroft C, Kezouh A, et al. Comparison of outcomes among patients aged 80 and over and younger patients with diffuse large B-cell lymphoma: a population based study. Leuk Lymphoma 2014;55:533-7.

8. Diem S, Ess S, Cerny T, Fruh M, Hitz F. Diffuse large B-cell lymphoma in elderly patients: a retrospective analysis. Eur J Intern Med 2014;25:577-82.

9. Tien YY, Link BK, Brooks JM, Wright K, Chrischilles E. Treatment of diffuse large B-cell lymphoma in the elderly: regimens without anthracyclines are common and not futile. Leuk Lymphoma 2014.

10. Thieblemont C, Grossoeuvre A, Houot R, et al. Non-Hodgkin's lymphoma in very elderly patients over 80 years. A descriptive analysis of clinical presentation and outcome. Ann Oncol 2008;19:774-9.

11. van de Schans SA, Wymenga AN, van Spronsen DJ, Schouten HC, Coebergh JW, Janssen-Heijnen ML. Two sides of the medallion: poor treatment tolerance but better survival by standard chemotherapy in elderly patients with advanced-stage diffuse large B-cell lymphoma. Ann Oncol 2012;23:1280-6.

12. Peters FP, Lalisang RI, Fickers MM, et al. Treatment of elderly patients with intermediate- and highgrade non-Hodgkin's lymphoma: a retrospective population-based study. Ann Hematol 2001;80: 155-9.

13. van der Poel MW, Mulder WJ, Ossenkoppele GJ, et al. Comorbidity and treatment decision-making in elderly non-Hodgkin's lymphoma patients: a survey among haematologists. Neth J Med 2014;72: 165-9.

14. http://www.hovon.nl. (Accessed September 7th 2014)

15. http://www.stz.nl. (Accessed September 7th, 2014)

16. Wieringa $A$, Boslooper $K$, Hoogendoorn $M$, et al. Comorbidity is an independent prognostic factor in patients with advanced-stage diffuse large B-cell lymphoma treated with R-CHOP: a population-based cohort study. Br J Haematol 2014;165:489-96.

17. van Spronsen DJ, Janssen-Heijnen ML, Lemmens VE, Peters WG, Coebergh JW. Independent prognostic effect of co-morbidity in lymphoma patients: results of the population-based Eindhoven Cancer Registry. Eur J Cancer 2005;41:1051-7.

18. Lin TL, Kuo MC, Shih LY, et al. The impact of age, Charlson comorbidity index, and performance status on treatment of elderly patients with diffuse large B cell lymphoma. Ann Hematol 2012;91:1383-91.

19. Merli F, Luminari S, Rossi G, et al. Outcome of frail elderly patients with diffuse large B-cell lymphoma prospectively identified by Comprehensive Geriatric Assessment: results from a study of the Fondazione Italiana Linfomi. Leuk Lymphoma 2014;55:38-43.

20. Janssen-Heijnen ML, van Spronsen DJ, Lemmens VE, Houterman S, Verheij KD, Coebergh JW. A population-based study of severity of comorbidity among patients with non-Hodgkin's lymphoma: prognostic impact independent of International Prognostic Index. Br J Haematol 2005;129:597-606.

21. Kobayashi Y, Miura K, Hojo A, et al. Charlson Comorbidity Index is an independent prognostic factor among elderly patients with diffuse large B-cell lymphoma. J Cancer Res Clin Oncol 2011;137:1079-84. 
22. Wildes TM, Ruwe AP, Fournier $C$, et al. Geriatric assessment is associated with completion of chemotherapy, toxicity, and survival in older adults with cancer. J Geriatr Oncol 2013;4:227-34.

23. Nabhan C, Smith SM, Helenowski I, et al. Analysis of very elderly $(>/=80$ years) non-hodgkin lymphoma: impact of functional status and co-morbidities on outcome. $\mathrm{Br} J$ Haematol 2012;156: 196-204.

24. Oerlemans S, Mols F, Nijziel MR, Zijlstra WP, Coebergh JW, van de Poll-Franse LV. The course of anxiety and depression for patients with Hodgkin's lymphoma or diffuse large B cell lymphoma: a longitudinal study of the PROFILES registry. J Cancer Surviv 2014;8:555-64.

25. Mols F, Husson O, Roukema JA, van de Poll-Franse LV. Depressive symptoms are a risk factor for allcause mortality: results from a prospective population-based study among 3,080 cancer survivors from the PROFILES registry. J Cancer Surviv 2013;7:484-92.

26. Arrieta O, Angulo LP, Nunez-Valencia C, et al. Association of depression and anxiety on quality of life, treatment adherence, and prognosis in patients with advanced non-small cell lung cancer. Ann Surg Oncol 2013;20:1941-8.

27. Wedding U, Kodding D, Pientka L, Steinmetz HT, Schmitz S. Physicians' judgement and comprehensive geriatric assessment (CGA) select different patients as fit for chemotherapy. Crit Rev Oncol Hematol 2007;64:1-9.

28. Tucci A, Ferrari S, Bottelli C, Borlenghi E, Drera M, Rossi G. A comprehensive geriatric assessment is more effective than clinical judgment to identify elderly diffuse large cell lymphoma patients who benefit from aggressive therapy. Cancer 2009;115:4547-53.

29. Repetto L, Fratino L, Audisio RA, et al. Comprehensive geriatric assessment adds information to Eastern Cooperative Oncology Group performance status in elderly cancer patients: an Italian Group for Geriatric Oncology Study. J Clin Oncol 2002;20:494-502.

30. Horgan AM, Leighl NB, Coate L, et al. Impact and feasibility of a comprehensive geriatric assessment in the oncology setting: a pilot study. Am J Clin Oncol 2012;35:322-8.

31. Aaldriks AA, Giltay EJ, Nortier JW, et al. Prognostic significance of Geriatric Assessment in combination with Laboratory Parameters in Elderly patients with aggressive non-Hodgkin Lymphoma. Leuk Lymphoma 2014:1-29. 


\section{Appendix 3.1}

\section{Survey 'Treatment of the elderly with a haematologic malignancy'}

In the outpatient clinic you see a 64 year old patient who is diagnosed with diffuse large B-cell lymphoma. Could you indicate in each of the following cases whether you would treat the patient with curative intent by means of full dose chemotherapy or chemotherapy with dose reduction or if you would not treat the patient with curative intent. You can also declare that you do not know.

The same cases were presented to respondents for a 75 year old and an 83 year old patient.

\begin{tabular}{|c|c|c|c|c|}
\hline & $\begin{array}{c}\text { Full dose } \\
\text { chemotherapy }\end{array}$ & $\begin{array}{c}\text { Chemotherapy with } \\
\text { dose reduction }\end{array}$ & $\begin{array}{c}\text { No treatment with } \\
\text { curative intent }\end{array}$ & $\begin{array}{l}\text { Do not } \\
\text { know }\end{array}$ \\
\hline $\begin{array}{l}\text { The patient has no relevant medical } \\
\text { history }\end{array}$ & & & & \\
\hline $\begin{array}{l}\text { The patient is known with mild } \\
\text { cognitive impairment and lives at home } \\
\text { without additional care. }\end{array}$ & & & & \\
\hline $\begin{array}{l}\text { The patient is known with mild } \\
\text { cognitive impairment and lives at home } \\
\text { with additional household care. }\end{array}$ & & & & \\
\hline $\begin{array}{l}\text { The patient has dementia and lives at } \\
\text { home with a good health care system. }\end{array}$ & & & & \\
\hline $\begin{array}{l}\text { The patient has dementia and lives in a } \\
\text { nursing home }\end{array}$ & & & & \\
\hline $\begin{array}{l}\text { The patient has a depression that has } \\
\text { not been treated. }\end{array}$ & & & & \\
\hline $\begin{array}{l}\text { The patient has a depression that has } \\
\text { been adequatly treated with } \\
\text { antidepressants. }\end{array}$ & & & & \\
\hline $\begin{array}{l}\text { The patient is known with diabetes } \\
\text { mellitus } 2 \text {, hypertension and myocardial } \\
\text { infarction and lives at home with a } \\
\text { good support system. }\end{array}$ & & & & \\
\hline $\begin{array}{l}\text { The patient is known with diabetes } \\
\text { mellitus } 2 \text {, hypertension, myocardial } \\
\text { infarction and lives at home with no } \\
\text { support system. }\end{array}$ & & & & \\
\hline $\begin{array}{l}\text { The patient has a history of mild } \\
\text { cognitive impaiment, diabetes mellitus } \\
2, \text { hypertension and myocardial } \\
\text { infarction. }\end{array}$ & & & & \\
\hline $\begin{array}{l}\text { The patients has a medical history with } \\
\text { hypertension, heart failure NYHA } 3 \text { and } \\
\text { COPD gold } 2 \text {. }\end{array}$ & & & & \\
\hline
\end{tabular}



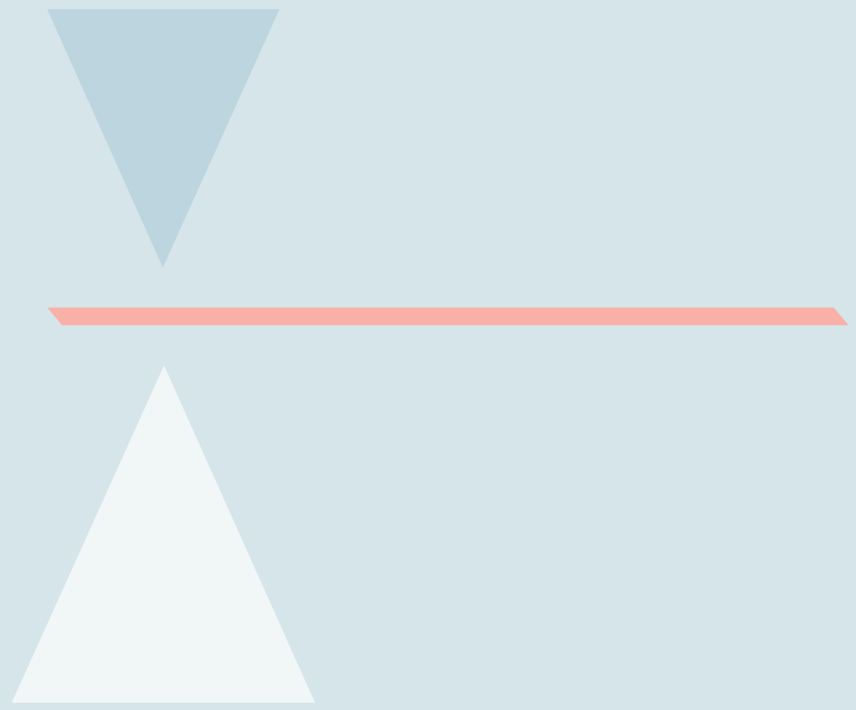
The impact of comorbidity on primary treatment with curative intent of elderly patients with diffuse large B-cell lymphoma: a nationwide study in the Netherlands 


\section{Abstract}

\section{Background}

The objective of this study was to investigate the impact of comorbidity on primary treatment with curative intent in elderly patients with diffuse large B-cell lymphoma (DLBCL).

\section{Methods}

We conducted a nationwide population-based study among 799 elderly DLBCL patients, selected from the nationwide Netherlands Cancer Registry and diagnosed in 2014. Patients were categorized into four age groups (65-69, 70-74, 75-79 and $\geq 80$ years). Treatment modality was divided into four groups: rituximab with anthracycline-containing chemotherapy (i.e. treatment with curative intent), rituximab and chemotherapy without anthracyclines, other therapies and no anti-lymphoma treatment.

\section{Results}

Overall, the application of treatment with curative intent decreased with advancing age, from $89 \%$ of patients aged $65-69$ years to $50 \%$ in patients aged $\geq 80$ years. In patients treated with RCHOP for stage II-IV DLBCL, $21 \%$ received less than six cycles. The prevalence of comorbid conditions was $88 \%$. Age $\geq 75$ years and ischemic heart disease or heart failure, muscle, connective tissue and joint disease, genitourinary disease, and central nervous system disease were associated with a lower odds of receiving treatment with curative intent. Age $\geq 80$ years and diabetes mellitus were associated with a lower odds of completion of R-CHOP. Overall survival among patients treated intensively did not differ between the four age groups.

\section{Conclusion}

The use of treatment with curative intent decreased with advancing age and a large proportion of patients received a suboptimal number of cycles. Several comorbidities, but also age, were associated with the likelihood of receiving chemotherapy with curative intent and for completion of R-CHOP. Overall survival for patients treated with intensive treatment did not differ between age groups, suggesting that this treatment has equal benefit for these patients. Curative treatment should therefore always be considered in elderly DLBCL patients, irrespective of chronological age and also in patients with comorbidities. 


\section{Introduction}

Non-Hodgkin lymphoma (NHL) is most frequently diagnosed among people aged 65-74, with a median age at diagnosis of 66 years. ${ }^{1}$ Diffuse large B-cell lymphoma (DLBCL) is the most common type of aggressive NHL. R-CHOP (rituximab, cyclophosphamide, doxorubicin, vincristine and prednisolone) is considered standard treatment for younger and elderly patients with DLBCL. Prospective studies have demonstrated that R-CHOP is effective in and well tolerated by elderly patients. ${ }^{2,3}$ In these studies, however, mainly fit and relatively 'young' elderly patients were included. That particular population may not be representative of the real-world population of elderly lymphoma patients.

Population-based studies demonstrated improved overall survival in very elderly patients (aged $\geq 75$ years) with DLBCL who were treated with R-CHOP compared to incomplete or suboptimal chemotherapy. ${ }^{4-6}$ These studies also showed that the R-CHOP regimen is accompanied by significant treatment-related toxicity, which hampers completion of therapy. ${ }^{4-7}$ Indeed, elderly DLBCL patients managed in daily practice frequently do not receive standard treatment. ${ }^{4-6}$

The comorbidity burden is high among elderly NHL patients. Comorbid conditions are present in $43-79 \%$ of patients older than 60 years, with severe types of comorbidity being more frequent in the very old. ${ }^{8-10} \mathrm{~A}$ study among lymphoma patients over 80 years old found at least one comorbid condition in $87 \%$ of patients. ${ }^{11}$ Cardiovascular diseases have the highest prevalence, occurring in $22 \%$ of patients older than 60 years and in more than $50 \%$ of patients older than 80 years. ${ }^{9,11}$ The presence of comorbidities may influence treatment decision-making in elderly patients with DLBCL. ${ }^{6,8,12,13}$ Comorbidity is associated with inferior overall survival in elderly DLBCL patients. ${ }^{8-10,14-18}$ It is unclear whether the poorer outcome is due to the comorbidity itself, due to treatment-related mortality or due to suboptimal lymphoma treatment in the presence of comorbidity.

Here we report the results of a nationwide population-based study in almost 800 elderly ( $\geq 65$ years) patients diagnosed with DLBCL in the Netherlands in 2014 reported to the Netherlands Cancer Registry (NCR). The aim of the study was to assess the impact of comorbidity on primary treatment with curative intent and on completion of R-CHOP therapy. In addition, we evaluated the primary treatment among elderly DLBCL patients according to age and disease stage at diagnosis. Furthermore, we evaluated overall survival according to age among patients receiving intensive therapy. Our hypotheses was that in the presence of comorbidities, patients less frequently received intensive chemotherapy and more frequently could not complete intensive therapy. 


\section{Patients and methods}

\section{The Netherlands Cancer Registry}

Established in 1989, the nationwide population-based NCR, which is hosted and maintained by the Netherlands Comprehensive Cancer Organization (IKNL), has an overall coverage of at least $95 \%$ of all malignant diseases in the Netherlands. ${ }^{19}$ The NCR is notified of newly diagnosed malignancies by the Nationwide Network and Registry of Histo- and Cytopathology in the Netherlands (PALGA) and the National Registry of Hospital Discharges. Several patient- (e.g. date of birth and sex), disease(e.g. stage and morphology) and treatment-related characteristics (i.e. primary therapy) are routinely collected by trained registrars of IKNL through retrospective medical records review. Information on vital statistics (i.e. alive, dead or emigration) is obtained by annually linking the NCR to the municipal registries that holds vital statistics of all Dutch residents.

Since its establishment in 1989, the NCR registered primary treatment in broad categories (e.g. chemotherapy or immunochemotherapy). Therefore, it is not known what the chemotherapeutic regimen consisted of. For patients diagnosed with a haematological malignancy as from January 1, 2014, more detailed data on treatment are registered in the NCR, such as the exact type of (immuno)chemotherapy and number of treatment cycles. ${ }^{20}$ In addition, more detailed data on diagnosis, such as comorbidities and lymphoma-related characteristics, are collected.

\section{Study population, comorbidities and treatment}

We selected all patients aged $\geq 65$ years who were diagnosed with DLBCL not otherwise specified (NOS) in 2014 from the NCR using the following International Classification of Diseases for Oncology Third Edition (ICD-O-3) morphology code: 9680. None of the patients were diagnosed at autopsy. Patients diagnosed with other subtypes of DLBCL were not included in the current study, because these subtypes generally require a different treatment approach than DLBCL NOS. Patients were observed from date of diagnosis to date of death, date of emigration or end of followup (i.e. February 1, 2017).

Comorbidities were subdivided into the following ten categories: (i) ischemic heart disease and heart failure, (ii) other cardiovascular disease, (iii) prior malignant disease, (iv) diabetes mellitus, (v) pulmonary disease, (vi) digestive tract disease, (vii) muscle, connective tissue and joint disease, (viii) genitourinary disease, (ix) central nervous system (CNS) disease and ( $x$ ) infectious disease.

Primary treatment was divided into four groups. The first group consisted of patients receiving treatment schedules with rituximab and anthracycline-containing chemotherapy, that is, R-CHOP every three weeks (R-CHOP21), R-CHOP every two 
weeks (R-CHOP14) or R-CHOEP (R-CHOP plus etoposide). These patients were considered to be treated with curative intent. The second group consisted of patients being treated with suboptimal immunochemotherapy defined as patients who received schedules with rituximab and chemotherapy, but without anthracyclines. These schedules included rituximab, cyclophosphamide, vincristine and prednisolone (R-CVP), rituximab, prednisolone, etoposide, lomustine, chlorambucil (R-PECC), rituximab, lomustine, vincristine, procarbazine and prednisone (R-LOPP), rituximab, cyclophosphamide, etoposide, vincristine, prednisolone (R-CEOP), and rituximab monotherapy or other rituximab combinations ( $+/$ - other). In the third group termed 'other therapy', patients were included who received radiotherapy only or corticosteroids only. The fourth group consisted of patients who received no antilymphoma therapy.

\section{Statistical analysis}

Differences in demographic and clinical characteristics between patients of different age categories (65-69, 70-74, 75-79 and $\geq 80$ years) were compared with the KruskalWallis test for continuous variables and the chi-square test for categorical variables. Primary treatment according to the four abovementioned treatment groups was assessed for patients in the four different age categories. The percentage of patients treated with R-CHOP as primary treatment was evaluated separately for patients with stage I versus patients with stage II-IV disease in the four different age categories, since treatment of stage I DLBCL differs from treatment of stage II-IV DLBCL.

Multivariable logistic regression analyses were carried out to investigate the independent association between socio-demographic and clinical variables and immunochemotherapy with curative intent. Curative treatment was defined as rituximab with anthracycline-containing chemotherapy. The independent association between socio-demographic and clinical variables and the ability to complete R-CHOP treatment was evaluated for patients with stage II-IV DLBCL using multivariable logistic regression analyses. Complete R-CHOP therapy was defined as at least six courses of R-CHOP14 or R-CHOP21. Variables that were selected for the multivariable logistic regression models were sex, age at diagnosis, disease stage, number of comorbidities, and type of comorbidity. Patients in which the comorbidity was unknown were excluded from the analysis, as comorbidity was the variable of interest. Only statistically significant covariates with $P<0.05$ were retained in the final models (i.e. backward selection method). Results from the logistic regression analysis were expressed as odds ratios (ORs) with 95\% confidence intervals (Cls).

Overall survival (OS) according to age category for patients treated with intensive therapy was analysed using the log-rank test and expressed as Kaplan-Meier plot. OS was measured from the date of first-line treatment until death or end of follow-up (February 1, 2017), whichever occurred first. 
All statistical analyses were performed with STATA/SE 14.1 (StataCorp, College Station, TX, USA). According to the Central Committee on Research involving Human Subjects (CCMO), this non-interventional, retrospective study does not require approval from an ethics committee in the Netherlands. The Internal Review Board of the NCR approved the study.

\section{Results}

\section{Patients' characteristics}

In 2014, there were 799 patients aged 65 years and older diagnosed with DLBCL in the Netherlands. There were more male (54\%) than female (46\%) patients and most patients had stage II-IV disease (75\%) (Table 4.1). In 37 patients (5\%), the disease stage was unknown. The age-adjusted International Prognostic Index (aalPI) score was unknown in more than half of patients, primarily as a result of missing data regarding the World Health Organization (WHO) performance status, which is a prerequisite to calculate the aalPI. Further, the overall comorbidity burden increased with older age. With respect to the type of comorbidity, cardiovascular disease was the most frequent comorbidity in patients of all age categories, although its prevalence increased with higher age up to $70 \%$ in patients $\geq 80$ years.

\section{Primary treatment according to age at diagnosis}

Rituximab with anthracycline-containing chemotherapy (that is, treatment with curative intent) was the most frequently applied primary therapy in 160 of 179 patients (89\%) aged 65-69 years (Table 4.1). With advancing age, the percentage of patients treated with curative intent decreased to $50 \%$ in patients $\geq 80$ years. Treatment modalities without curative intent were more frequently applied in the very old age group ( $\geq 80$ years), as compared to their relatively younger counterparts (65-79 years). In the oldest age group, $25 \%$ of patients received no anti-lymphoma treatment, in contrast to $6 \%$ of patients in the youngest age category (65-69 years).

\section{Treatment with R-CHOP in patients with DLBCL stage I}

Of the 160 patients with stage I DLBCL, 126 patients (79\%) were treated with R-CHOP. According to age category, 36 of 38 patients (95\%) aged 65-69 years, 25 of 30 patients (83\%) aged $70-74$ years, 34 of 44 patients (70\%) aged $75-79$ years and 31 of 48 patients $(65 \%)$ aged $\geq 80$ years were treated with R-CHOP (data not shown). 
Table 4.1 Patient characteristics.

\begin{tabular}{|c|c|c|c|c|c|c|c|c|c|c|}
\hline \multirow[t]{3}{*}{ Characteristics } & \multicolumn{8}{|c|}{ Age at diagnosis, years } & \multirow{3}{*}{$\begin{array}{l}\text { Total } \\
\text { No. } \\
\end{array}$} & \multirow[t]{3}{*}{$\mathrm{p}$} \\
\hline & \multicolumn{2}{|c|}{$65-69$} & \multicolumn{2}{|c|}{$70-74$} & \multicolumn{2}{|c|}{ 75-79 } & \multicolumn{2}{|c|}{$\geq 80$} & & \\
\hline & No. & $(\%)$ & No. & $(\%)$ & No. & $(\%)$ & No. & $(\%)$ & & \\
\hline Total No. of patients & 179 & $(22)$ & 173 & $(22)$ & 196 & (25) & 251 & (31) & 799 & \\
\hline \multicolumn{11}{|l|}{ Sex } \\
\hline Male & 95 & (53) & 100 & (58) & 118 & (60) & 116 & $(46)$ & 429 & 0.017 \\
\hline Female & 84 & (47) & 73 & (42) & 78 & (40) & 135 & (54) & 370 & \\
\hline \multicolumn{11}{|l|}{ Stage } \\
\hline I & 38 & (21) & 30 & (17) & 44 & $(22)$ & 48 & (19) & 160 & 0.235 \\
\hline II & 28 & (16) & 31 & (18) & 34 & (17) & 52 & (21) & 145 & \\
\hline III & 28 & (16) & 36 & (21) & 26 & (13) & 47 & (19) & 137 & \\
\hline IV & 81 & (45) & 74 & (43) & 84 & (43) & 81 & $(32)$ & 320 & \\
\hline Unknown & 4 & $(2)$ & 2 & $(1)$ & 8 & $(4)$ & 23 & (9) & 37 & \\
\hline \multicolumn{11}{|l|}{ aalPI score } \\
\hline Low & 24 & (13) & 18 & (10) & 29 & (15) & 22 & (9) & 93 & 0.031 \\
\hline Low-Int & 28 & (16) & 33 & (19) & 28 & (14) & 36 & (14) & 125 & \\
\hline High-Int & 30 & (17) & 26 & (15) & 19 & (10) & 24 & (10) & 99 & \\
\hline High & 5 & (3) & 8 & $(5)$ & 15 & $(8)$ & 9 & $(4)$ & 37 & \\
\hline Undetermined & 92 & (51) & 88 & (51) & 105 & (54) & 160 & (64) & 445 & \\
\hline \multicolumn{11}{|l|}{ Primary therapy } \\
\hline No therapy & 11 & (6) & 14 & $(8)$ & 20 & (10) & 64 & (25) & 109 & $<0.001$ \\
\hline $\mathrm{R}$ w/ anthracyclines & 160 & (89) & 144 & (83) & 148 & (76) & 126 & (50) & 578 & \\
\hline R w/o anthracyclines & 5 & (3) & 9 & $(5)$ & 12 & $(6)$ & 18 & $(7)$ & 44 & \\
\hline Other therapy & 3 & (2) & 6 & (3) & 16 & (8) & 43 & (17) & 68 & \\
\hline \multicolumn{11}{|l|}{ No. of comorbidities } \\
\hline None & 35 & (20) & 21 & (12) & 15 & $(8)$ & 23 & (9) & 94 & $<0.001$ \\
\hline One & 51 & (28) & 45 & (26) & 41 & (21) & 40 & (16) & 177 & \\
\hline Two or more & 73 & (41) & 88 & (51) & 124 & (63) & 169 & (67) & 454 & \\
\hline Unknown & 20 & (11) & 19 & (11) & 16 & $(8)$ & 19 & $(8)$ & 74 & \\
\hline \multicolumn{11}{|l|}{ Type of comorbidity } \\
\hline Ischemic heart disease/heart failure & 14 & (8) & 35 & (20) & 43 & $(22)$ & 58 & (23) & 150 & 0.003 \\
\hline Other cardiovascular diseases & 61 & (34) & 66 & (38) & 91 & (46) & 117 & (47) & 335 & 0.119 \\
\hline Prior malignant disease & 32 & (18) & 41 & (24) & 42 & (21) & 69 & (27) & 184 & 0.120 \\
\hline Diabetes mellitus & 33 & (18) & 33 & (19) & 38 & (19) & 41 & (16) & 145 & 0.715 \\
\hline Pulmonary disease & 23 & (13) & 28 & (16) & 28 & (14) & 32 & (13) & 111 & 0.677 \\
\hline Digestive tract disease & 19 & (11) & 19 & (11) & 24 & $(12)$ & 32 & (13) & 94 & 0.823 \\
\hline $\begin{array}{l}\text { Muscle, connective tissue and joint } \\
\text { disease }\end{array}$ & 10 & $(6)$ & 14 & (8) & 18 & (9) & 14 & (6) & 56 & 0.465 \\
\hline Genitourinary disease & 7 & (4) & 9 & (5) & 8 & (4) & 16 & (6) & 40 & 0.651 \\
\hline CNS disease & 8 & (4) & 4 & (2) & 9 & (5) & 10 & (4) & 31 & 0.675 \\
\hline Infectious disease & 3 & (2) & 2 & (1) & 4 & $(2)$ & 7 & (3) & 16 & 0.691 \\
\hline
\end{tabular}

For stage I DLBCL, three courses of R-CHOP21 plus radiotherapy or six courses of R-CHOP21 are considered standard treatment according to current Dutch guidelines. Of all patients treated with R-CHOP, these regimens were applied to 26 patients ( $72 \%$ ) aged 65-69 years, 15 patients (60\%) aged 70-74 years, 27 patients (79\%) aged $75-79$ years and 18 patients (58\%) aged $\geq 80$ years (Figure 4.1 ). In 33 patients (26\%), other R-CHOP21 regimens were applied, including the following: $3 x$ R-CHOP21 
without radiotherapy ( $n=6)$, 8x R-CHOP21 ( $n=5)$, 1-2x R-CHOP21 ( $n=4), 4-5 x$ R-CHOP21 $(n=8), 7 x$ R-CHOP21 $(n=2)$ and 6x R-CHOP21 + 2 additional cycles of rituximab $(n=8)$. In addition, R-CHOP14 was applied to 7 patients $(6 \%)$ in various schedules, namely $6 x$ R-CHOP14 $(n=4), 8 x$ R-CHOP14 $(n=1)$ and 1-5 or 7x R-CHOP14 $(n=2)$.

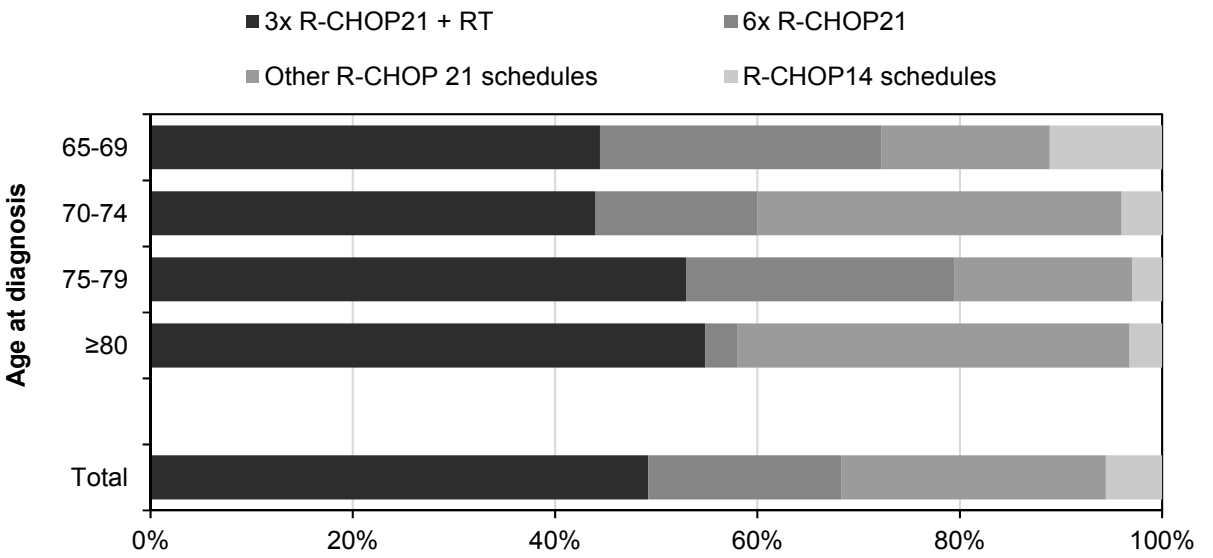

Figure 4.1 R-CHOP chemotherapy in DLBCL stage I according to age at diagnosis.

\section{Treatment with R-CHOP in patients with DLBCL stage II-IV}

Of the 602 patients with stage II-IV DLBCL, 443 patients (74\%) were treated with R-CHOP. According to age category, 120 of 137 patients (88\%) aged 65-69 years, 119 of 141 patients (84\%) aged 70-74 years, 111 of 144 patients (77\%) aged $75-79$ years and 93 of 180 patients $(52 \%)$ aged $\geq 80$ years were treated with R-CHOP (data not shown).

According to current Dutch guidelines, standard therapy for DLBCL stage II-IV consists of six cycles of R-CHOP21 in case of an aalPI of zero. In all other cases, eight courses of R-CHOP21 or six courses of R-CHOP14 followed by two additional cycles of rituximab are recommended. Of the patients aged 65-69 years, 51\% were treated according to one of these recommendations. This percentage decreased with advancing age to $43 \%$ in patients aged $70-74$ years, $36 \%$ in patients aged $75-79$ years and $33 \%$ in patients aged $\geq 80$ years (Figure 4.2 ).

In 239 of the 443 patients (54\%) treated with R-CHOP, other R-CHOP21 regimens than recommended by the Dutch guidelines were applied, namely 6x R-CHOP21 + 2 additional cycles of rituximab ( $n=132), 1-2 x$ R-CHOP21 ( $n=50), 4-5 x$ R-CHOP21 ( $n=26)$, 7x R-CHOP21 ( $n=15), 3 x$ R-CHOP21 without radiotherapy $(n=13)$, and 3x R-CHOP21 plus radiotherapy $(n=3)$. 
Other R-CHOP14 regimens that were used in 20 patients include 6x R-CHOP14 (n=9), 1-5 or 7x R-CHOP 14 ( $n=8)$, and 8x R-CHOP14 ( $n=3)$.

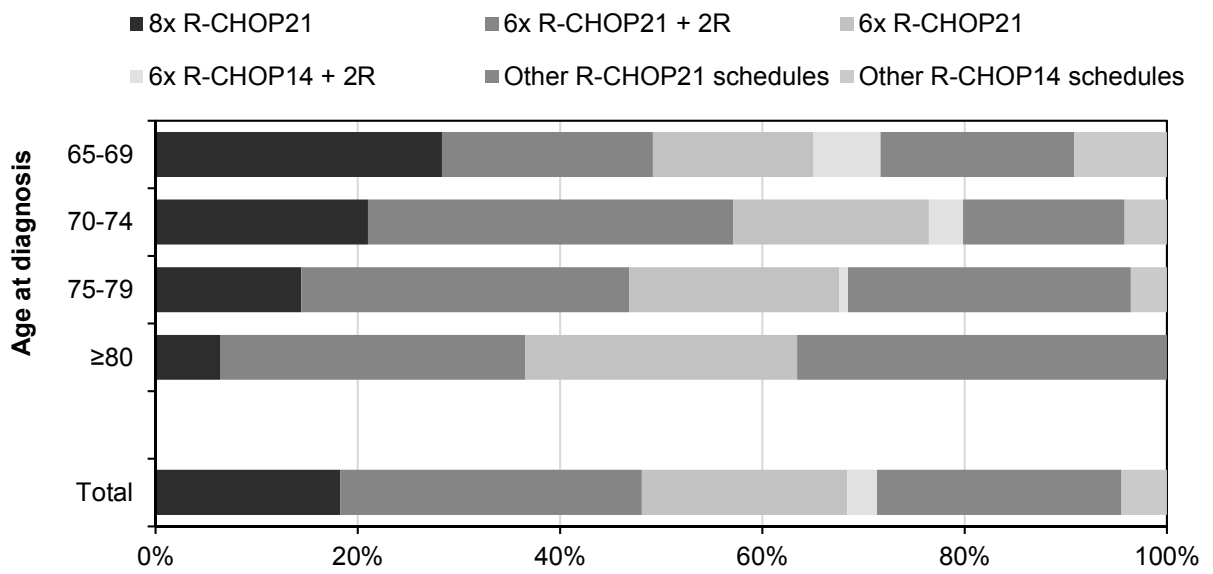

Figure 4.2 R-CHOP chemotherapy in DLBCL stage II-IV according to age at diagnosis.

\section{Factors associated with curative immunochemotherapy in elderly DLBCL patients}

Multivariable logistic regression analyses showed that patients aged 75 or above at diagnosis less frequently received immunochemotherapy with curative intent, as compared to patients aged 65-69 years (OR: $0.35,95 \% \mathrm{Cl} 0.18-0.69, p=0.002$ for patients aged $75-79$ years and OR: $0.10,95 \% \mathrm{Cl} 0.05-0.20, p<0.001$ for patients $\geq 80$ years; Table 4.2 ). In addition, immunochemotherapy with curative intent was less frequently applied in patients with unknown disease stage (OR: $0.04,95 \% \mathrm{Cl}$ $0.01-0.14, p<0.001)$. With respect to comorbidity, patients with ischemic heart disease or heart failure (OR: $0.39,95 \% \mathrm{Cl} 0.25-0.60, \mathrm{p}<0.001$ ), muscle, connective tissue and joint disease (OR: $0.48,95 \% \mathrm{Cl} 0.25-0.94, \mathrm{p}=0.032$ ), genitourinary disease (OR: 0.30, 95\% $\mathrm{Cl}$ 0.14-0.63, $\mathrm{p}=0.001$ ), or CNS disease (OR: 0.10, 95\% $\mathrm{Cl} 0.04-0.25, \mathrm{p}<0.001$ ) were less likely to receive curative treatment. In the multivariable analysis, number of comorbidities, prior malignant disease and pulmonary disease lost statistical significance, indicating that they were not related to the application of immunochemotherapy with curative intent. 
Table 4.2 Results of the logistic regression analyses on potential predictors associated with the decision to apply intensive therapy among patients with DLBCL in the Netherlands, 2014.

\begin{tabular}{|c|c|c|c|c|c|}
\hline \multirow[t]{2}{*}{ Independent variable } & \multirow[t]{2}{*}{$\begin{array}{l}\text { Intensive therapy } \\
\text { (n/N; \%) }\end{array}$} & \multicolumn{2}{|c|}{ Univariable } & \multicolumn{2}{|c|}{$\begin{array}{c}\text { Multivariable } \\
\text { (backward selection) }\end{array}$} \\
\hline & & OR $95 \% \mathrm{Cl}$ & $\mathbf{p}$ & OR $95 \% \mathrm{Cl}$ & $\mathbf{p}$ \\
\hline \multicolumn{6}{|l|}{ Sex } \\
\hline Male & $288 / 392(73.5)$ & 1 (ref) & & & \\
\hline Female & 231/333 (69.4) & $0.820 .59-1.13$ & 0.223 & & \\
\hline \multicolumn{6}{|l|}{ Age at diagnosis } \\
\hline 65-69 years & $143 / 159(90.0)$ & 1 (ref) & & 1 (ref) & \\
\hline $70-74$ years & $128 / 154(83.1)$ & $0.55 \quad 0.28-1.07$ & 0.080 & $0.550 .26-1.14$ & 0.105 \\
\hline $75-79$ years & $134 / 180(74.4)$ & $0.330 .18-0.60$ & $<0.001$ & $0.350 .18-0.69$ & 0.002 \\
\hline$\geq 80$ years & $114 / 232(49.1)$ & $0.110 .06-0.19$ & $<0.001$ & $0.100 .05-0.20$ & $<0.001$ \\
\hline \multicolumn{6}{|l|}{ Stage } \\
\hline 1 & $108 / 141(76.6)$ & 1 (ref) & & 1 (ref) & \\
\hline II-IV & 407/552 (73.7) & $0.860 .56-1.32$ & 0.488 & $0.850 .52-1.39$ & 0.521 \\
\hline Unknown & $4 / 32(12.5)$ & $0.040 .01-0.13$ & $<0.001$ & $0.040 .01-0.14$ & $<0.001$ \\
\hline \multicolumn{6}{|l|}{ No. of comorbidity } \\
\hline None & 79/94 (84.0) & 1 (ref) & & & \\
\hline One & $144 / 177(81.4)$ & $0.830 .43-1.64$ & 0.582 & & \\
\hline Two or more & $296 / 454(65.2)$ & $0.360 .20-0.64$ & 0.001 & & \\
\hline \multicolumn{6}{|l|}{ Type of comorbidity } \\
\hline $\begin{array}{l}\text { Ischemic heart disease/ } \\
\text { heart failure }\end{array}$ & $83 / 150(55.3)$ & $0.390 .27-0.57$ & $<0.001$ & $0.390 .25-0.60$ & $<0.001$ \\
\hline $\begin{array}{l}\text { Other cardiovascular } \\
\text { diseases }\end{array}$ & 246/335 (73.4) & $1.180 .39-0.80$ & 0.307 & & \\
\hline Prior malignant disease & $103 / 165(62.4)$ & $0.580 .40-0.83$ & 0.003 & & \\
\hline Diabetes mellitus & $101 / 145(69.7)$ & $0.890 .60-1.32$ & 0.564 & & \\
\hline Pulmonary disease & $69 / 111(62.2)$ & $0.600 .39-0.91$ & 0.018 & & \\
\hline Digestive tract disease & $62 / 94(66.0)$ & $0.740 .47-1.17$ & 0.196 & & \\
\hline $\begin{array}{l}\text { Muscle, connective tissue } \\
\text { and joint disease }\end{array}$ & $34 / 56(60.7)$ & $0.590 .33-1.03$ & 0.063 & $0.48 \quad 0.25-0.94$ & 0.032 \\
\hline Genitourinary disease & $18 / 40(45.0)$ & $0.300 .16-0.57$ & $<0.001$ & $0.300 .14-0.63$ & 0.001 \\
\hline CNS disease & 9/31 (29.0) & $0.150 .07-0.33$ & $<0.001$ & $0.100 .04-0.25$ & $<0.001$ \\
\hline Infectious disease & $12 / 16(75.0)$ & $1.200 .38-3.75$ & 0.760 & & \\
\hline
\end{tabular}

\section{Factors associated with completion of R-CHOP therapy among elderly stage II-IV DLBCL patients}

Multivariable logistic regression analyses showed that in patients aged 80 years or older were less able to complete R-CHOP therapy, as compared to their relatively younger counterparts (OR: $0.48,95 \% \mathrm{Cl} 0.25-0.93, \mathrm{p}=0.03$; Table 4.3). Furthermore, R-CHOP therapy was less often completed in patients with diabetes mellitus (OR: 0.41, $\mathrm{Cl}$ 0.24-0.70, $\mathrm{p}=0.001$ ). No association was found between other comorbidities or the number of comorbidities and completion of R-CHOP treatment. 
Table 4.3 Results of the logistic regression analyses on potential predictors associated with the completion of R-CHOP therapy among stage II-IV patients with DLBCL in the Netherlands, 2014.

\begin{tabular}{|c|c|c|c|c|c|c|c|c|}
\hline \multirow[b]{2}{*}{ Independent variable } & \multicolumn{2}{|c|}{$\begin{array}{l}\text { Intensive therapy } \\
\text { (n/N; \%) }\end{array}$} & \multicolumn{3}{|c|}{ Univariable } & \multicolumn{3}{|c|}{$\begin{array}{c}\text { Multivariable } \\
\text { (backward selection) }\end{array}$} \\
\hline & & & OR & $95 \% \mathrm{Cl}$ & $\mathbf{p}$ & OR & $95 \% \mathrm{Cl}$ & $\mathbf{p}$ \\
\hline \multicolumn{9}{|l|}{ Sex } \\
\hline Male & $175 / 224$ & (78.1) & 1 & (ref) & & & & \\
\hline Female & $136 / 180$ & (75.6) & 0.87 & $0.54-1.38$ & 0.542 & & & \\
\hline \multicolumn{9}{|l|}{ Age at diagnosis } \\
\hline 65-69 years & $88 / 109$ & $(80.7)$ & 1 & (ref) & & 1 & (ref) & \\
\hline 70-74 years & $91 / 106$ & (85.9) & 1.45 & $0.70-2.99$ & 0.317 & 1.36 & $0.65-2.83$ & 0.415 \\
\hline $75-79$ years & $72 / 101$ & (71.3) & 0.59 & $0.31-1.13$ & 0.110 & 0.58 & $0.30-1.11$ & 0.104 \\
\hline$\geq 80$ years & $60 / 88$ & $(68.2)$ & 0.51 & $0.27-0.98$ & 0.044 & 0.48 & $0.25-0.93$ & 0.030 \\
\hline \multicolumn{9}{|l|}{ No. of comorbidity } \\
\hline None & $48 / 61$ & (78.7) & 1 & (ref) & & & & \\
\hline One & $84 / 103$ & (81.6) & 1.20 & $0.54-2.64$ & 0.655 & & & \\
\hline Two or more & $179 / 240$ & (74.6) & 0.79 & $0.40-1.57$ & 0.507 & & & \\
\hline \multicolumn{9}{|l|}{ Type of comorbidity } \\
\hline $\begin{array}{l}\text { Ischemic heart disease/heart } \\
\text { failure }\end{array}$ & $46 / 66$ & $(69.7)$ & 0.63 & $0.35-1.14$ & 0.127 & & & \\
\hline Other cardiovascular diseases & $148 / 194$ & $(76.3)$ & 0.93 & $0.58-1.47$ & 0.751 & & & \\
\hline Prior malignant disease & $62 / 79$ & (79.5) & 1.20 & $0.65-2.20$ & 0.559 & & & \\
\hline Diabetes mellitus & $51 / 81$ & (63.0) & 0.41 & $0.24-0.70$ & 0.001 & 0.41 & $0.24-0.70$ & 0.001 \\
\hline Pulmonary disease & $43 / 57$ & (75.4) & 0.91 & $0.47-1.74$ & 0.766 & & & \\
\hline Digestive tract disease & $36 / 45$ & $(80.0)$ & 1.22 & $0.57-2.64$ & 0.610 & & & \\
\hline $\begin{array}{l}\text { Muscle, connective tissue and } \\
\text { joint disease }\end{array}$ & $25 / 28$ & $(89.3)$ & 2.62 & $0.77-8.89$ & 0.122 & & & \\
\hline Genitourinary disease & $11 / 16$ & $(68.8)$ & 0.65 & $0.22-1.91$ & 0.428 & & & \\
\hline CNS disease & $7 / 9$ & (77.8) & 1.05 & $0.21-5.13$ & 0.954 & & & \\
\hline Infectious disease & $6 / 9$ & $(66.7)$ & 0.59 & $0.14-2.41$ & 0.462 & & & \\
\hline
\end{tabular}

\section{Mortality and overall survival among elderly DLBCL patients treated with intensive therapy}

Median follow-up of patients treated with intensive therapy was 28 months (range, 0-37 months) and this did no differ between the four age categories.

Of the 160 patients treated with curative intent in the age category 65-69 years, 47 patients $(29.4 \%)$ died during follow-up. According to age category, 41 of 144 patients $(28.5 \%)$ aged $70-74$ years, 45 of 148 patients (30.4\%) and 44 of 126 patients (34.9\%) aged older than 79 years died during follow-up (data not shown). There was no statistically significant difference in mortality between patients of the four age categories $(p=0.68)$.

Median OS was not reached for elderly DLBCL patients treated with intensive therapy and no difference was observed between the four age categories (Figure 4.3; $p=0.75$ ). The 2-year OS for elderly DLBCL patients treated with intensive therapy in the four age categories were $75 \%$ (95\% Cl 68\%-81\%), 76\% (68\%-82\%), 74\% (66\%-80\%) and 67\% (58\%-75\%), respectively. 


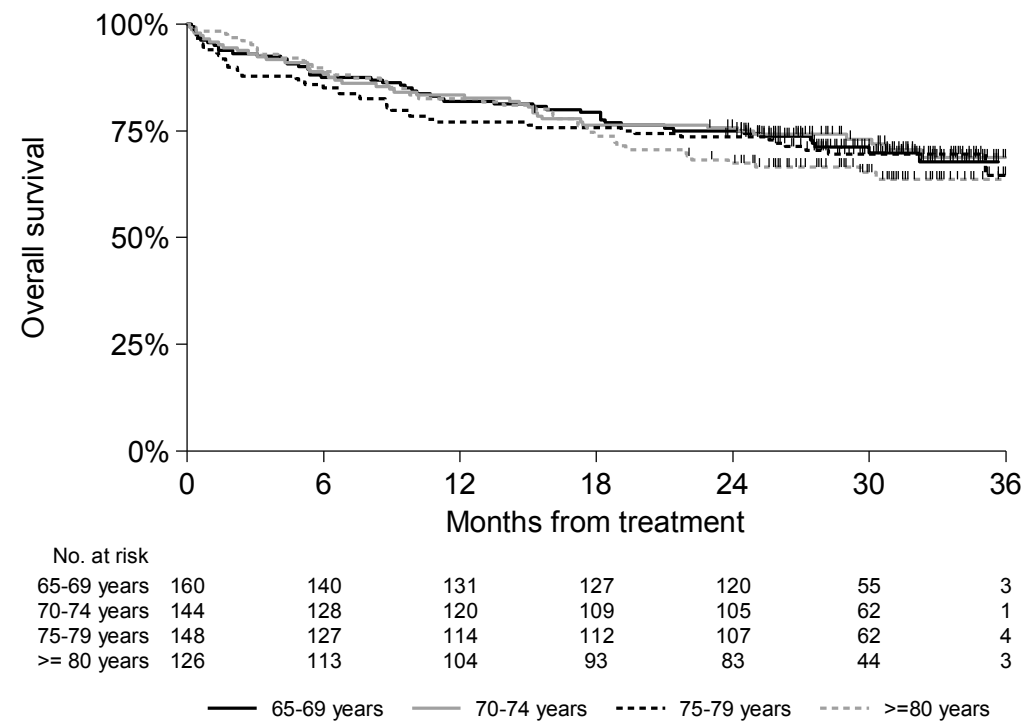

Figure 4.3 Overall survival of patients with DLBCL treated with intensive therapy according to age. OS was measured with the Kaplan-Meier method as the time from treatment to death or last follow-up, and compared with the log-rank test.

\section{Discussion}

In this nationwide population-based analysis on the primary treatment of elderly DLBCL patients in the Netherlands, treatment schedules with rituximab and anthracycline-containing chemotherapy were frequently applied in all age categories. These results compare well to those observed in other population-based studies among elderly patients with DLBCL, in which $33-70 \%$ of patients were treated with curative intent (that is, CHOP or CHOP-like chemotherapy). ${ }^{4-6}$ In our study, only $50 \%$ of patients aged $\geq 80$ years were treated with regimens containing rituximab and anthracyclines; this is much less than their younger counterparts aged 65-79 years. Multivariable logistisic regression analysis confirmed an association between higher age and less frequent application of intensive treatment. In addition, up to $25 \%$ of patients aged $\geq 80$ years received no anti-lymphoma therapy at all. As shown in previous studies, refrainment from standard immunochemotherapy in elderly DLBCL patients confers a negative impact on survival and chemotherapy regimes without anthracyclines are known to be less effective. ${ }^{4-6,14,21,22}$ Also in very elderly DLBCL patients, standard therapy does improve survival compared to suboptimal or no antilymphoma treatment. ${ }^{5,6,21,23}$ Therefore, also in the very elderly, treatment with $\mathrm{R}$ - 
CHOP should always be considered, because age alone should not be a contraindication for treatment with curative intent.

In the present study, the prevalence of comorbidities ranged from $80 \%$ in patients aged $65-69$ years to $91 \%$ in patients aged $\geq 80$ years. This high prevalence is congruent with findings from other population-based studies. ${ }^{8-11}$ With respect to the decision to apply intensive treatment, we found no association between numbers of comorbidities and application of intensive therapy. However, we did observe an association between the type of comorbidity and intensive treatment, whereby patients with ischemic heart disease or heart failure, muscle, connective tissue and joint disease, genitourinary disease, or CNS disease were less often treated with curative intent. These results are in accordance with the results of a survey among Dutch haematologists, in which cognitive disorders and cardiovascular comorbidities were the most important factors related to treatment decision-making in elderly DLBCL patients. ${ }^{12,13}$ Several population-based studies suggest, in accordance with our findings, that chemotherapy is less frequently applied in the presence of comorbidity. ${ }^{8-10,14,17}$ As observed in our study, in the presence of cardiovascular morbidity, the likelihood of receiving chemotherapy is significantly lower compared to those without comorbidity. ${ }^{6,8}$ In addition, cardiovascular comorbidity is associated with a higher likelihood of developing toxicity and has a strong adverse prognostic effect. $^{8,9}$ This might be explained by the use of doxorubicin in R-CHOP, which is associated with cardiotoxicity. ${ }^{24}$

Of all patients treated with $\mathrm{R}-\mathrm{CHOP}$ for stage II-IV DLBCL, $21 \%$ received less than six cycles of R-CHOP, suggesting that a relatively large proportion of patients is unable to complete the planned number of cycles. With respect to completion of intensive treatment, we observed that patients aged 80 years or older and patients with diabetes mellitus more frequently did not complete R-CHOP therapy. This might be explained by a restricted performance status in these patient categories or by treatment-related toxicity. An association between diabetes mellitus and inability to complete chemotherapy was not described before. Although a positive association between diabetes mellitus and the risk of $\mathrm{NHL}$ is described, the prognostic significance of diabetes mellitus on lymphoma outcome is inconclusive. ${ }^{25-27}$ In other studies, it was observed that patients with a high Charlson comorbidity index were less likely to complete their planned scheme, as compared to patients with a low Charlson comorbidity. ${ }^{15,16}$ We did not observe an association between number of comorbidities and completion of R-CHOP therapy or between other comorbidities than diabetes mellitus and completion of R-CHOP, and this may reflect a selection bias of the most fit patients with comorbidities receiving R-CHOP.

It is generally well accepted that incomplete administration of treatment is largely associated with inferior survival. ${ }^{4-6,28}$ Prior population-based studies observed that almost $70 \%$ of elderly patients treated with CHOP-like therapy experience toxicity, predominantly febrile neutropenia, infections and haematological toxicity. ${ }^{4,6}$ Toxicity 
is the main reason for incomplete R-CHOP treatment, but also decline in performance status during treatment, patient's decision and progressive disease are arguments for incomplete administration of chemotherapy. . $6,11,22,29,30$ The association between comorbidity and treatment-related toxicity remains unclear, with studies showing opposite results. ${ }^{8,15}$ Before discontinuing R-CHOP chemotherapy in elderly patients for reasons related to (febrile) neutropenia or infections, additional treatment with granulocyte colony-stimulating factor should be considered, since this might increase the absolute number of treatable elderly patients. ${ }^{29}$

Interestingly, there were patients treated more intensively than recommended by the current guidelines, with a higher number of cycles of R-CHOP14 or R-CHOP21 being administered. This was regardless of disease stage. Although the reasons for more intensive treatment are unclear, it may cause excess toxicity in a patient group that is already prone to treatment-related toxicity; therefore, this should be avoided. ${ }^{4,6,31-33}$ We observed no difference in mortality and overall survival between old and very old patients, suggesting that patients in the oldest age category can tolerate treatment with curative intent as well as their younger counterparts and have an equal benefit. This finding apparently suggests that haematologists are well capable in selecting older patients who are fit enough to receive intensive treatment. This does not imply, however, that there were no patients in the non-intensive group that would have benefitted from intensive therapy.

A limitation of this study is that information on reasons for non-adherence to treatment guidelines is not recorded in the NCR. The main strength of our study is the population-based nature, which reflects treatment in the general population of elderly DLBCL patients, as opposed to randomized controlled trials in which only highly selected patients are included.

In conclusion, curative treatment with rituximab and anthracycline-containing chemotherapy was the most frequently applied therapy in elderly DLBCL patients. However, as shown in our study, older age and certain comorbid conditions are currently, in a modern era of well-established $\mathrm{NHL}$ therapy, still associated with treatment decision-making with less frequent application of intensive treatment and less completion of R-CHOP. Overall survival and mortality did not differ between patients of different age categories treated intensively, suggesting that this treatment has equal benefit for these patients. Curative treatment should always be considered in elderly DLBCL patients, irrespective of chronological age and also in patients with comorbidities, since DLBCL is a curable disease. 


\section{References}

1. https://seer.cancer.gov/.

2. Coiffier B, Lepage E, Briere J, Herbrecht R, Tilly H, Bouabdallah R, et al. CHOP chemotherapy plus rituximab compared with $\mathrm{CHOP}$ alone in elderly patients with diffuse large-B-cell lymphoma. N Engl J Med 2002;346(4):235-42.

3. Feugier $P$, Van Hoof A, Sebban C, Solal-Celigny $P$, Bouabdallah R, Ferme $C$, et al. Long-term results of the R-CHOP study in the treatment of elderly patients with diffuse large B-cell lymphoma: a study by the Groupe d'Etude des Lymphomes de I'Adulte. J Clin Oncol 2005;23(18):4117-26.

4. Boslooper K, Kibbelaar R, Storm H, Veeger NJ, Hovenga S, Woolthuis G, et al. Treatment with rituximab, cyclophosphamide, doxorubicin, vincristine and prednisolone is beneficial but toxic in very elderly patients with diffuse large B-cell lymphoma: a population-based cohort study on treatment, toxicity and outcome. Leuk Lymphoma 2014;55(3):526-32.

5. Varga C, Holcroft C, Kezouh A, Bucatel S, Johnson N, Petrogiannis-Haliotis T, et al. Comparison of outcomes among patients aged 80 and over and younger patients with diffuse large B-cell lymphoma: a population based study. Leuk Lymphoma 2014;55(3):533-7.

6. van de Schans SA, Wymenga AN, van Spronsen DJ, Schouten HC, Coebergh JW, Janssen-Heijnen ML. Two sides of the medallion: poor treatment tolerance but better survival by standard chemotherapy in elderly patients with advanced-stage diffuse large B-cell lymphoma. Ann Oncol 2012;23(5):1280-6.

7. Oerlemans S, Issa DE, van den Broek EC, Nijziel MR, Coebergh JW, Huijgens PC, et al. Health-related quality of life and persistent symptoms in relation to (R-)CHOP14, (R-)CHOP21, and other therapies among patients with diffuse large B-cell lymphoma: results of the population-based PHAROS-registry. Ann Hematol 2014;93(10):1705-15.

8. Janssen-Heijnen ML, van Spronsen DJ, Lemmens VE, Houterman S, Verheij KD, Coebergh JW. A population-based study of severity of comorbidity among patients with non-Hodgkin's lymphoma: prognostic impact independent of International Prognostic Index. Br J Haematol 2005;129(5):597-606.

9. van Spronsen DJ, Janssen-Heijnen ML, Lemmens VE, Peters WG, Coebergh JW. Independent prognostic effect of co-morbidity in lymphoma patients: results of the population-based Eindhoven Cancer Registry. Eur J Cancer 2005;41(7):1051-7.

10. van Spronsen DJ, Janssen-Heijnen ML, Breed WP, Coebergh JW. Prevalence of co-morbidity and its relationship to treatment among unselected patients with Hodgkin's disease and non-Hodgkin's lymphoma, 1993-1996. Ann Hematol 1999;78(7):315-9.

11. Thieblemont C, Grossoeuvre A, Houot R, Broussais-Guillaumont F, Salles G, Traulle C, et al. NonHodgkin's lymphoma in very elderly patients over 80 years. A descriptive analysis of clinical presentation and outcome. Ann Oncol 2008;19(4):774-9.

12. van der Poel MW, Mulder WJ, Ossenkoppele GJ, Maartense E, Hoogendoorn M, Wijermans P, et al. Factors that influence treatment decision-making in elderly $D L B C L$ patients: a case vignette study. Ann Hematol 2015;94(8):1373-9.

13. van der Poel MW, Mulder WJ, Ossenkoppele GJ, Maartense E, Wijermans P, Hoogendoorn M, et al. Comorbidity and treatment decision-making in elderly non-Hodgkin's lymphoma patients: a survey among haematologists. Neth J Med 2014;72(3):165-9.

14. Tien YY, Link BK, Brooks JM, Wright K, Chrischilles E. Treatment of diffuse large B-cell lymphoma in the elderly: regimens without anthracyclines are common and not futile. Leuk Lymphoma 2015;56(1): 65-71.

15. Wieringa A, Boslooper K, Hoogendoorn M, Joosten P, Beerden T, Storm H, et al. Comorbidity is an independent prognostic factor in patients with advanced-stage diffuse large B-cell lymphoma treated with R-CHOP: a population-based cohort study. Br J Haematol 2014;165(4):489-96.

16. Kobayashi Y, Miura K, Hojo A, Hatta Y, Tanaka T, Kurita D, et al. Charlson Comorbidity Index is an independent prognostic factor among elderly patients with diffuse large B-cell lymphoma. J Cancer Res Clin Oncol 2011;137(7):1079-84. 
17. Lin TL, Kuo MC, Shih LY, Dunn P, Wang PN, Wu JH, et al. The impact of age, Charlson comorbidity index, and performance status on treatment of elderly patients with diffuse large B cell lymphoma. Ann Hematol 2012;91(9):1383-91.

18. Merli F, Luminari S, Rossi G, Mammi C, Marcheselli L, Ferrari A, et al. Outcome of frail elderly patients with diffuse large B-cell lymphoma prospectively identified by Comprehensive Geriatric Assessment: results from a study of the Fondazione Italiana Linfomi. Leuk Lymphoma 2014;55(1):38-43.

19. Schouten LJ, Hoppener P, van den Brandt PA, Knottnerus JA, Jager JJ. Completeness of cancer registration in Limburg, The Netherlands. Int J Epidemiol 1993;22(3):369-76.

20. Dinmohamed AG, Huijgens PC, Brink M, Posthuma EF, Uyl de Groot CA, Blijlevens NM, et al. Het hemato-oncologieregister van de Nederlandse Kankerregistratie: verleden, heden en toekomst. NTvH 2017;14:55-63.

21. Bairey O, Benjamini O, Blickstein D, Elis A, Ruchlemer R. Non-Hodgkin's lymphoma in patients 80 years of age or older. Ann Oncol 2006;17(6):928-34.

22. Chihara D, Westin JR, Oki Y, Ahmed MA, Do B, Fayad LE, et al. Management strategies and outcomes for very elderly patients with diffuse large B-cell lymphoma. Cancer 2016;122(20):3145-51.

23. Peyrade F, Jardin F, Thieblemont C, Thyss A, Emile JF, Castaigne S, et al. Attenuated immunochemotherapy regimen (R-miniCHOP) in elderly patients older than 80 years with diffuse large B-cell lymphoma: a multicentre, single-arm, phase 2 trial. Lancet Oncol 2011;12(5):460-8.

24. Hershman DL, McBride RB, Eisenberger A, Tsai WY, Grann VR, Jacobson JS. Doxorubicin, cardiac risk factors, and cardiac toxicity in elderly patients with diffuse B-cell non-Hodgkin's lymphoma. J Clin Oncol 2008;26(19):3159-65.

25. Lin SY, Hsieh MS, Chen LS, Chiu YH, Yen AM, Chen TH. Diabetes mellitus associated with the occurrence and prognosis of non-Hodgkin's lymphoma. Eur J Cancer Prev 2007;16(5):471-8.

26. Lu HJ, Huang YC, Liu $\mathrm{CY}$, Hung $\mathrm{MH}, \mathrm{Hu} \mathrm{MH}, \mathrm{Wu} \mathrm{CY}$, et al. Diminishing prognostic role of preexisting diabetes mellitus for patients with diffuse large B-cell lymphoma in the rituximab era. Ann Hematol 2013;92(11):1495-501.

27. Chao C, Page JH. Type 2 diabetes mellitus and risk of non-Hodgkin lymphoma: a systematic review and meta-analysis. Am J Epidemiol 2008;168(5):471-80.

28. Kanemasa Y, Shimoyama T, Sasaki Y, Tamura M, Sawada T, Omuro Y, et al. The impacts of initial and relative dose intensity of $\mathrm{R}-\mathrm{CHOP}$ on outcomes of elderly patients with diffuse large B-cell lymphoma. Leuk Lymphoma 2017;58(3):736-9.

29. Peters FP, Fickers MM, Erdkamp FL, Wals J, Wils JA, Schouten HC. The effect of optimal treatment on elderly patients with aggressive non-Hodgkin's lymphoma: more patients treated with unaffected response rates. Ann Hematol 2001;80(7):406-10.

30. Peters FP, Lalisang RI, Fickers MM, Erdkamp FL, Wils JA, Houben SG, et al. Treatment of elderly patients with intermediate- and high-grade non-Hodgkin's lymphoma: a retrospective populationbased study. Ann Hematol 2001;80(3):155-9.

31. Delarue R, Tilly H, Mounier N, Petrella T, Salles G, Thieblemont C, et al. Dose-dense rituximab-CHOP compared with standard rituximab-CHOP in elderly patients with diffuse large B-cell lymphoma (the LNH03-6B study): a randomised phase 3 trial. Lancet Oncol 2013;14(6):525-33.

32. Gonzalez-Barca E, Canales MA, Salar A, Ferrer S, Domingo-Domenech E, Vidal MJ, et al. Long-Term Follow-Up of a Phase II Trial of Six Cycles of Dose-Dense R-CHOP-14 for First-Line Treatment of Diffuse Large B-Cell Lymphoma in Young and Elderly Patients. Acta Haematol 2016;136(2):76-84.

33. Pfreundschuh $M$, Schubert J, Ziepert $M$, Schmits $R$, Mohren $M$, Lengfelder $E$, et al. Six versus eight cycles of bi-weekly CHOP-14 with or without rituximab in elderly patients with aggressive CD20+ Bcell lymphomas: a randomised controlled trial (RICOVER-60). Lancet Oncol 2008;9(2):105-16. 



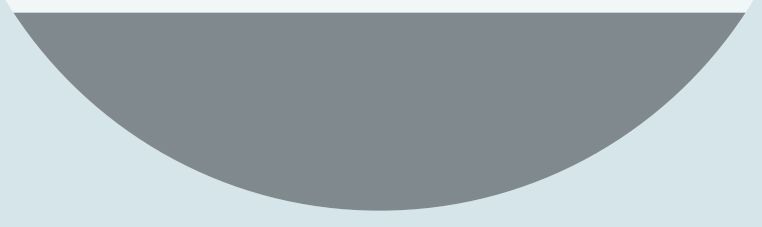




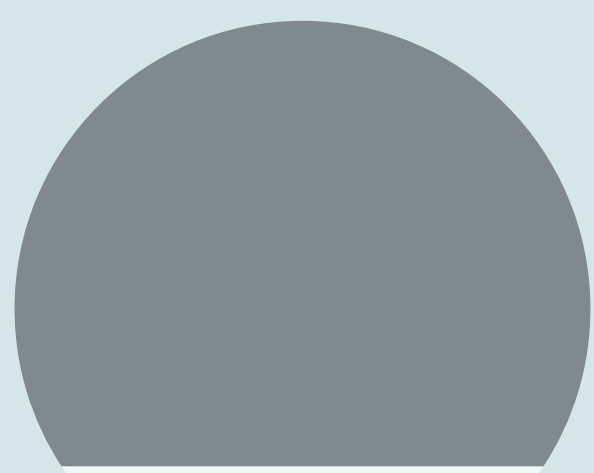

Quality of life more impaired in younger than in older diffuse large B-cell lymphoma survivors compared to a normative population: A study from the population-based PROFILES registry

Ann Hematol. 2014;93:811-9 


\section{Abstract}

\section{Purpose}

The objective of this study was to compare Health-Related Quality of Life (HRQOL) between Diffuse Large B-Cell Lymphoma (DLBCL) survivors of different age categories (18-59 years/ 60-75 years/ 76-85 years) and to compare their HRQOL with an age- and sex-matched normative population.

\section{Methods}

The population-based Eindhoven Cancer Registry was used to select all patients diagnosed with DLBCL from 1999 to 2010. Patients $(n=363)$ were invited to complete the EORTC QLQ-C30 questionnaire and 307 survivors responded (85\%). Data from an age-and sex-matched normative population $(n=596)$ were used for comparison.

\section{Results}

DLBCL survivors aged 18-59 years scored better on physical functioning, quality of life, appetite loss and constipation than survivors of $76-85$ years old (all $p<.05$ ). Financial problems more often occurred in survivors aged 18-59 years compared to survivors of 76-85 years old $(p<.01)$. Compared to the normative population, DLBCL survivors aged $18-59$ years showed worse scores on cognitive and social functioning and on dyspnea and financial problems $(p<.01$, large and medium size effects). In survivors of the other age categories only differences with trivial or small size effects were found.

\section{Conclusion}

Although younger DLBCL survivors have better HRQOL than older survivors, the differences found between younger survivors and the normative population were the largest. This suggests that having DLBCL has a greater impact on younger than on older survivors and that the worse HRQOL observed in older DLBCL survivors in comparison with younger survivors is caused mostly by age itself and not by the disease. 


\section{Introduction}

In the Netherlands, approximately 1,572 patients were newly diagnosed with aggressive non-Hodgkin lymphoma (NHL) in the year 2007 and this number is expected to increase to almost 1,900 in the year 2020. More than $50 \%$ of them are older than 50 years at time of diagnosis. The ten-year prevalence of aggressive $\mathrm{NHL}$, with 6,570 patients in the year 2009, is expected to increase to approximately 10,600 patients in $2020 .^{1}$

Diffuse large B-cell lymphoma (DLBCL) is the most common subtype of aggressive B-cell NHL with a median age at diagnosis of over 60 years. There is an increasing number of DLBCL survivors due to effective treatments and the ageing of the population. A patient is defined as a cancer survivor from the time of diagnosis through the rest of his life. ${ }^{2}$

Several studies show that treatment with standard chemotherapy in combination with rituximab improves complete remission rates and survival also in elderly DLBCL patients. ${ }^{3-6}$ However, in daily clinical practice elderly patients less often receive standard chemotherapy schedules in comparison with younger patients. ${ }^{5-7}$ Reasons for suboptimal treatment are, amongst others, co-morbidity and poor performance status but also high age in itself is considered by doctors as a reason to not give standard treatment. ${ }^{5-9}$ Furthermore, the effect of cancer treatment on the quality of life of elderly patients is an important concern.

There is a growing interest in the impact of disease-related effects of NHL and its treatment on the health-related quality of life (HRQOL) of (elderly) NHL survivors. Several studies showed that having $\mathrm{NHL}$ is accompanied by a deterioration in various domains of HRQOL. ${ }^{10-18}$ Although there are indications that HRQOL improves after treatment, there are also indications that it remains reduced in comparison with the general population. ${ }^{10-13,16}$ there are also indications that it remains reduced in comparison with the general population ${ }^{15}$ Little is known about age-related differences in HRQOL among DLBCL survivors.

Therefore, the aims of the present study were to compare HRQOL between DLBCL survivors younger than 60 years, those aged 60 to 75 years and those older than 75 years, to assess age-related differences and to identify possible associations between socio-demographic and clinical characteristics with HRQOL. Furthermore, we compared the HRQOL of DLBCL survivors with an age-matched general population to distinguish between the impact of DLBCL on HRQOL and of age itself on HRQOL. We hypothesize that HRQOL is more impaired in older survivors in comparison with younger survivors and that HRQOL is worse among DLBCL survivors in comparison with the normative population. 


\section{Methods}

\section{Setting and population}

This study is part of a dynamic population-based survey among NHL survivors registered with the Eindhoven Cancer Registry (ECR) of the Comprehensive Cancer Centre South (CCCS). The ECR records data on all patients who are newly diagnosed with cancer in the southern part of the Netherlands, an area with 2.3 million inhabitants, 18 hospital locations and 2 large radiotherapy institutes. The ECR was used to select all patients who were diagnosed with DLBCL between 1/1/1999 and $1 / 12 / 2010$. We included all patients with DLBCL as defined by the International Classification of Diseases for Oncology-3 codes (ICD-O-3). ${ }^{19}$

Participants aged $\geq 85$ years were excluded, because it was expected that they would have difficulty in completing self-administered questionnaires without assistance. To exclude all patients who had died our database was linked with the database of the Central Bureau for Genealogy, which collects data on all deceased Dutch citizens through the civil municipal registries. Ethical approval for the study was obtained from a local, certified Medical Ethics Committee.

\section{Data collection}

Data collection was done within PROFILES (Patient Reported Outcomes Following Initial treatment and Long term Evaluation of Survivorship). PROFILES is a registry for the study of the physical and psychosocial impact of cancer and its treatment from a dynamic, growing population-based cohort of both short and long-term cancer survivors. PROFILES contains a large web-based component and is linked directly to clinical data from ECR. Details of the data collection method have been previously described. ${ }^{20}$

In May 2009, patients between 6 months and 10 years after diagnosis received the first questionnaire. Patients were included from 6 months after diagnosis to minimize the direct effect of the primary treatment, which takes place around the first 6 months after diagnosis, on the study results. In November 2009, patients diagnosed between May 2008 and May 2009 were invited to participate and in May 2011, patients diagnosed between May 2009 and December 2010 were invited to participate.

In 2009, our research group assigned CentERdata (www.centerdata.nl), a research institute at Tilburg University, to collect normative data on HRQOL via the CentERpanel. The CentERpanel is an online household panel consisting of over 2000 households which are representative of the Dutch-speaking population in the Netherlands. For households without internet access, additional provisions were provided to assist in data collection. Of the 1731 cancer-free panel members of 
$\geq 18$ years who completed theEuropean Organization for Research and Treatment of Cancer Quality of Life Questionnaire-Core 30 (EORTC QLQ-C30), 596 could be age- and sex-matched with our DLBCL sample. ${ }^{21}$ For matching, ten strata were formed using sex and age (5 categories). Within each stratum a maximum number of cancer-free panel members were randomly matched according to the "strata frequency distribution" of the patients. This resulted in 596 matched cancer-free panel members for 307 patients.

\section{Study measures}

The validated Dutch version of the EORTC QLQ-C30 was used to assess HRQOL. This is a self-report questionnaire developed by the European Organization for Research and Treatment of Cancer for assessing quality of life in cancer patients. The questionnaire includes five scales on physical, role, emotional, cognitive and social functioning, a global health status/quality of life scale, three symptom scales on fatigue, nausea and vomiting and pain and six single items assessing dyspnea, sleeping problems, appetite loss, constipation, diarrhea and financial problems. Answer categories range from one (not at all) to four (very much). After linear transformation, all scales and single item measures range in score from 0 to 100 . A higher score on the functional scales and global health and quality of life scale means a better HRQOL, whereas a higher score on the symptom scales refers to more symptoms. ${ }^{22}$

Co-morbidity at time of survey was categorized according to the adapted Selfadministered Co-morbidity Questionnaire (SCQ). ${ }^{23}$

Survivors' educational level and marital status was also assessed in the questionnaire. Clinical information was available from the ECR that routinely collects data on tumor characteristics, including date of diagnosis, tumor grade, histology, Ann Arbor stage, primary treatment, and patients' background characteristics, including gender and date of birth.

\section{Statistical analysis}

All statistical analyses were performed using SAS (version 9.1 for Windows; SAS Institute Inc.,Cary, NC). P-values of $<.05$ were considered statistically significant. Clinical important differences were determined using the evidence-based guidelines for interpretation of the EORTC QLQ-C30. ${ }^{24}$ The size effect as measured by the EORTC QLQ-C30 is divided into four size classes. Large: one representing unequivocal clinical relevance. Medium: likely to be clinically relevant but to a lesser extent. Small: subtle but nevertheless clinically relevant. Trivial: circumstances unlikely to have any clinical relevance or where there was no difference. Patients and respondents of the normative population were categorized into three age groups, namely younger than 60 years, 60-75 years and older than 75 years. 
Differences in demographic and clinical characteristics between respondents, nonrespondents, and patients with unverifiable addresses were compared with analysis of variance (ANOVA) for continuous variables and chi-square analyses for categorical variables.

The mean EORTC QLQ-C30 scores between different age groups of DLBCL survivors were compared using ANOVA with Tukey post-hoc tests.

Analyses of covariance (ANCOVA) were carried out to compare the mean EORTC QLQ-C30 scores in the DLBCL survivors with the normative population adjusted for sex, age and co-morbidity.

\section{Results}

\section{Patients' characteristics and normative population}

Questionnaires were sent to 363 DLBCL survivors, 307 completed questionnaires were returned ( $85 \%$ response rate) (Figure 5.1 ). The mean age at time of survey completion was 63.7 years with a mean time since diagnosis of 3.4 years. Sixty-five percent was male and $80 \%$ had a partner. Almost all patients were treated with chemotherapy (95\%) and $29 \%$ received radiotherapy.

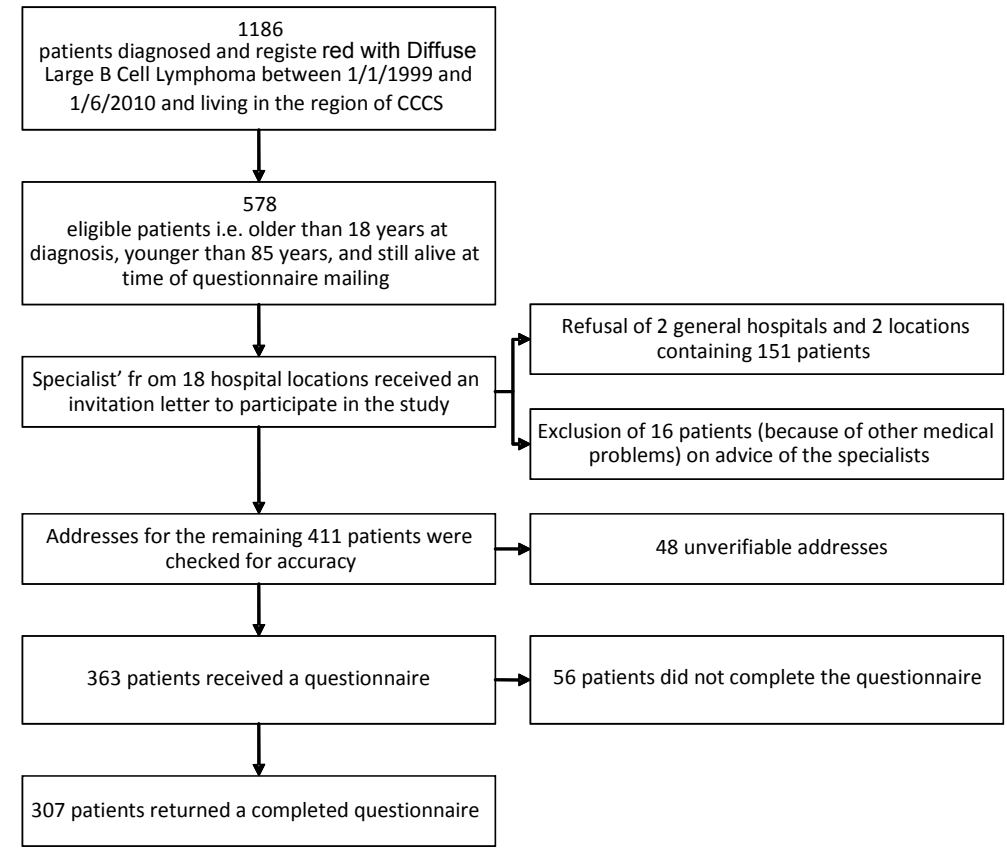

Figure 5.1 Flow chart of the data collection process. 
Compared to respondents, non-respondents were more often female (35\% versus $55 \% ; p<0.01$ ) and patients with unverifiable addresses more often did not receive chemotherapy as primary treatment (95\% versus $85 \% \mathrm{p}=0.05)$. No significant differences between respondents, non-respondents and patients with unverifiable addresses were observed for age, years since diagnosis, and stage at diagnosis (data not shown).

With respect to the age- and sex matched normative population, mean age at survey completion was 63.5 years and $67 \%$ was male. Seventy-seven percent had a partner. Almost two thirds (64\%) of respondents reported one or more comorbid conditions, the most common were hypertension, back pain and arthritis. Of the 596 participants, 192 participants were younger than 60 years, 268 participants were aged $60-75$ years and 136 participants were older than 75 years (Table 5.1 ).

Table 5.1 Socio-demographic characteristics of DLBCL survivors ( $N=307)$, and respondents of an ageand sex-matched normative population $(\mathrm{N}=598)$.

\begin{tabular}{|c|c|c|}
\hline & $\begin{array}{c}\text { DLBCL survivors } \\
\begin{array}{c}\mathrm{N}=307 \\
\mathrm{~N}(\%)\end{array} \\
\end{array}$ & $\begin{array}{c}\text { Norm population } \\
\mathrm{N}=596 \\
\mathrm{~N}(\%)\end{array}$ \\
\hline \multicolumn{3}{|l|}{ Sex } \\
\hline Male & $200(65)$ & $398(67)$ \\
\hline Female & $107(35)$ & $198(33)$ \\
\hline Age (at time of survey) (mean \pm SD) & $63.7(12.9)$ & $63.5(13.2)$ \\
\hline $18-59$ & $96(31)$ & $192(32)$ \\
\hline $60-75$ & $145(47)$ & $268(45)$ \\
\hline $76-85$ & $66(22)$ & $136(23)$ \\
\hline \multicolumn{3}{|l|}{ Self-reported comorbidity } \\
\hline No comorbid condition & $88(29)$ & $213(36)$ \\
\hline 1 comorbid condition & $97(32)$ & $166(28)$ \\
\hline 2 comorbid conditions & $54(18)$ & 111 (19) \\
\hline$>2$ comorbid conditions & $44(14)$ & $106(17)$ \\
\hline \multicolumn{3}{|l|}{ Most frequent comorbid conditions } \\
\hline Arthritis & $63(21)$ & $111(21)$ \\
\hline Back pain & $63(21)$ & $149(29)$ \\
\hline Hypertension & $53(17)$ & $147(28)$ \\
\hline Heart condition & $60(20)$ & $69(13)$ \\
\hline \multicolumn{3}{|l|}{ Marital status } \\
\hline Partner & $240(80)$ & $458(77)$ \\
\hline No partner & $59(20)$ & $138(23)$ \\
\hline \multicolumn{3}{|l|}{ Education level $^{\$}$} \\
\hline Low & 56 (19) & $35(6)$ \\
\hline Medium & $176(59)$ & 337 (57) \\
\hline High & $67(22)$ & $222(37)$ \\
\hline
\end{tabular}

$\$$ Education levels included low = no/primary school; medium = lower general secondary education/ vocational training; or high = pre-university education/ high vocational training/university. 
DLBCL survivors aged 18-59 years reported more often no co-morbid conditions and less often more than two co-morbid conditions in comparison with survivors of 76-85 years old $(p<.05)$. The most frequently reported co-morbid conditions were arthritis, back pain, hypertension and heart conditions. All these conditions were less common in respondents between $18-59$ years old $(p<.05)$. No significant differences were found between the three age categories regarding years since diagnosis, stage at diagnosis or primary treatment (Table 5.2).

Table 5.2 Clinical characteristics of DLBCL survivors according to age category at time of questionnaire.

\begin{tabular}{|c|c|c|c|c|}
\hline & $\begin{array}{c}\text { DLBCL } \\
\text { survivors } \\
\text { 18-59 years } \\
\mathrm{N}=96 \\
\end{array}$ & $\begin{array}{c}\text { DLBCL } \\
\text { survivors } \\
60-75 \text { years } \\
\mathrm{N}=145\end{array}$ & $\begin{array}{c}\text { DLBCL } \\
\text { survivors } \\
\text { 76-85 years } \\
\mathrm{N}=66 \\
\end{array}$ & \\
\hline & $\mathbf{N}(\%)$ & $\mathbf{N}(\%)$ & $\mathbf{N}(\%)$ & p-value \\
\hline Years since diagnosis & & & & 0.33 \\
\hline $0.5-1$ & $30(31)$ & $59(41)$ & $27(41)$ & \\
\hline $2-4$ & $40(42)$ & $55(38)$ & $26(39)$ & \\
\hline $5-7$ & $19(20)$ & $24(17)$ & $6(9)$ & \\
\hline $8-10$ & $7(7)$ & $7(5)$ & $7(11)$ & \\
\hline Stage at diagnosis & & & & 0.90 \\
\hline 1 & $34(35)$ & $51(35)$ & $20(32)$ & \\
\hline II & $24(25)$ & $34(24)$ & $16(26)$ & \\
\hline III & $22(23)$ & 27 (19) & $11(18)$ & \\
\hline IV & $16(17)$ & $32(22)$ & $15(24)$ & \\
\hline \multicolumn{5}{|l|}{ Primary treatment } \\
\hline Radiotherapy & $35(36)$ & $39(27)$ & $16(24)$ & 0.17 \\
\hline Chemotherapy & $93(97)$ & $135(93)$ & $63(95)$ & 0.42 \\
\hline Stem cell transplantation & $3(3)$ & $2(1)$ & $2(3)$ & 0.61 \\
\hline No therapy & $1(1)$ & $5(3)$ & $1(2)$ & 0.42 \\
\hline Self-reported comorbidity & & & & $<.05^{\mathrm{a}}$ \\
\hline No comorbid condition & $43(47)$ & $33(25)$ & $12(20)$ & \\
\hline 1 comorbid condition & $23(25)$ & $51(39)$ & $23(38)$ & \\
\hline 2 comorbid conditions & $16(17)$ & $24(18)$ & $14(23)$ & \\
\hline$>2$ comorbid conditions & $9(10)$ & $23(17)$ & $12(20)$ & \\
\hline Most frequent comorbid conditions & & & & $<.05^{\mathrm{b}}$ \\
\hline Arthritis & $11(11)$ & $33(23)$ & $19(29)$ & \\
\hline Back pain & $13(14)$ & $35(24)$ & $15(23)$ & \\
\hline Hypertension & $11(11)$ & $28(19)$ & $14(21)$ & \\
\hline Heart condition & $10(10)$ & $31(21)$ & $19(29)$ & \\
\hline
\end{tabular}

$\mathrm{DLBCL}=$ Diffuse Large B-Cell Lymphoma; a $\mathrm{p}<.05$ between survivors aged 18-59 years and survivors aged 76-85 years; $b$ p $<.05$ between survivors aged $18-59$ years and survivors aged $60-75$ years and between survivors aged $18-59$ years and survivors aged $76-85$ years. 


\section{Comparison between younger and older DLBCL survivors and normative population}

A comparison between patients in the three age categories (18-59 years/ 60-75 years/ 75-85 years) showed that survivors aged 18-59 years scored better on physical functioning $(p<.01)$, global health status/quality of life $(p<.05)$, appetite loss $(p<.01)$ and constipation $(p<.05)$ than survivors aged $76-85$ years (Table 5.3 ). Furthermore, survivors in the age of 60-75 years scored better on global health status/quality of life $(p<.05)$ and appetite loss $(p<.01)$ in comparison with survivors of $76-85$ years old. The size effects of these differences were all trivial or small. Financial problems more often occurred in survivors of 18-59 years old compared to survivors in the age of 76-85 years and this difference has of medium size effect $(p<.01)$.

Compared to an age- and sex-matched normative population, DLBCL survivors of 18-59 years old showed worse scores with a large size effect on cognitive functioning and social functioning $(p<.01$; Figure $5.2 \mathrm{~A})$. Furthermore, there was a small size effect regarding worse scores in physical and role functioning in comparison with the normative population $(p<.01)$. In survivors in the age of $60-75$ years and $76-85$ years worse scores with a small size effect were observed on all EORTC QLQ-C30 functional scales except for global quality of life and except for emotional functioning in survivors of $76-85$ years old ( $\mathrm{p}<.01$; Figure $5.2 \mathrm{~B}-\mathrm{C})$.

With regard to EORTC QLQ-C30 symptom scores, survivors aged 18-59 years old more often reported dyspnea and financial problems ( $p<.01$, medium size effect) and fatigue and sleeping problems ( $p<.01$, small size effect) in comparison with the normative population (Figure 5.3A). A small size effect was observed in survivors between 60 and 75 years with worse scores on fatigue, nausea and vomiting, dyspnea, sleeping problems and financial problems ( $p<.01$; Figure $5.3 B$ ). Survivors between 76-85 years reported more often fatigue, dyspnea, sleeping problems and appetite loss than the normative population. These differences had a small size effect $(p<.01$; Figure 5.3C). 


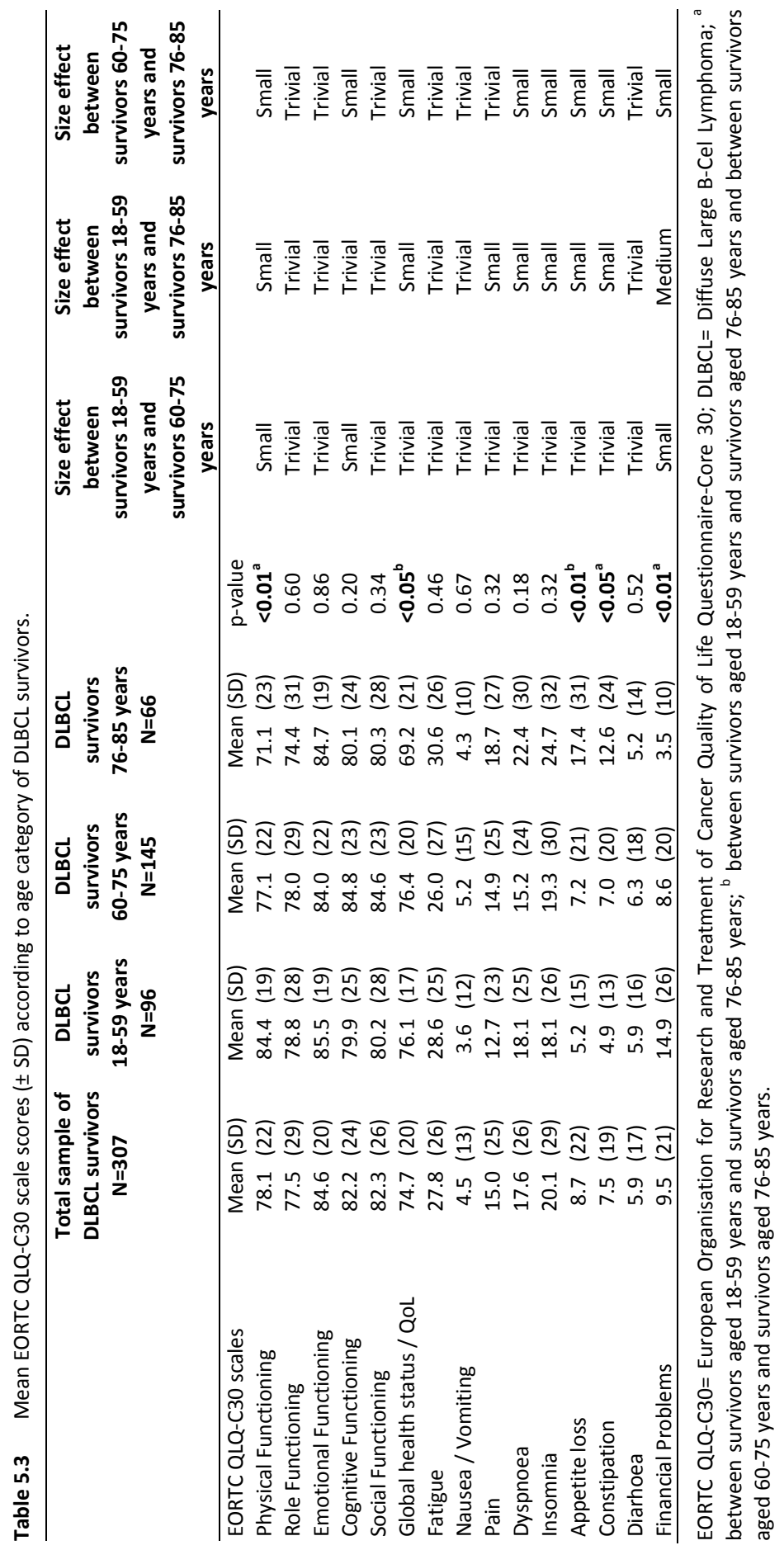


A

DLBCL survivors aged 18-59 years

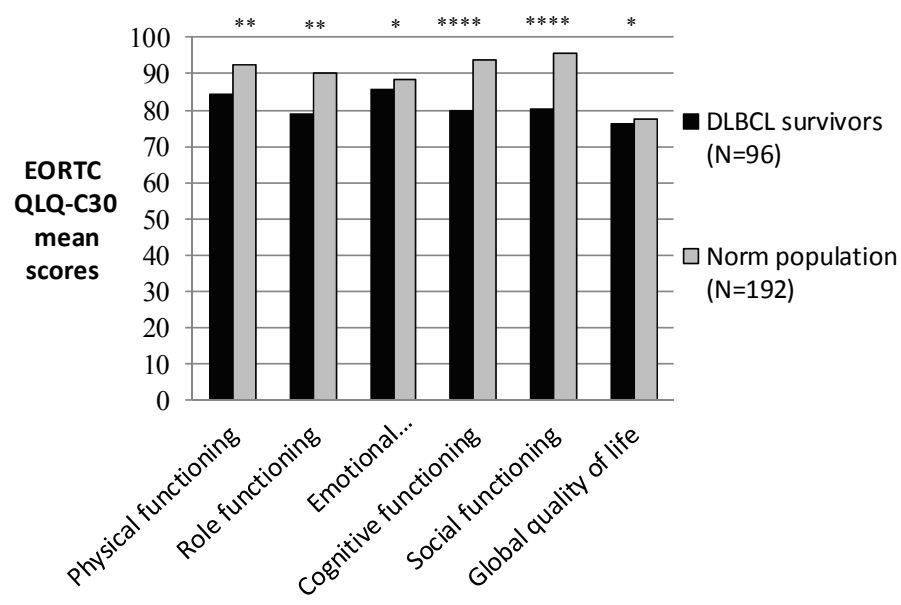

B

DLBCL survivors aged 60-75 years

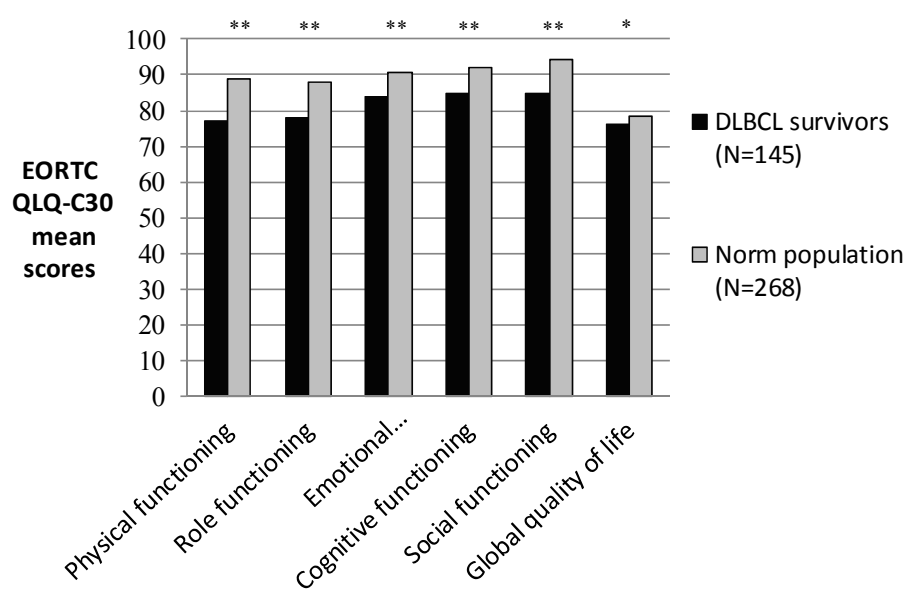


C

DLBCL survivors aged 76-85 years

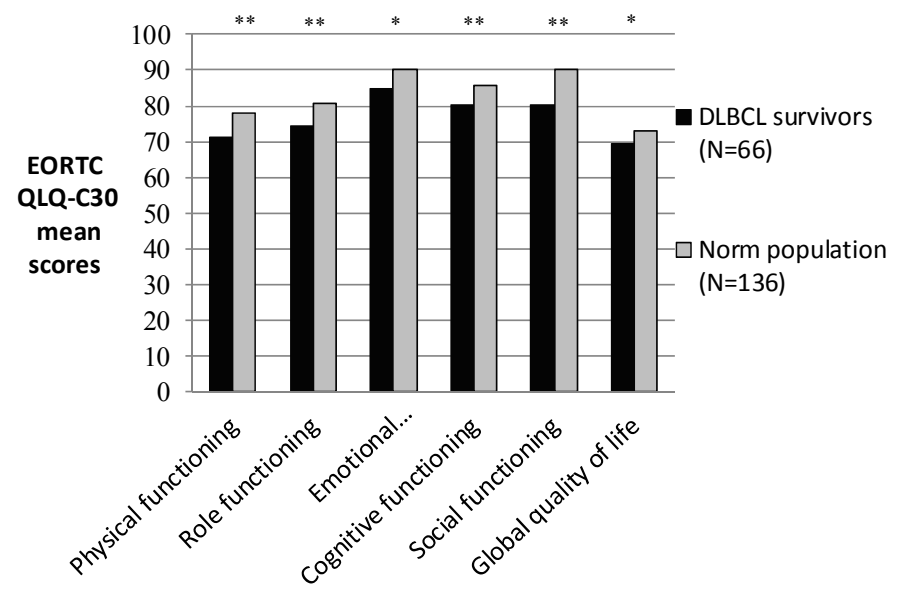

Figure 5.2 Differences on EORTC QLQ-C30 mean functioning and global quality of life scores between DLBCL survivors and an age- and sex-matched normative population. ${ }^{*} \mathrm{p}<.01 ;{ }^{*} \mathrm{p}<.01$ and small size effect; ${ }^{* * *} p<.01$ and medium size effect, ${ }^{* * * *} p<.01$ and large size effect. A higher score implies a better HRQOL.

A

DLBCL survivors aged 18-59 years

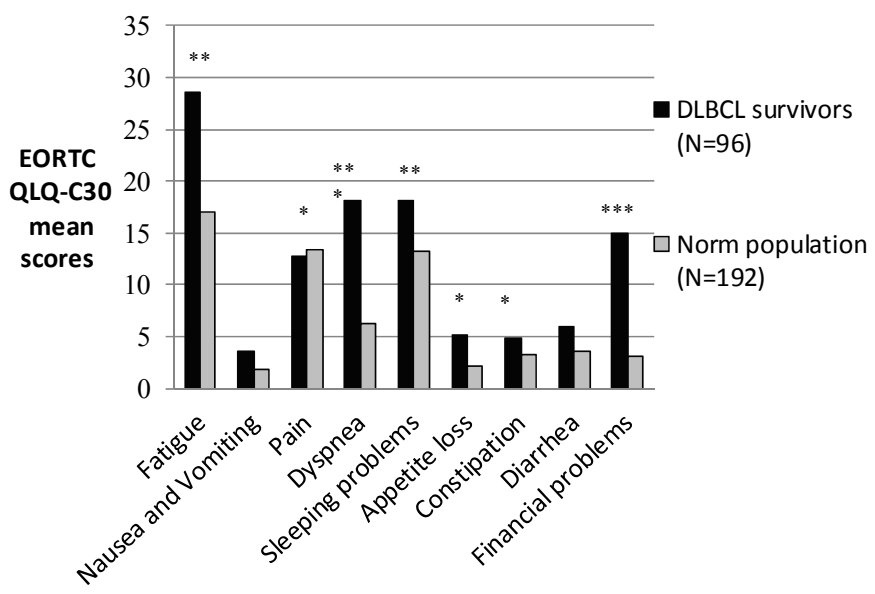


B DLBCL survivors aged 60-75 years

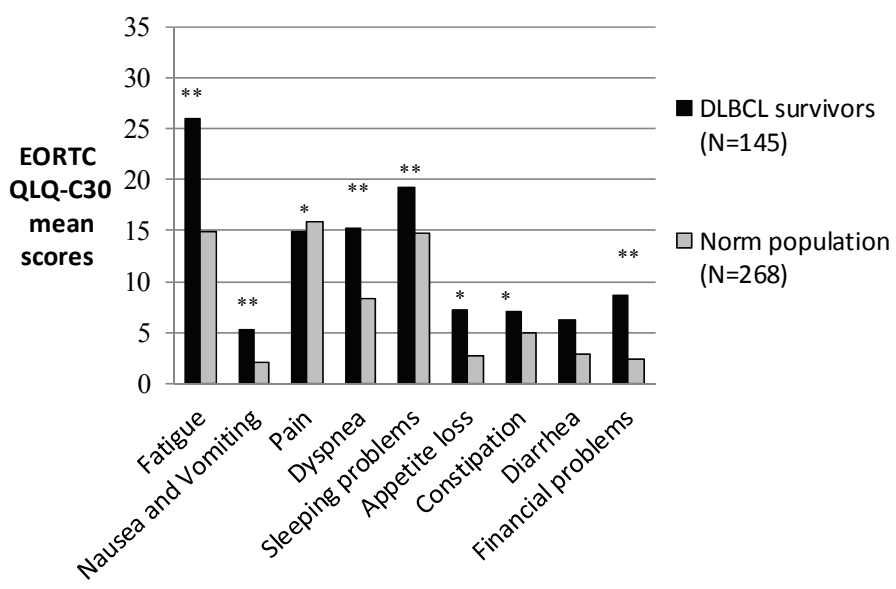

C DLBCL survivors aged 76-85 years

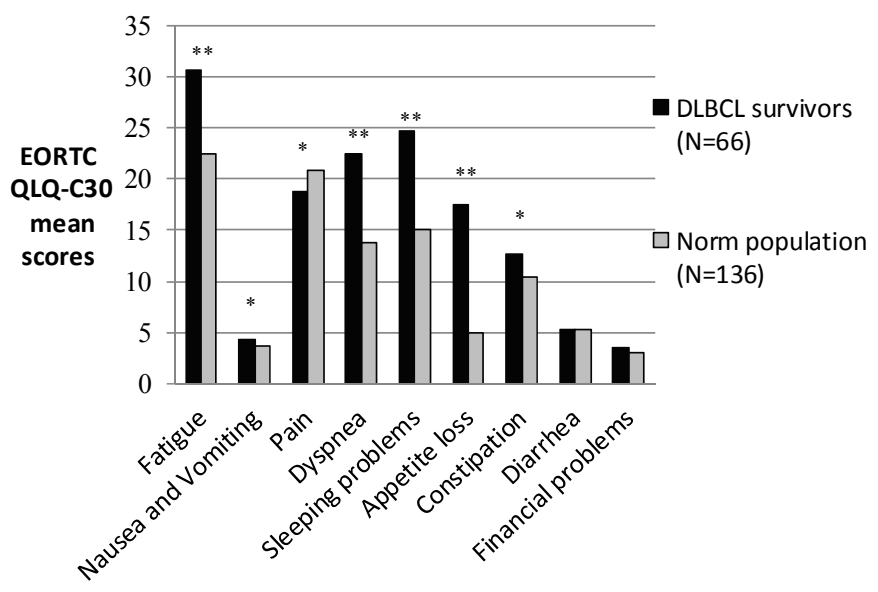

Figure 5.3 Differences on EORTC QLQ-C30 mean symptom scores between DLBCL survivors and an ageand sex-matched normative population. ${ }^{*} p<.01 ;{ }^{* *} p<.01$ and small size effect; ${ }^{* * *} p<.01$ and medium size effect, ${ }^{* * * *} \mathrm{p}<.01$ and large size effect. A higher score refers to more of that symptom. 


\section{Discussion}

The aim of this study was to compare HRQOL between younger and older DLBCL survivors and to compare this with the HRQOL of an age- and sex-matched normative population. In all three age categories deteriorations in several domains of EORTC QLQ-C30 functioning scales were observed. The largest differences were observed between survivors of $18-59$ years old and the normative population with regard to social and cognitive functioning. These results indicate that being diagnosed with and treated for DLBCL has a greater impact with respect to functional status on patients aged 18-59 years than for the elderly in comparison with the age- and sex-matched normative population. This was also found in other studies that compared quality of life between younger and older survivors with different types of malignancies. ${ }^{25,26} \mathrm{~A}$ possible explanation for the differences between younger and older survivors could be that in the natural course of ageing a decline in functional status occurs. Furthermore, elderly survivors might have better coping strategies through more life experience and they are likely to be faced with lower work-related and social demands.

However, we cannot exclude that the elderly DLBCL survivors participating in the present study received less aggressive treatment schedules than the younger survivors and that therefore their HRQOL is relatively well. With respect to cognitive functioning, there are studies suggesting that chemotherapy is associated with cognitive dysfunction, although these studies fail to show unequivocal results. ${ }^{27-31}$

Differences in HRQOL between NHL survivors and the normative population are in line with previous studies. ${ }^{11,12,15,32,33}$ In three studies, which included patients with and without active disease, it was observed that NHL survivors scored worse on various HRQOL domains in comparison to a normative population. ${ }^{12,15,32}$ Another study showed that, in comparison with the general population, patients with active NHL scored lower on physical and mental health status, whereas disease-free individuals scored only worse on mental health status. ${ }^{11}$

Younger DLBCL survivors experienced better physical functioning and global health status/quality of life in comparison with older survivors, although these differences had a trivial or small size effect. Three other studies showed that elderly NHL survivors reported worse physical functioning but better overall quality of life and mental health compared to younger survivors, although they often did not indicate whether the observed differences were of clinical relevance. ${ }^{14,15,33}$ Since we observed that the differences in quality of life/global health status between DLBCL survivors in all three age categories and the normative population only had a small size effect, it seems that the worse quality of life/global health status found in older DLBCL survivors in comparison with younger survivors is caused mostly by age itself and not by the disease. Another explanation might be a cohort-effect of this age group towards their 
appraisal of declining health and functional status, with elderly possibly having less high expectations towards their health.

With respect to EORTC QLQ-C30 symptom scales, financial problems occurred more often in survivors between 18-59 years in comparison with the normative population. These problems had a medium size effect. Previous studies also mentioned that NHL survivors experience more financial difficulties in comparison with a normative population. ${ }^{12,34}$ Possible causes are problems in obtaining work, health insurance, life insurance and a mortgage. ${ }^{15,35-37}$ of course, work-related problems affect younger survivors more, since older patients will probably be retired. DLBCL survivors aged 18-59 years showed worse scores on dyspnea with a medium size effect, which might be explained by the effect of treatment with chemotherapy or radiotherapy on cardiopulmonary function..$^{3,5,7,8,38}$ Especially doxorubicin, the anthracycline most used in treatment of DLBCL patients, is associated with risk of cardiotoxicity. ${ }^{39}$ Unfortunately we do not have information on the chemotherapy schedules or doses patients received. Therefore, we cannot exclude that elderly patients received less anthracycline based chemotherapy in comparison with younger patients.

The treatment of first choice for both younger and older DLBCL patients is the R-CHOP regimen (rituximab, cyclophosphamide, doxorubicin, vincristine, prednisolone), ${ }^{3,4,40}$ Elderly NHL survivors more often do not receive standard treatment compared with younger survivors. ${ }^{5-8,41}$ This may contribute to the poorer survival of elderly patients. ${ }^{3-8,38,42}$ Several studies show that high age in itself is stated by doctors as a reason for suboptimal treatment, even in the absence of a poor performance status. ${ }^{5-7}$ It is often assumed that standard treatment will lead to deterioration in HRQOL. The results in our study suggest that this is not the case. Therefore, treatment with chemotherapy and even intensive chemotherapy schedules should always be considered in elderly DLBCL patients. We cannot exclude however, that in the present study the elderly DLBCL survivors received less aggressive treatment schedules and that therefore their HRQOL is relatively well. This should be a focus for future studies. The current study has some limitations. We lack detailed information about the exact primary treatment, the patients' response to this treatment, whether patients received additional treatment after their primary treatment or whether they received treatment at the time of completion of the questionnaire. Furthermore, we cannot exclude that a selection bias has occurred, among others due to death of patients, since the respondents comprised only $53 \%$ of eligible patients. At last, we cannot exclude that patients did not participate because of poor health or absence of symptoms. The strengths of our study are that we compare DLBCL survivors of different age categories with an age- and sex-matched normative population and to the best of our knowledge, this is the first study investigating this. In addition, the study is performed in a population-based setting instead of a hospital-based setting and there was a high response rate, which makes it possible to generalize the results. 
In conclusion, although younger survivors score better on several domains of quality of life in comparison with elderly patients, the impact of DLBCL and its treatment is greater for younger survivors than for older survivors, when compared with an ageand sex-matched normative population. Especially cognitive and social functioning were relatively more impaired in younger survivors and financial problems and dyspnea more often occurred. Our results suggest that a decrease in HRQOL in elderly DLBCL survivors may not be the related to the primary treatment. Therefore, a premise of declining HRQOL may not be dominant in the choice of treatment. 


\section{References}

1. KWF kankerbestrijding, Signaleringcommissie Kanker. Kanker in Nederland tot 2020. Trends and Prognoses (in Dutch). http://www.kwfkankerbestrijding.nl.

2. US National Coalition for Cancer Survivorship. http://www.canceradvocacy.org. assessed on May 29, 2013.

3. Coiffier B, Lepage E, Briere J, Herbrecht R, Tilly H, Bouabdallah R, et al. CHOP chemotherapy plus rituximab compared with $\mathrm{CHOP}$ alone in elderly patients with diffuse large-B-cell lymphoma. N Engl J Med 2002;346:235-42.

4. Feugier P, Van Hoof A, Sebban C, Solal-Celigny P, Bouabdallah R, Ferme C, et al. Long-term results of the R-CHOP study in the treatment of elderly patients with diffuse large B-cell lymphoma: a study by the Groupe d'Etude des Lymphomes de I'Adulte. J Clin Oncol 2005;23:4117-26.

5. van de Schans SA, Wymenga AN, van Spronsen DJ, Schouten HC, Coebergh JW, Janssen-Heijnen ML. Two sides of the medallion: poor treatment tolerance but better survival by standard chemotherapy in elderly patients with advanced-stage diffuse large B-cell lymphoma. Ann Oncol 2012;23:1280-6.

6. Peters FP, Lalisang RI, Fickers MM, Erdkamp FL, Wils JA, Houben SG, et al. Treatment of elderly patients with intermediate- and high-grade non-Hodgkin's lymphoma: a retrospective populationbased study. Ann Hematol 2001;80:155-9.

7. Thieblemont C, Grossoeuvre A, Houot R, Broussais-Guillaumont F, Salles G, Traulle C, et al. NonHodgkin's lymphoma in very elderly patients over 80 years. A descriptive analysis of clinical presentation and outcome. Ann Oncol 2008;19:774-9.

8. Peters FP, Fickers MM, Erdkamp FL, Wals J, Wils JA, Schouten HC. The effect of optimal treatment on elderly patients with aggressive non-Hodgkin's lymphoma: more patients treated with unaffected response rates. Ann Hematol 2001;80:406-10.

9. Kobayashi Y, Miura K, Hojo A, Hatta Y, Tanaka T, Kurita D, et al. Charlson Comorbidity Index is an independent prognostic factor among elderly patients with diffuse large B-cell lymphoma. J Cancer Res Clin Oncol 2011;137:1079-84.

10. Heutte N, Haioun C, Feugier P, Coiffier B, Tilly H, Ferme C, et al. Quality of life in 269 patients with poor-risk diffuse large B-cell lymphoma treated with rituximab versus observation after autologous stem cell transplant. Leuk Lymphoma 2011;52:1239-48.

11. Smith SK, Zimmerman S, Williams CS, Zebrack BJ. Health status and quality of life among non-Hodgkin lymphoma survivors. Cancer 2009;115:3312-23.

12. Jerkeman M, Kaasa S, Hjermstad M, Kvaloy S, Cavallin-Stahl E. Health-related quality of life and its potential prognostic implications in patients with aggressive lymphoma: a Nordic Lymphoma Group Trial. Med Oncol 2001;18:85-94.

13. Merli F, Bertini M, Luminari S, Mozzana R, Berte R, Trottini M, et al. Quality of life assessment in elderly patients with aggressive non-Hodgkin's Lymphoma treated with anthracycline-containing regimens. Report of a prospective study by the Intergruppo Italiano Linfomi. Haematologica 2004; 89:973-8.

14. Smith SK, Crespi CM, Petersen L, Zimmerman S, Ganz PA. The impact of cancer and quality of life for post-treatment non-Hodgkin lymphoma survivors. Psychooncology 2010;19:1259-67.

15. Mols F, Aaronson NK, Vingerhoets AJ, Coebergh JW, Vreugdenhil G, Lybeert ML, et al. Quality of life among long-term non-Hodgkin lymphoma survivors: a population-based study. Cancer 2007;109: 1659-67.

16. Doorduijn J, Buijt I, Holt B, Steijaert M, Uyl-de Groot C, Sonneveld P. Self-reported quality of life in elderly patients with aggressive non-Hodgkin's lymphoma treated with CHOP chemotherapy. Eur J Haematol 2005;75:116-23.

17. Persson L, Larsson G, Ohlsson O, Hallberg IR. Acute leukaemia or highly malignant lymphoma patients' quality of life over two years: a pilot study. Eur J Cancer Care (Engl) 2001;10:36-47.

18. Geffen DB, Blaustein A, Amir MC, Cohen Y. Post-traumatic stress disorder and quality of life in longterm survivors of Hodgkin's disease and non-Hodgkin's lymphoma in Israel. Leuk Lymphoma 2003; 44:1925-9. 
19. Fritz A PC, Jack A, et al. . International Classification of Diseases for Oncology (ed 3rd). . Geneva, World Health Organisation. 2000.

20. van de Poll-Franse LV, Horevoorts N, van Eenbergen M, Denollet J, Roukema JA, Aaronson NK, et al. The Patient Reported Outcomes Following Initial treatment and Long term Evaluation of Survivorship registry: scope, rationale and design of an infrastructure for the study of physical and psychosocial outcomes in cancer survivorship cohorts. Eur J Cancer 2011;47:2188-94.

21. van de Poll-Franse LV, Mols F, Gundy CM, Creutzberg CL, Nout RA, Verdonck-de Leeuw IM, et al. Normative data for the EORTC QLQ-C30 and EORTC-sexuality items in the general Dutch population. Eur J Cancer 2011;47:667-75.

22. Aaronson NK, Ahmedzai S, Bergman B, Bullinger M, Cull A, Duez NJ, et al. The European Organization for Research and Treatment of Cancer QLQ-C30: a quality-of-life instrument for use in international clinical trials in oncology. J Natl Cancer Inst 1993;85:365-76.

23. Sangha O, Stucki G, Liang MH, Fossel AH, Katz JN. The Self-Administered Comorbidity Questionnaire: a new method to assess comorbidity for clinical and health services research. Arthritis Rheum 2003;49:156-63.

24. Cocks K, King MT, Velikova G, Martyn St-James M, Fayers PM, Brown JM. Evidence-based guidelines for determination of sample size and interpretation of the European Organisation for the Research and Treatment of Cancer Quality of Life Questionnaire Core 30. J Clin Oncol 2011;29:89-96.

25. Hall AE, Boyes AW, Bowman J, Walsh RA, James EL, Girgis A. Young adult cancer survivors' psychosocial well-being: a cross-sectional study assessing quality of life, unmet needs, and health behaviors. Support Care Cancer 2012;20:1333-41.

26. Bifulco G, De Rosa N, Tornesello ML, Piccoli R, Bertrando A, Lavitola G, et al. Quality of life, lifestyle behavior and employment experience: a comparison between young and midlife survivors of gynecology early stage cancers. Gynecol Oncol 2012;124:444-51.

27. Wefel JS, Saleeba AK, Buzdar AU, Meyers CA. Acute and late onset cognitive dysfunction associated with chemotherapy in women with breast cancer. Cancer 2010;116:3348-56.

28. Hermelink K, Untch M, Lux MP, Kreienberg R, Beck T, Bauerfeind I, et al. Cognitive function during neoadjuvant chemotherapy for breast cancer: results of a prospective, multicenter, longitudinal study. Cancer 2007;109:1905-13.

29. Schagen SB, Muller MJ, Boogerd W, Rosenbrand RM, van Rhijn D, Rodenhuis S, et al. Late effects of adjuvant chemotherapy on cognitive function: a follow-up study in breast cancer patients. Ann Oncol 2002;13:1387-97.

30. Wefel JS, Lenzi R, Theriault RL, Davis RN, Meyers CA. The cognitive sequelae of standard-dose adjuvant chemotherapy in women with breast carcinoma: results of a prospective, randomized, longitudinal trial. Cancer 2004;100:2292-9.

31. Donovan KA, Small BJ, Andrykowski MA, Schmitt FA, Munster P, Jacobsen PB. Cognitive functioning after adjuvant chemotherapy and/or radiotherapy for early-stage breast carcinoma. Cancer 2005;104: 2499-507.

32. Jensen RE, Arora NK, Bellizzi KM, Rowland JH, Hamilton AS, Aziz NM, et al. Health-related quality of life among survivors of aggressive non-Hodgkin lymphoma. Cancer 2013;119: 672-80.

33. Zebrack BJ, Yi J, Petersen L, Ganz PA. The impact of cancer and quality of life for long-term survivors. Psychooncology 2008;17:891-900.

34. Brandt J, Dietrich S, Meissner J, Neben K, Ho AD, Witzens-Harig M. Quality of life of long-term survivors with Hodgkin lymphoma after high-dose chemotherapy, autologous stem cell transplantation, and conventional chemotherapy. Leuk Lymphoma 2010;51:2012-20.

35. Mols F, Thong MS, Vissers P, Nijsten T, van de Poll-Franse LV. Socio-economic implications of cancer survivorship: results from the PROFILES registry. Eur J Cancer 2012;48:2037-42.

36. Mols F, Vingerhoets AJ, Coebergh JW, Vreugdenhil G, Aaronson NK, Lybeert ML, et al. Better quality of life among 10-15 year survivors of Hodgkin's lymphoma compared to 5-9 year survivors: a population-based study. Eur J Cancer 2006;42:2794-801.

37. Mols F, Thong MS, Vreugdenhil G, van de Poll-Franse LV. Long-term cancer survivors experience work changes after diagnosis: results of a population-based study. Psychooncology 2009;18:1252-60. 
38. Hasselblom S, Stenson M, Werlenius O, Sender M, Lewerin C, Hansson U, et al. Improved outcome for very elderly patients with diffuse large B-cell lymphoma in the immunochemotherapy era. Leuk Lymphoma 2012;53:394-9.

39. Hershman DL, McBride RB, Eisenberger A, Tsai WY, Grann VR, Jacobson JS. Doxorubicin, cardiac risk factors, and cardiac toxicity in elderly patients with diffuse B-cell non-Hodgkin's lymphoma. J Clin Oncol 2008;26:3159-65.

40. Lee L, Crump M, Khor S, Hoch JS, Luo J, Bremner K, et al. Impact of rituximab on treatment outcomes of patients with diffuse large b-cell lymphoma: a population-based analysis. Br J Haematol 2012; 158:481-8.

41. Lin TL, Kuo MC, Shih LY, Dunn P, Wang PN, Wu JH, et al. The impact of age, Charlson comorbidity index, and performance status on treatment of elderly patients with diffuse large B cell lymphoma. Ann Hematol 2012;91:1383-91.

42. Griffiths RI, Gleeson ML, Mikhael J, Dreyling MH, Danese MD. Comparative effectiveness and cost of adding rituximab to first-line chemotherapy for elderly patients diagnosed with diffuse large B-cell lymphoma. Cancer 2012;118:6079-88. 
<smiles>C#C</smiles> 
Elderly multiple myeloma patients experience less deterioration in health-related quality of life than younger patients compared to a normative population: A study from the population-based PROFILES registry

Ann Hematol 2015;94:651-61 


\section{Abstract}

\section{Purpose}

The objective of this study was to compare health related quality of life (HRQOL) between multiple myeloma (MM) patients aged $\leq 65$ and $>65$ years and to compare this with a normative population. Factors associated with $\mathrm{HRQOL}$ were identified.

\section{Methods}

The population-based Eindhoven Cancer Registry was used to select MM patients diagnosed from 1999 to 2010. Patients $(n=289)$ were invited to complete the EORTC QLQ-C3O and QLQ-MY20 questionnaire and 212 patients responded (73\%). Data from a normative population $(n=568)$ were used for comparison.

\section{Results}

MM patients $>65$ years scored better on emotional functioning $(p<.05)$ and financial problems $(p<.01)$ compared to patients $\leq 65$ years. Patients $\leq 65$ years reported better body image and future perspective $(p<.01)$. Compared to the normative population, patients $\leq 65$ years scored worse on all EORTC QLQ-C30 functioning scales and on global health/QOL, fatigue, pain, dyspnea, appetite loss and financial problems $(p<.01)$. Patients $>65$ years scored worse on social, physical and role functioning and on global health/QOL, fatigue, pain and dyspnea $(p<.01)$. Younger patients had worse HRQOL compared to the normative population than elderly patients. Patients with comorbidities reported lower QOL. The longer the time since diagnosis, the better the physical functioning.

\section{Conclusion}

No major differences in HRQOL were found between younger and older MM patients. Compared to a normative population HRQOL in younger patients was worse than in older patients. Number of comorbidities and time since diagnosis was associated with HRQOL. MM patients report a high symptom burden and therapy should, besides prolonging survival, be aimed at improving HRQOL. 


\section{Introduction}

Multiple myeloma ( $\mathrm{MM}$ ) is a disease that mainly occurs in elderly patients. At time of diagnosis, the median age is 69 years and more than $60 \%$ of patients are older than 65 years. Due to the ageing of the population, the absolute incidence of elderly patients with $\mathrm{MM}$ is expected to increase. The five-year relative survival is much higher among patients younger than 65 years at diagnosis (56\%) compared to patients who were 65 years or older at diagnosis (33\%). ${ }^{1}$

Currently, the standard treatment for fit patients aged $\leq 65$ years contains high-dose chemotherapy followed by autologous stem cell transplantation (ASCT). This treatment improves event-free, progression-free and overall survival in comparison with conventional chemotherapy. ${ }^{2-4}$ Some studies indicated that ASCT might be feasible in selected older patients who have limited comorbid conditions and a good performance status. ${ }^{5-9}$ However, in general it is thought that this therapy is too toxic for the elderly and therefore the combination of melphalan and prednisone (MP) was the only treatment option for elderly MM patients for many decades. Since the addition of the relatively new agents bortezomib (VMP), thalidomide (MPT) or lenalidomide (MPR-R) leads to better event-free, progression-free and overall survival, this is now the standard treatment for elderly patients. ${ }^{10-17}$

Since MM cannot be cured, treatment focuses on prolonging survival and controlling symptoms, such as anemia and bone pain due to skeletal destruction. An important aim of treatment is to preserve and improve quality of life. Population-based studies observed that health-related quality of life (HRQOL) of patients with MM is impaired compared to a normative population. ${ }^{18,19}$ Several randomized controlled trials showed that treatment with VMP, MPT or MPR-R leads to improvement in several domains of HRQOL compared to baseline. ${ }^{20-22}$ This is probably the result of better treatment efficacy and consequently a reduction of $\mathrm{MM}$ related symptoms.

Little is known about age-related differences in HRQOL among MM patients. Since treatment of MM differs between younger and elderly patients, it is important to study the potential different influence of treatment on HRQOL. Therefore the aims of this population-based study were to assess age-related differences in HRQOL between MM patients of 65 years and younger and those older than 65 years and to identify factors associated with HRQOL. In addition, we compared HRQOL in MM patients with HRQOL in an age- and sex-matched general population to distinguish between the impact of MM on HRQOL and of age itself on HRQOL. Furthermore, we assessed the impact of symptoms on global health status/quality of life (QoL). We hypothesised that HRQOL is worse in MM patients older than 65 years compared to patients of 65 years and younger and that HRQOL is worse in both younger and older MM patients compared to a normative population. 


\section{Methods}

\section{Setting and population}

This study is part of a population-based survey among MM patients registered with the Eindhoven Cancer Registry (ECR) of Comprehensive Cancer Centre the Netherlands. The ECR records data on all patients who are newly diagnosed with cancer in the southern part of the Netherlands, an area with 2.3 million inhabitants, 10 hospitals and 2 large radiotherapy institutes. The ECR was used to select all patients who were diagnosed with MM between 1/1/1999 and 31/12/2010. We included all patients with $\mathrm{MM}$ as defined by the International Classification of Diseases for Oncology-3 codes (ICD-O-3). ${ }^{23}$

To exclude all patients who had deceased our database was linked with the database of the Central Bureau for Genealogy, which collects data on all deceased Dutch citizens through the civil municipal registries. Ethical approval for the study was obtained from a local, certified Medical Ethics Committee (of the Maxima Medical Centre in Veldhoven, The Netherlands; number 0734).

\section{Data collection}

Data collection was done within PROFILES (Patient Reported Outcomes Following Initial treatment and Long term Evaluation of Survivorship). PROFILES is a registry for the study of the physical and psychosocial impact of cancer and its treatment from a dynamic, growing population-based cohort of both short and long-term cancer survivors. PROFILES contains a large web-based component and is linked directly to clinical data from ECR. Details of the data collection method have been previously described. $^{24}$

Questionnaires were sent out in batches and this was done on three time points. In May 2009, patients diagnosed between January 1999 and January 2009 were included in the study and received the first questionnaire. In November 2009 and May 2011 patients newly diagnosed after the last inclusion date were subsequently invited to participate to include all patients up to December 31, 2010.

In 2009, CentERdata (www.centerdata.nl), a research institute at Tilburg University, was assigned to collect normative data on HRQOL via the CentERpanel. The CentERpanel is an online household panel consisting of over 2000 households which are representative of the Dutch-speaking population in the Netherlands. For households without internet access, additional provisions were provided to assist in data collection. In total 1731 cancer-free panel members of $\geq 18$ years completed the EORTC QLQ-C30. ${ }^{25}$ We matched this sample on age and sex with our MM sample. The normative population consisted of 568 participants. 


\section{Study measures}

The validated Dutch version of the EORTC QLQ-C30 was used to assess HRQOL. ${ }^{26}$ This is a self-report questionnaire developed by the European Organization for Research and Treatment of Cancer for assessing quality of life in cancer patients. The questionnaire includes five scales on physical, role, emotional, cognitive and social functioning, a global health status/quality of life scale, three symptom scales on fatigue, nausea and vomiting and pain and six single items assessing dyspnea, sleeping problems, appetite loss, constipation, diarrhea and financial problems. In addition, the EORTC QLQ-MY20 was used to assess disease specific complaints. ${ }^{27}$ This questionnaire contains two symptom scales on disease symptoms and side effects of treatment, one functional scale on future perspective and one single item on body image. Answer categories for the EORTC QLQ-C30 and the EORTC QLQ-MY20 range from one (not at all) to four (very much). After linear transformation, all scales and single item measures range in score from 0 to 100. A higher score on the functional scales, global health and quality of life scale and on body image means a better HRQOL, whereas a higher score on the symptom scales refers to more symptoms. ${ }^{26,27}$

Co-morbidity at time of survey was categorized according to the adapted Selfadministered Co-morbidity Questionnaire (SCQ). ${ }^{28}$

Patients' educational level and marital status were also assessed in the questionnaire. Clinical information was available from the ECR that routinely collects data on tumor characteristics, including date of diagnosis, tumor grade, histology, Ann Arbor stage, primary treatment, and patients' background characteristics, including gender and date of birth.

\section{Statistical analysis}

All statistical analyses were performed using SPSS (IBM SPSS Statistics version 20). P-values of <.05 were considered statistically significant. For the EORTC QLQ-C30, clinically important differences between groups were determined using the evidencebased guidelines for interpretation of the EORTC QLQ-C30. ${ }^{29}$ The effect size as measured by the EORTC QLQ-C30 is divided into four size classes. Large: representing unequivocal clinical relevance. Medium: likely to be clinically relevant but to a lesser extent. Small: subtle but nevertheless clinically relevant. Trivial: circumstances unlikely to have any clinical relevance or where there was no difference. For the EORTC QLQ-MY20, clinically important differences were determined using the anchorbased method, distinguishing in a small, moderate or large size effect. ${ }^{30}$ Patients were categorized into two age groups: 65 years and younger and older than 65 years at time of questionnaire.

Differences in socio-demographic and clinical characteristics between respondents, non-respondents, and patients with unverifiable addresses were compared with analysis of variance (ANOVA) for continuous variables and chi-square analyses for 
categorical variables. Differences between MM patients of the two age categories were compared with independent-Samples T-test for continuous variables and chisquare analyses for categorical variables.

Mean EORTC QLQ-C30 scores between the two age groups of MM patients adjusted for sex, co-morbidity and time since diagnosis were compared using analyses of covariance (ANCOVA). ANCOVA were also carried out to compare mean EORTC QLQ-C30 scores in the MM patients with the normative population for both age categories adjusted for sex, age and comorbidity.

Logistic regression analyses were carried out to investigate the independent association between socio-demographic and clinical variables and EORTC QLQ-C30 and EORTC MY-20 subscales. Variables that were selected a priori for the logistic model were age, sex, number of comorbidities, time since diagnosis, and treatment (stem cell transplantation versus no stem cell transplantation). Five EORTC QLQ-C30 subscales and one EORTC QLQ-MY20 subscale were selected for analysis because of their expected impact on HRQOL: physical functioning, cognitive functioning, global health/QOL, pain, fatigue and side effects of treatment. In the logistic model, MM patients with clinically important worse scores than the normative population according to the guidelines of the EORTC QLQ-C30 were compared with MM patients without clinically important worse scores. ${ }^{29}$ For the EORTC QLQ-MY20 subscale side effects of treatment, MM patients that scored higher than the upper quartile were compared with patients that scored lower than the upper quartile, since comparison with the normative population was not possible, as they did not complete the EORTC QLQ-MY20 questionnaire. The results of the logistic regression were categorized as having no clinically relevant difference on the concerning subscale (0) versus having a clinically relevant worse score on the concerning subscale (1).

ANCOVA was carried out to compare the mean score of the EORTC QLQ-C30 global health status/QoL scale between MM patients with and without symptoms, adjusted for age, sex and number of comorbidities. The following symptoms were selected based on their presumed clinical relevance: bone aches, back pain, hip pain, pain in arms and shoulders, chest pain and tingling hands or feet.

\section{Results}

\section{Patients' characteristics and normative population}

Questionnaires were sent to $289 \mathrm{MM}$ patients and 212 completed questionnaires were returned (73\% response rate)(Figure 6.1). Most patients had undergone chemotherapy (39\%) and $26 \%$ of respondents had received stem cell transplantation in addition to chemotherapy as primary treatment. Thirteen percent of respondents did not receive any therapy. 


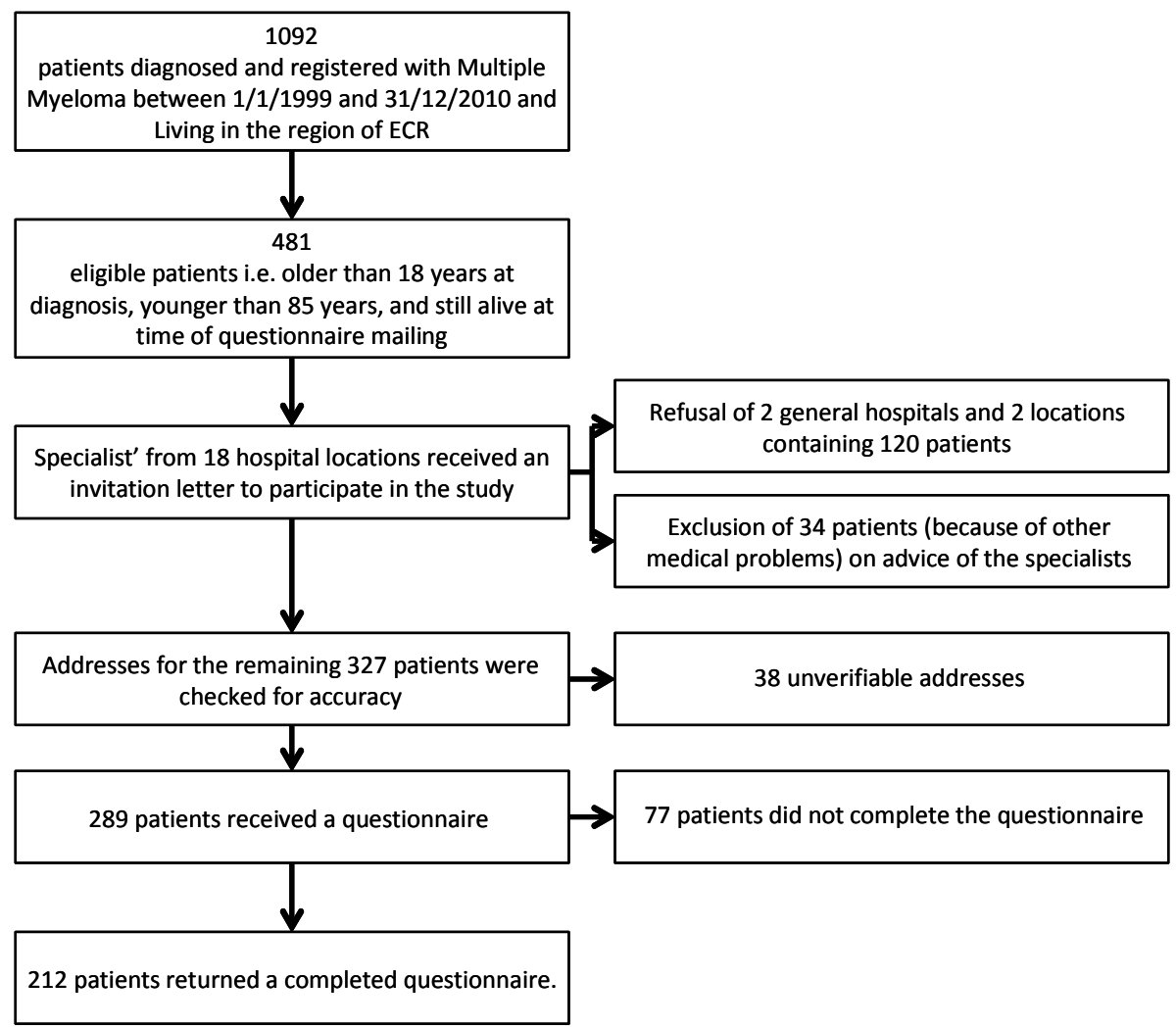

Figure 6.1 Flow chart of the data collection process.

In comparison with respondents, non-respondents $(\mathrm{N}=77)$ were older at time of survey (69 years versus 66 years, $\mathrm{p}<.05$ ). Respondents more often underwent chemotherapy compared to patients with unverifiable addresses (39\% versus $16 \%$, $\mathrm{p}<.01)$. Furthermore, non-respondents and patients with unverifiable addresses more frequently did not receive any therapy in comparison with respondents (34\%, $29 \%$ and $13 \%$ respectively, $\mathrm{p}<.05$ ) (data not shown).

Compared to MM patients $>65$ years, MM patients $\leq 65$ years were more often treated with stem cell transplantation and less often with chemotherapy alone $(p<.01)$ (Table 6.1). In addition, MM patients $>65$ years more often reported two or more comorbidities in comparison with their younger counterparts $(p<.05)$. No differences were observed for gender and time since diagnosis.

The mean age of MM patients at time of survey was 66 years. Fifty-eight percent of respondents were male and $77 \%$ of respondents had a partner. Forty-six percent of respondents reported two or more comorbidities, of which back pain was the most 
frequent reported comorbidity (Table 6.2). The mean age of the age -and sex matched normative population was 65 years, $58 \%$ was male and $70 \%$ had a partner. Forty-four percent reported two or more comorbidities, of which hypertension was reported the most frequently. Two hundred and ninety participants were 65 years or younger and 278 participants were older than 65 years (Table 6.2).

Table 6.1 Clinical characteristics of MM patients according to age category at time of questionnaire.

\begin{tabular}{|c|c|c|c|}
\hline & $\begin{array}{c}\text { MM patients } \\
\text { 35-65 years } \\
\mathrm{N}=102 \\
\mathrm{~N}(\%)\end{array}$ & $\begin{array}{c}\text { MM patients } \\
66-88 \text { years } \\
\mathrm{N}=110 \\
\mathrm{~N}(\%)\end{array}$ & p-value \\
\hline Age (at time of survey) (mean \pm SD) & $58.2(6.3)$ & $73.2(5.2)$ & \\
\hline Gender & & & 0.45 \\
\hline Male & $56(55)$ & $66(60)$ & \\
\hline Female & $46(45)$ & $44(40)$ & \\
\hline Years since diagnosis (mean $\pm S D$ ) & $2.81(2.0)$ & $2.74(2.0)$ & 0.79 \\
\hline $0-1$ & $44(43)$ & $46(42)$ & \\
\hline $2-4$ & $46(45)$ & $51(46)$ & \\
\hline $5-7$ & $6(6)$ & $10(9)$ & \\
\hline 8-10 & $6(6)$ & $3(3)$ & \\
\hline Primary treatment & & & $<0.01$ \\
\hline Chemotherapy alone & $26(26)$ & $56(51)$ & \\
\hline Radiotherapy alone & $4(4)$ & $9(8)$ & \\
\hline Chemoradiation alone & $9(9)$ & $26(24)$ & \\
\hline Chemoradiation and transplantation & 19 (19) & $2(2)$ & \\
\hline Chemotherapy and transplantation & $32(31)$ & $1(1)$ & \\
\hline No therapy & $12(12)$ & $16(15)$ & \\
\hline Self-reported comorbidity & & & $<0.05$ \\
\hline No comorbid condition & $19(19)$ & $19(17)$ & \\
\hline 1 comorbid condition & $36(35)$ & $21(19)$ & \\
\hline$\geq 2$ comorbid conditions & $39(38)$ & $58(53)$ & \\
\hline Unknown & $8(8)$ & $12(11)$ & \\
\hline \multicolumn{4}{|l|}{ Most frequent comorbid conditions } \\
\hline Back pain & $35(34)$ & $40(36)$ & 0.27 \\
\hline Hypertension & $22(22)$ & $35(32)$ & 0.06 \\
\hline Arthrosis & $18(18)$ & $29(26)$ & 0.06 \\
\hline Anemia & $17(17)$ & $17(16)$ & 0.96 \\
\hline
\end{tabular}

$\mathrm{MM}=$ Multiple Myeloma.

\section{Comparison of HRQOL between younger and older MM patients}

MM patients $>65$ years scored better on emotional functioning $(p<.05$, trivial effect size) and reported fewer financial problems ( $p<.01$, medium effect size) compared to younger patients (data not shown). In contrast, younger patients reported better body image and future perspectives than older patients $(p<.01$, small effect size). No differences on the other HRQOL subscales nor EORTC QLQ-MY20 subscales or items were observed between younger and older MM patients. 
Table 6.2 Socio-demographic characteristics of MM patients, and respondents of an age- and sexmatched normative population.

\begin{tabular}{|c|c|c|}
\hline & $\begin{array}{c}\text { MM patients } \\
\text { N = 212 } \\
\text { N (\%) }\end{array}$ & $\begin{array}{c}\text { Norm population } \\
\begin{array}{c}\mathbf{N}=\mathbf{5 6 8} \\
\mathrm{N}(\%)\end{array}\end{array}$ \\
\hline \multicolumn{3}{|l|}{ Gender } \\
\hline Male & $122(58)$ & $328(58)$ \\
\hline Female & $90(43)$ & $240(42)$ \\
\hline Age (at time of survey) (mean \pm SD) & $66.0(9.4)$ & $65.3(9.5)$ \\
\hline $35-65$ & $102(48)$ & $290(51)$ \\
\hline $66-88$ & $110(52)$ & $278(49)$ \\
\hline \multicolumn{3}{|l|}{ Self-reported comorbidity } \\
\hline No comorbid condition & $38(18)$ & $177(31)$ \\
\hline 1 comorbid condition & $57(27)$ & $143(25)$ \\
\hline$\geq 2$ comorbid conditions & $97(46)$ & $248(44)$ \\
\hline \multicolumn{3}{|l|}{ Most frequent comorbid conditions } \\
\hline Back pain & $75(35)$ & $179(32)$ \\
\hline Hypertension & $57(27)$ & $189(33)$ \\
\hline Arthrosis & $47(22)$ & $158(28)$ \\
\hline Anemia & $34(16)$ & $18(3)$ \\
\hline \multicolumn{3}{|l|}{ Marital status } \\
\hline Partner & $164(77)$ & $400(70)$ \\
\hline No partner & $45(21)$ & $168(30)$ \\
\hline \multicolumn{3}{|l|}{ Education level\$ } \\
\hline Low & $34(16)$ & $31(6)$ \\
\hline Medium & $133(63)$ & $310(55)$ \\
\hline High & $43(20)$ & $226(40)$ \\
\hline
\end{tabular}

\section{Comparison of HRQOL between MM patients and the normative population}

In comparison with the normative population, MM patients $\leq 65$ years scored worse on all EORTC QLQ-C30 functioning scales and global health/QoL ( $p<.01)$ (Figure 6.2a). The effect sizes for cognitive and social functioning were large, while medium for the other scales. Patients $>65$ years scored worse on social functioning $(p<.01$ and large effect size) compared to the normative population (Figure 6.2b). In addition, they scored worse on physical and role functioning, global health/QoL $(p<.01$, medium effect sizes) and on emotional and cognitive functioning ( $p<.01$, small effect sizes). 


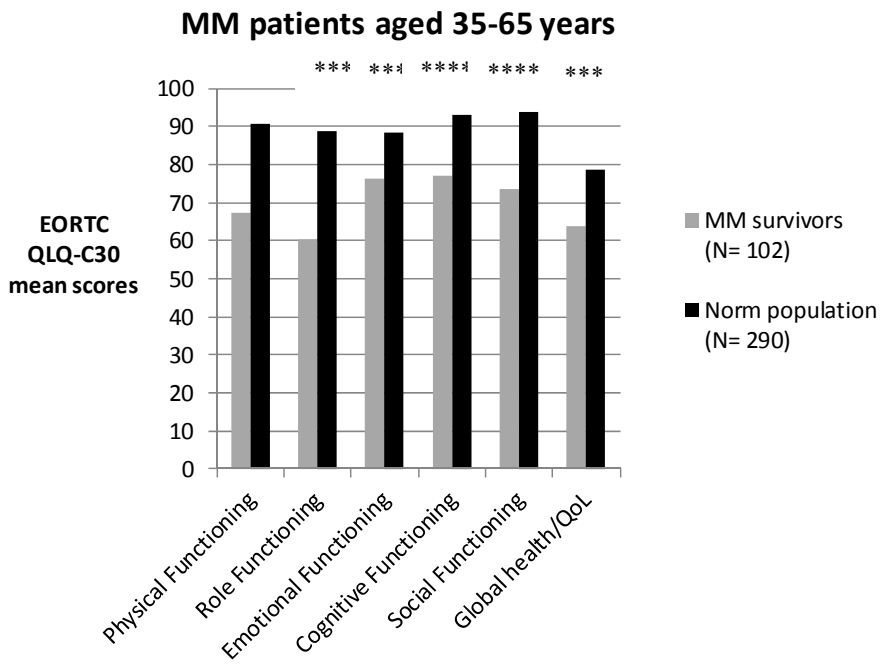

Figure 6.2a. Differences on EORTC QLQ-C30 mean functioning and global health/quality of life scores between $\mathrm{MM}$ patients aged $\leq 65$ years $(\mathrm{N}=102)$ and an age -and sex matched normative population $(\mathrm{N}=290) .{ }^{* *} \mathrm{p}<.01$ and small size effect; ${ }^{* * *} \mathrm{p}<.01$ and medium size effect; $* * * * p<.01$ and large size effect.

B MM patients aged $66-88$ years

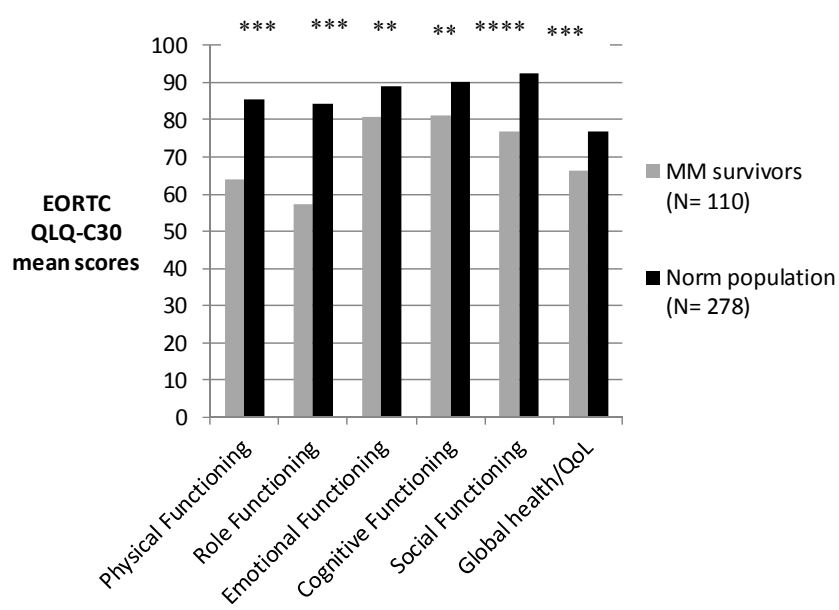

Figure 6.2b Differences on EORTC QLQ-C30 mean functioning and global health/quality of life scores between $M M$ patients aged $\geq 66$ years $(\mathrm{N}=110)$ and an age -and sex matched normative population $(\mathrm{N}=278) .{ }^{* *} \mathrm{p}<.01$ and small size effect; ${ }^{* * *} \mathrm{p}<.01$ and medium size effect; ${ }^{* * * *} \mathrm{p}<.01$ and large size effect.

Patients $\leq 65$ years scored worse on fatigue and pain $(p<.01$, large effect sizes), on dyspnea, appetite loss and financial problems ( $p<.01$, medium effect sizes) and on 
nausea/vomiting, insomnia and constipation ( $p<.01$, small effect sizes) in comparison with the normative population (Figure 6.3a). Patients $>65$ years scored worse on fatigue ( $p<.01$, large effect size), pain and dyspnea ( $p<.01$, medium effect sizes) and on nausea/vomiting, appetite loss and constipation ( $p<.01$, small effect sizes) compared to the normative population (Figure 6.3b).

A

MM patients aged 35-65 years

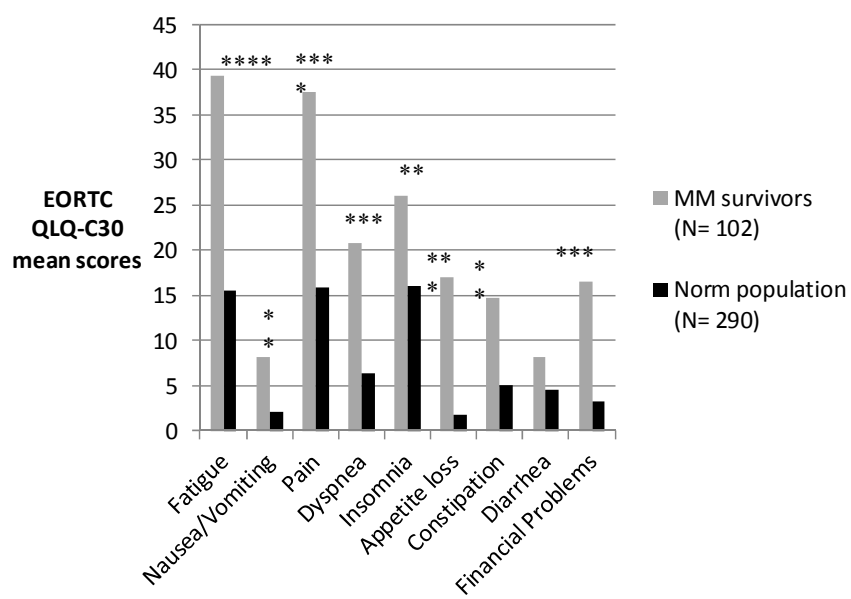

Figure 6.3a Differences on EORTC QLQ-C30 mean symptom scores between MM patients aged $\leq 65$ years $(\mathrm{N}=102)$ and an age - and sex matched normative population $(\mathrm{N}=290) .{ }^{* *} \mathrm{p}<.01$ and small size effect; ${ }^{* * *} p<.01$ and medium size effect; ${ }^{* * * *} p<.01$ and large size effect

B MM patients aged $66-88$ years

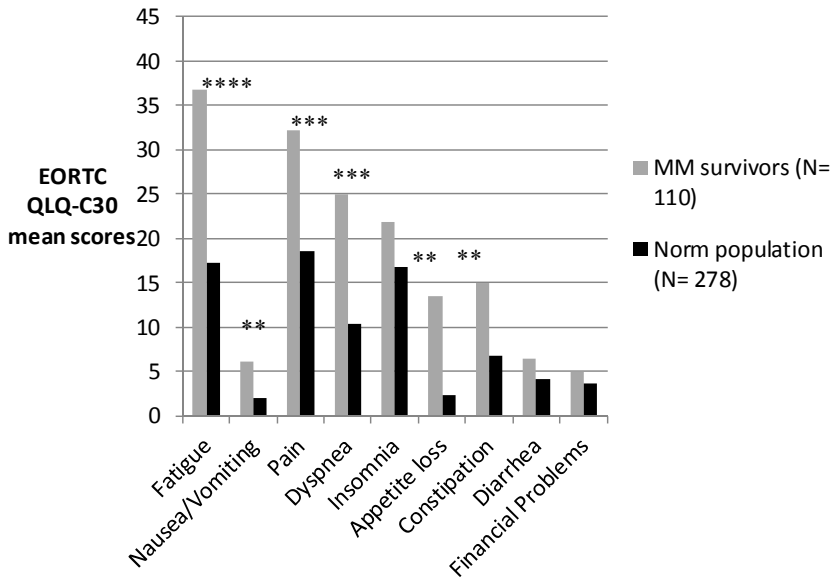

Figure 6.3b Differences on EORTC QLQ-C30 mean symptom scores between MM patients aged $\geq 66$ years $(\mathrm{N}=110)$ and an age -and sex matched normative population $(\mathrm{N}=278) . * * \mathrm{p}<.01$ and small size effect; ${ }^{* *} p<.01$ and medium size effect; ${ }^{* * * *} p<.01$ and large size effect. 


\section{Factors associated with $\mathrm{HRQOL}$ in MM patients}

Logistic regression analysis comparing MM patients with versus without clinically important worse scores on several HRQOL domains than the normative population, showed that patients with comorbid conditions more often reported low physical functioning (OR 1.83, Cl: 1.34-2.50; $\mathrm{p}<.01$ ), worse global health/QoL (OR 1.38, $\mathrm{Cl}: 1.07-1.78 ; \mathrm{p}<.01$ ) and more pain (OR 1.49, $\mathrm{Cl}: 1.15-1.94 ; \mathrm{p}<.01)$, fatigue (OR 1.51, $\mathrm{Cl}: 1.13-2.03 ; \mathrm{p}<.01$ ) and side effects of treatment (OR 1.40, $\mathrm{Cl}: 1.07-1.83, \mathrm{p}<.01$ ) (Table 6.3). In addition, patients with a longer time since diagnosis less often reported low physical functioning (OR 0.84, $\mathrm{Cl}$ : 0.71-0.99; $\mathrm{p}<.05$ ). No association was observed between age, sex and treatment (stem cell transplantation versus no stem cell transplantation) and the selected EORTC QLQ-C30 and QLQ-MY20 subscales. Furthermore, none of the selected variables was associated with low cognitive functioning.

\section{Impact of symptoms on global health status/QoL}

Patients $\leq 65$ years reporting chest pain had a significantly lower global health status/QoL than patients without this symptom ( $p<.05$ )(Figure 6.4a). For patients $>65$ bone aches and hip pain, pain in arms and shoulders and tingling hands or feet had a negative impact on global health status/QoL compared to patients without these symptoms $(p<.05)$ (Figure 6.4b).

Table 6.3 Logistic model of variables associated with EORTC QLQ-C30 and QLQ-MY20 subscales.

\begin{tabular}{lccccccccc}
\hline & \multicolumn{3}{c}{ Low physical functioning } & \multicolumn{3}{c}{ Low cognitive functioning } & \multicolumn{3}{c}{ Low global health/QoL } \\
Variables & OR & $95 \% \mathrm{Cl}$ & $\mathrm{p}$-value & $\mathrm{OR}$ & $95 \% \mathrm{Cl}$ & $\mathrm{p}$-value & OR & $95 \% \mathrm{Cl}$ & $\mathrm{p}$-value \\
\hline Age & 0.98 & $0.95-1.02$ & 0.42 & 0.99 & $0.93-1.01$ & 0.09 & 0.98 & $0.94-1.02$ & 0.25 \\
Male vs female & 0.68 & $0.34-1.35$ & 0.27 & 0.70 & $0.38-1.29$ & 0.25 & 0.92 & $0.49-1.71$ & 0.78 \\
Number of comorbidities & 1.83 & $1.34-2.50$ & 0.00 & 1.11 & $0.87-1.40$ & 0.40 & 1.38 & $1.07-1.78$ & 0.01 \\
Time since diagnosis & 0.84 & $0.71-0.99$ & 0.04 & 1.08 & $0.92-1.26$ & 0.34 & 0.88 & $0.76-1.03$ & 0.12 \\
Treatment: SCT vs no SCT & 0.86 & $0.38-1.99$ & 0.86 & 0.92 & $0.42-2.03$ & 0.84 & 0.54 & $0.25-1.17$ & 0.54 \\
\hline & & Pain & & & Fatigue & & Side effects of treatment \\
Variables & OR & $95 \% \mathrm{Cl}$ & p-value & OR & $95 \% \mathrm{Cl}$ & p-value & OR & $95 \% \mathrm{Cl}$ & $\mathrm{p}$-value \\
\hline Age & 0.97 & $0.94-1.01$ & 0.12 & 1.00 & $0.96-1.04$ & 0.95 & 1.00 & $0.96-1.05$ & 0.92 \\
Male vs female & 0.85 & $0.45-1.59$ & 0.61 & 0.82 & $0.41-1.64$ & 0.58 & 0.51 & $0.25-1.02$ & 0.06 \\
Number of comorbidities & 1.49 & $1.15-1.94$ & 0.00 & 1.51 & $1.13-2.03$ & 0.01 & 1.40 & $1.07-1.83$ & 0.01 \\
Time since diagnosis & 0.92 & $0.79-1.07$ & 0.27 & 0.99 & $0.84-1.17$ & 0.93 & 0.96 & $0.80-1.16$ & 0.68 \\
Treatment: SCT vs no SCT & 0.73 & $0.33-1.60$ & 0.43 & 1.01 & $0.44-2.34$ & 0.98 & 1.06 & $0.42-2.68$ & 0.90 \\
\hline
\end{tabular}

Results of logistic regression analyses for the odds of having no clinically relevant difference on the concerning subscale (0) versus having a clinically relevant worse score on the concerning subscale (1). OR = odds ratio. $\mathrm{Cl}=$ confidence interval. SCT = stem cell transplantation. 
A MM patients aged 35-65 years

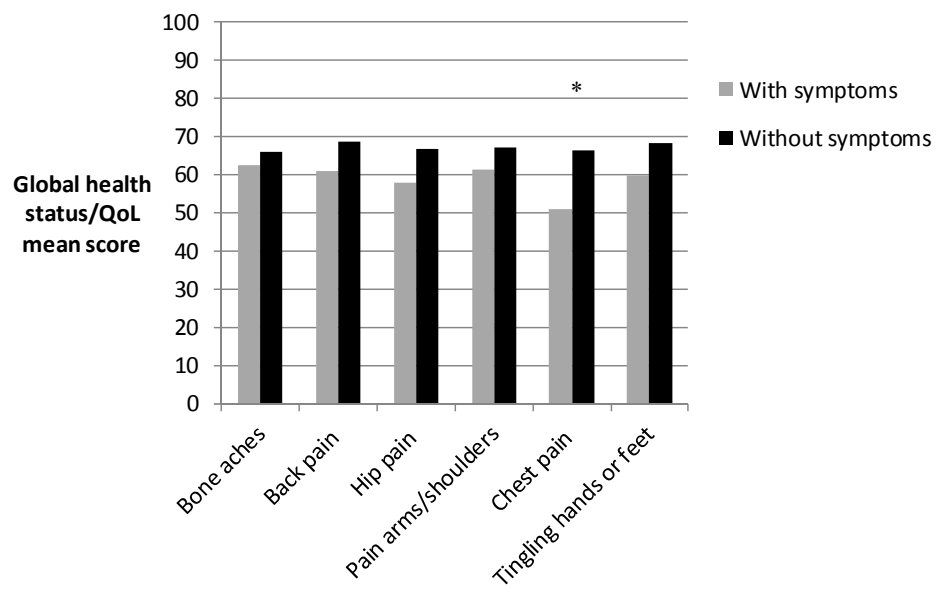

Figure 6.4a EORTC QLQ-C30 global health status/QoL mean scores between MM patients with symptoms and patients without symptoms aged $\leq 65$ years.

B

MM patients aged $66-88$ years

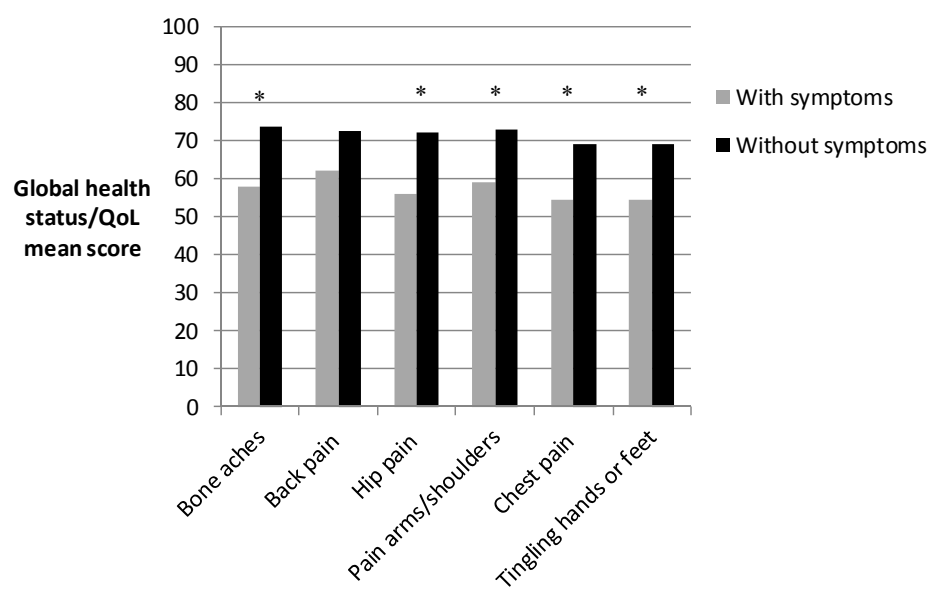

Figure 6.4b EORTC QLQ-C30 global health status/QoL mean scores between MM patients with symptoms and patients without symptoms aged $\geq 66$ years. 


\section{Discussion}

The results of our study did not reveal major differences in HRQOL between younger and older $\mathrm{MM}$ patients, except that older MM patients reported better emotional functioning and less financial problems and that younger MM patients had a better body image and future perspectives.

HRQOL differences between younger patients and the normative population were larger than HRQOL differences between older patients and the normative population. This was most evident for cognitive functioning, insomnia and financial problems, but also for physical and emotional functioning, pain and appetite loss. These results indicate that being diagnosed with and treated for $\mathrm{MM}$ has a larger impact on $\mathrm{HRQOL}$ of younger patients compared to elderly patients. This might be explained by the in general more intensive treatment that younger patients receive. Another explanation might be that elderly patients are confronted with lower work-related and social demands or that they have better coping strategies through more life experience.

Compared to the normative population, both younger and older patients scored in particular worse on fatigue, pain and dyspnea and on all EORTC QLQ-C30 functioning scales. It was previously observed in two population-based studies, of which one study contains partially the same data as the present study, that MM patients had worse HRQOL compared to a normative population. ${ }^{18,19}$ However, these studies did not investigate age-related differences and our study showed that both younger and older patients experience a decreased HRQOL.

Patients of both age categories experienced a high level of pain and especially in elderly patients this had a negative impact on HRQOL. Pain in MM patients is caused by skeletal destruction and this symptom should be treated adequately. ${ }^{31}$ Financial problems occurred more frequently in patients $\leq 65$ years. A study among patients with diffuse large B-cell lymphoma also observed more financial difficulties in younger patients. ${ }^{32}$ Possible causes are changes in work situation and loss of income due to unemployment or sickness leave. ${ }^{33,34}$ Tingling hands or feet had a negative impact on HRQOL, especially in elderly patients. It can be caused by peripheral neuropathy, a well-known side effect of bortezomib and thalidomide and can be a reason for adjustment of treatment. ${ }^{13,15}$

Patients with a higher number of comorbidities more often reported lower HRQOL. We cannot exclude that patients with comorbidity received less intensive chemotherapy. This could lead to disease progression and deteriorated HRQOL. ${ }^{35-37}$ Also, comorbidity in itself might lead to deterioration in HRQOL.

We found no association between age, sex or treatment and HRQOL subscales. This is in contrast with a study among patients treated with MP, MPR or MPR-R that observed that female gender and age were negatively associated with HRQOL. ${ }^{37}$ Number of comorbidities was however not included in the analysis and therefore age may be a confounder in this study. In line with our results, a study comparing HRQOL 
in patients receiving high-dose chemotherapy followed by ASCT with patients treated with MP observed no differences in HRQOL. ${ }^{38}$

This study has some limitations. Since it is unknown whether non-respondents did not participate because of absence of symptoms or because of poor health status, a selection bias cannot be excluded. In addition, we do not have more detailed information about the primary treatment patients received, if they received any treatment after first-line treatment nor if patients received any treatment at time of questionnaire. Interestingly, the rate of stem cell transplantation in the study population was low (26\%). Although ASCT is currently the standard of care for fit younger patients, in the present study only $50 \%$ of the patients younger than 66 years received ASCT as primary treatment. Whether this is due to selection bias or due to suboptimal treatment is unclear.

The strengths of our study are that this is a population-based study that included a large number of patients and therefore the results can be generalized to the overall MM population. The results of our study provide more insight into the impact of MM on HRQOL and are an important addition to the limited amount of currently available data concerning HRQOL in MM patients.

In conclusion, this study shows that HRQOL is considerably impaired in both younger and older MM patients. For most EORTC QLQ-C30 and MY-20 subscales, no differences were found between younger and older patients. In comparison with a normative population, $\mathrm{HRQOL}$ was more impaired in younger than in older patients. A higher number of comorbidities and a shorter time since diagnosis, but not age, sex or treatment were associated with worse HRQOL. Furthermore, pain and tingling hands and feet are, especially in elderly patients, accompanied with deteriorated quality of life. Therapy is aimed at prolonging survival and preserving or improving HRQOL. However, patients report a high symptom burden and in order to improve HRQOL, therapy should also be aimed at alleviating these symptoms. 


\section{References}

1. Surveillance, Epidemiology, and End Results Program. http://seer.cancer.gov/statfacts/html/ mulmy.html.

2. Attal M, Harousseau JL, Stoppa AM, et al. A prospective, randomized trial of autologous bone marrow transplantation and chemotherapy in multiple myeloma. Intergroupe Francais du Myelome. N EnglJ Med 1996;335:91-7.

3. Child JA, Morgan GJ, Davies FE, et al. High-dose chemotherapy with hematopoietic stem-cell rescue for multiple myeloma. N Engl J Med 2003;348:1875-83.

4. Fermand JP, Katsahian S, Divine $M$, et al. High-dose therapy and autologous blood stem-cell transplantation compared with conventional treatment in myeloma patients aged 55 to 65 years: long-term results of a randomized control trial from the Group Myelome-Autogreffe. J Clin Oncol 2005;23:9227-33.

5. Qazilbash MH, Saliba RM, Hosing C, et al. Autologous stem cell transplantation is safe and feasible in elderly patients with multiple myeloma. Bone Marrow Transpl 2007;39:279-83.

6. Muta T, Miyamoto T, Fujisaki T, et al. Evaluation of the feasibility and efficacy of autologous stem cell transplantation in elderly patients with multiple myeloma. Intern Med 2013;52:63-70.

7. Siegel DS, Desikan KR, Mehta J, et al. Age is not a prognostic variable with autotransplants for multiple myeloma. Blood 1999;93:51-4.

8. Palumbo A, Bringhen S, Petrucci MT, et al. Intermediate-dose melphalan improves survival of myeloma patients aged 50 to 70: results of a randomized controlled trial. Blood 2004;104:3052-7.

9. Badros A, Barlogie B, Siegel E, et al. Autologous stem cell transplantation in elderly multiple myeloma patients over the age of 70 years. Br J Haematol 2001;114:600-7.

10. Facon T, Mary JY, Hulin C, et al. Melphalan and prednisone plus thalidomide versus melphalan and prednisone alone or reduced-intensity autologous stem cell transplantation in elderly patients with multiple myeloma (IFM 99-06): a randomised trial. Lancet 2007;370:1209-18.

11. Palumbo A, Bringhen S, Caravita T, et al. Oral melphalan and prednisone chemotherapy plus thalidomide compared with melphalan and prednisone alone in elderly patients with multiple myeloma: randomised controlled trial. Lancet 2006;367:825-31.

12. Fayers PM, Palumbo A, Hulin C, et al. Thalidomide for previously untreated elderly patients with multiple myeloma: meta-analysis of 1685 individual patient data from 6 randomized clinical trials. Blood 2011;118:1239-47.

13. Wijermans P, Schaafsma M, Termorshuizen F, et al. Phase III study of the value of thalidomide added to melphalan plus prednisone in elderly patients with newly diagnosed multiple myeloma: the HOVON 49 Study. J Clin Oncol 2010;28:3160-6.

14. Hulin C, Facon T, Rodon P, et al. Efficacy of melphalan and prednisone plus thalidomide in patients older than 75 years with newly diagnosed multiple myeloma: IFM 01/01 trial. J Clin Oncol 2009;27: 3664-70.

15. San Miguel JF, Schlag R, Khuageva NK, et al. Bortezomib plus melphalan and prednisone for initial treatment of multiple myeloma. N Engl J Med 2008;359:906-17.

16. Mateos MV, Richardson PG, Schlag R, et al. Bortezomib plus melphalan and prednisone compared with melphalan and prednisone in previously untreated multiple myeloma: updated follow-up and impact of subsequent therapy in the phase III VISTA trial. J Clin Oncol 2010;28:2259-66.

17. Palumbo $A$, Hajek $R$, Delforge $M$, et al. Continuous lenalidomide treatment for newly diagnosed multiple myeloma. N Engl J Med 2012;366:1759-69.

18. Mols F, Oerlemans S, Vos AH, et al. Health-related quality of life and disease-specific complaints among multiple myeloma patients up to $10 \mathrm{yr}$ after diagnosis: results from a population-based study using the PROFILES registry. Eur J Haematol 2012;89:311-9.

19. Gulbrandsen N, Hjermstad MJ, Wisloff F, Nordic Myeloma Study G. Interpretation of quality of life scores in multiple myeloma by comparison with a reference population and assessment of the clinical importance of score differences. Eur J Haematol 2004;72:172-80. 
20. Verelst SG, Termorshuizen F, Uyl-de Groot CA, et al. Effect of thalidomide with melphalan and prednisone on health-related quality of life (HRQoL) in elderly patients with newly diagnosed multiple myeloma: a prospective analysis in a randomized trial. Ann Hematol 2011;90:1427-39.

21. Delforge $M$, Dhawan R, Robinson D, Jr., et al. Health-related quality of life in elderly, newly diagnosed multiple myeloma patients treated with VMP vs. MP: results from the VISTA trial. Eur J Haematol 2012;89:16-27.

22. Dimopoulos MA, Delforge M, Hajek R, et al. Lenalidomide, melphalan, and prednisone, followed by lenalidomide maintenance, improves health-related quality of life in newly diagnosed multiple myeloma patients aged 65 years or older: results of a randomized phase III trial. Haematologica 2013;98:784-8.

23. Fritz A PC JA, et al. International Classification of Diseases for Oncology (ed 3rd). Geneva, World Health Organisation. 2000.

24. van de Poll-Franse LV, Horevoorts N, van Eenbergen M, et al. The Patient Reported Outcomes Following Initial treatment and Long term Evaluation of Survivorship registry: scope, rationale and design of an infrastructure for the study of physical and psychosocial outcomes in cancer survivorship cohorts. Eur J Cancer 2011;47:2188-94.

25. van de Poll-Franse LV, Mols F, Gundy CM, et al. Normative data for the EORTC QLQ-C30 and EORTCsexuality items in the general Dutch population. Eur J Cancer 2011;47:667-75.

26. Aaronson NK, Ahmedzai S, Bergman B, et al. The European Organization for Research and Treatment of Cancer QLQ-C30: a quality-of-life instrument for use in international clinical trials in oncology. J Natl Cancer Inst 1993;85:365-76.

27. Cocks $K$, Cohen D, Wisloff $F$, et al. An international field study of the reliability and validity of a disease-specific questionnaire module (the QLQ-MY20) in assessing the quality of life of patients with multiple myeloma. Eur J Cancer 2007;43:1670-8.

28. Sangha O, Stucki G, Liang MH, Fossel AH, Katz JN. The Self-Administered Comorbidity Questionnaire: a new method to assess comorbidity for clinical and health services research. Arthritis Rheum 2003;49:156-63.

29. Cocks K, King MT, Velikova G, Martyn St-James M, Fayers PM, Brown JM. Evidence-based guidelines for determination of sample size and interpretation of the European Organisation for the Research and Treatment of Cancer Quality of Life Questionnaire Core 30. J Clin Oncol 2011;29:89-96.

30. Osoba D, Rodrigues G, Myles J, Zee B, Pater J. Interpreting the significance of changes in healthrelated quality-of-life scores. J Clin Oncol 1998;16:139-44.

31. Kyle RA, Gertz MA, Witzig TE, et al. Review of 1027 patients with newly diagnosed multiple myeloma. Mayo Clinic proceedings 2003;78:21-33.

32. van der Poel MW, Oerlemans S, Schouten HC, et al. Quality of life more impaired in younger than in older diffuse large B cell lymphoma survivors compared to a normative population: a study from the population-based PROFILES registry. Ann Hematol 2014;93:811-9.

33. Mols F, Thong MS, Vissers P, Nijsten T, van de Poll-Franse LV. Socio-economic implications of cancer survivorship: results from the PROFILES registry. Eur J Cancer 2012;48:2037-42.

34. Goodwin JA, Coleman EA, Sullivan E, et al. Personal financial effects of multiple myeloma and its treatment. Cancer Nurs 2013;36:301-8.

35. Kleber $\mathrm{M}$, Ihorst $\mathrm{G}$, Terhorst $\mathrm{M}$, et al. Comorbidity as a prognostic variable in multiple myeloma: comparative evaluation of common comorbidity scores and use of a novel MM-comorbidity score. Blood Cancer J 2011;1:e35.

36. Kleber M, Ihorst G, Gross B, et al. Validation of the Freiburg Comorbidity Index in 466 multiple myeloma patients and combination with the international staging system are highly predictive for outcome. Clinical Lymphoma Myeloma Leuk 2013;13:541-51.

37. Dimopoulos MA, Palumbo A, Hajek R, et al. Factors that influence health-related quality of life in newly diagnosed patients with multiple myeloma aged $>/=65$ years treated with melphalan, prednisone and lenalidomide followed by lenalidomide maintenance: results of a randomized trial. Leuk Lymphoma 2014;55:1489-97. 
Chapter 6

38. Gulbrandsen N, Wisloff F, Brinch L, et al. Health-related quality of life in multiple myeloma patients receiving high-dose chemotherapy with autologous blood stem-cell support. Med Oncol 2001;18: 65-77. 


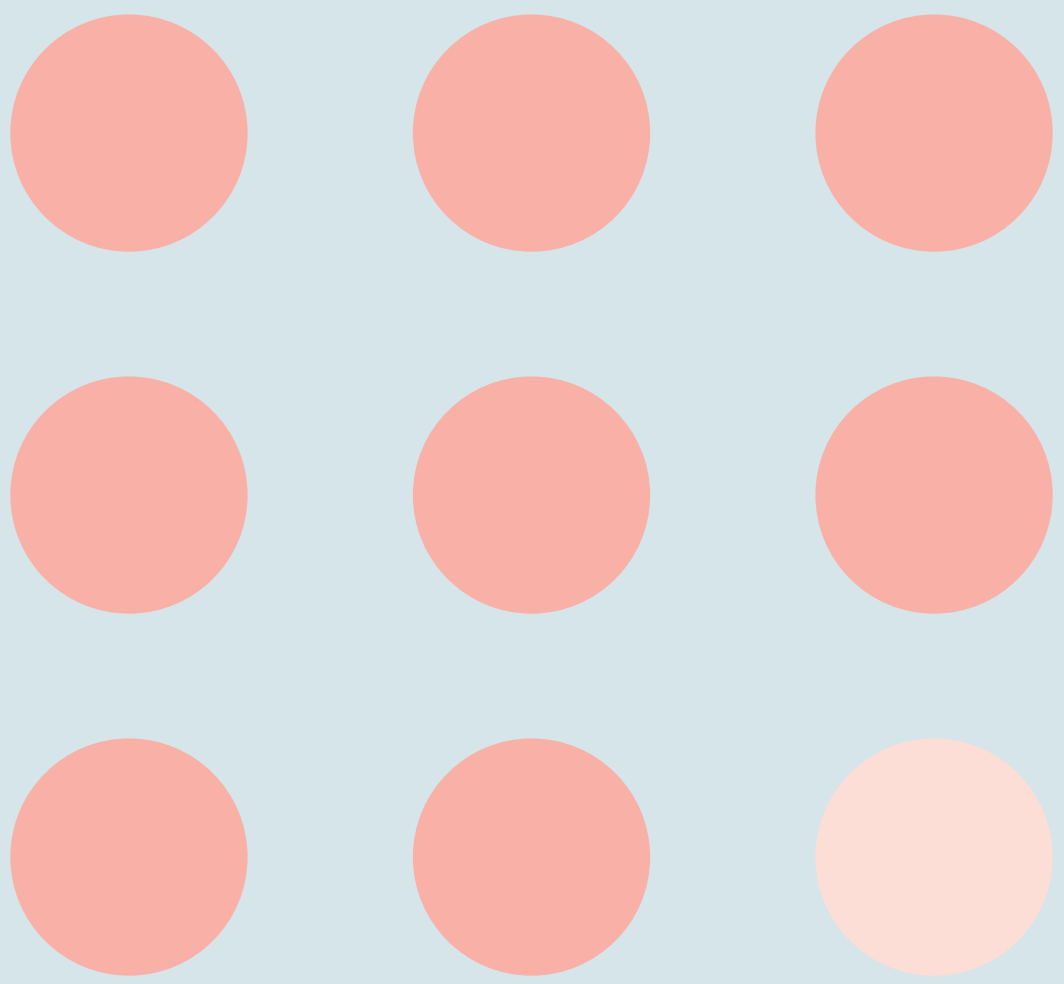
Summary and general discussion 



\section{Summary of results}

The aim of this thesis was to gain more insight into treatment decision-making by hematologists in elderly patients with hematological malignancies and to evaluate the impact of hematological malignancies on health related quality of life (HRQOL) in elderly diffuse large B-cell lymphoma (DLBCL) and multiple myeloma (MM) patients.

\section{Part I- Treatment-decision making}

In chapters 2, $\mathbf{3}$ and $\mathbf{4}$ we assessed treatment decision-making by hematologists in elderly patients with a hematological malignancy.

In chapter $\mathbf{2}$ we sought to investigate the determinants that influence treatment decision-making in elderly patients with a hematological malignancy by conducting a survey among Dutch hematologists. We showed that comorbidity plays an important role in decisions regarding treatment in elderly patients. Cognitive disorders and cardiovascular comorbidity were designated as the most important comorbidities that influence this decision-making. In addition, most hematologists take the presence of dementia and depressive disorders and activities of daily living (ADL) and instrumental activities of daily living (IADL) into consideration. Twenty-three percent of hematologists apply dose reductions in advance in elderly patients because of expected toxicity and almost $46 \%$ of hematologists feel that treatment in elderly patients is complex due to a lack of scientific evidence.

By presenting hematologists case vignettes of diffuse Large B-cell lymphoma (DLBCL) patients with varying age and extent of comorbidity more information was gathered about decision-making in daily clinical practice (chapter 3). Elderly DLBCL patients without a relevant medical history would be treated with full dose chemotherapy with curative intent irrespective of age by most hematologists. In the presence of a cognitive or depressive disorder, comorbidity or lack of social support the percentage of hematologists that would treat an older DLBCL patient with full dose chemotherapy decreases. This decrease is more pronounced in patients older than 80 years of age. Compared to hematologists working in tertiary medical teaching hospitals or general hospitals, hematologists in university hospitals more often declared to refrain from full dose chemotherapy with curative intent in patients of all age categories.

In chapter 4 we evaluated, using the Netherlands Cancer Registry, the impact of comorbidity on primary treatment with curative intent in elderly patients with $D L B C L$, also to assess treatment choices made in daily clinical routine. The application of treatment with curative intent decreased with advancing age, from $89 \%$ of patients aged $65-69$ years to $50 \%$ in patients aged $\geq 80$ years. In patients treated with R-CHOP for stage II-IV DLBCL, $21 \%$ received less than six cycles. The prevalence of comorbid conditions was $88 \%$. Age $\geq 75$ years and ischemic heart disease or heart failure, muscle, connective tissue and joint disease, genitourinary disease, and central 
nervous system disease were associated with lower odds of receiving treatment with curative intent. Age $\geq 80$ years and diabetes mellitus were associated with lower odds of completion of R-CHOP. Overall survival among patients treated intensively did not differ between the four age groups.

\section{Part II- Health-related quality of life}

In chapter 5 and 6, the impact of being diagnosed with and treated for DLBCL or multiple myeloma (MM) on the HRQOL of elderly patients was investigated, using the EORTC QLQ-C30 questionnaire and additionally the EORTC QLQ-MY20 questionnaire in MM patients. HRQOL of elderly patients was compared with HRQOL in younger patients and in an age- and sex-matched normative population.

Elderly DLBCL survivors aged 76-85 years had worse physical functioning and global health status/quality of life and more appetite loss and constipation compared to survivors aged 18-59 years. In addition, they also scored worse on global health status/quality of life and appetite loss compared to DLBCL survivors of 60-75 years old. The effect sizes of all these differences were trivial or small. Financial problems, however, occurred less frequently in older patients (medium effect size). Compared to the normative population, in the elderly population of $D L B C L$ survivors only differences with a trivial or small effect size were observed, while DLBCL survivors aged 18-59 years especially had deteriorated cognitive and social functioning and more often reported dyspnea and financial problems (all large and medium effect sizes). Based on these findings, it seems that being diagnosed with and treated for DLBCL has less impact on older compared to younger patients (chapter 5).

With respect to $\mathrm{MM}$, no major differences in $\mathrm{HRQOL}$ were found between patients aged older than 65 years versus patients of 65 years and younger, except for financial problems, which occurred more frequently in younger patients (medium effect size). Compared to the age- and sex- matched normative population, patients aged $\leq 65$ years scored worse on all EORTC QLQ-C30 functioning scales and on global health status/quality of life (large and medium effect sizes). In addition, they scored worse on almost all items of the EORCT QLQ-C30 symptom list compared to the normative population with large and medium effect sizes on fatigue, pain, dyspnea, appetite loss and financial problems. Patients older than 65 years especially scored worse on social, physical and role functioning and on global health status/quality of life (large and medium effect sizes) compared to the normative population. With respect to symptoms, patients $>65$ years in particular scored worse on fatigue, pain and dyspnea (large and medium effect sizes) compared to the normative population. Patients with comorbid conditions more often reported low physical functioning, worse global health status/quality of life and more pain, fatigue and side effects of treatment. In 
addition, patients with a longer time since diagnosis less often reported low physical functioning. These results indicate that HRQOL in younger MM patients is more deteriorated than HRQOL in older MM patients in comparison with an age- and sexmatched population. However, symptom burden is high in both age categories (chapter 6).

\section{General discussion}

For many hematological malignancies the incidence increases with advancing age. Due to ageing of the population, hematologists will increasingly be faced with elderly patients with a malignancy and the accompanying dilemmas regarding treatment decisions.

With respect to DLBCL, population-based studies showed that overall survival (OS) is improved in recent years for elderly DLBCL patients aged between 80 and 89 years and also for patients aged $>90$ years. ${ }^{1}$ However, the question is whether this improved OS is due to improved DLBCL management or due to general advances in medical care. Relative survival (RS) can be interpreted as disease-specific survival. In a population-based study among DLBCL patients in the Netherlands an improvement in RS over time was observed, although this improvement was more pronounced in patients $<75$ years than in older patients. ${ }^{2}$ More specifically, another populationbased study, also including DLBCL patients in the Netherlands, observed a significant improvement in RS in patients aged 80-84 years who were diagnosed in 2008-2015, and the application of rituximab seemed to have accounted for the improvement. ${ }^{3}$ However, among patients aged $\geq 85$ years no improvement in RS was observed between patients diagnosed in 2008-2015 versus patients diagnosed in 1989-2002. Therefore, despite the introduction of new treatment modalities such as rituximab, outcome of elderly DLBCL patients is not improving for the very elderly and is still disappointing. In part, this might be explained by different biological disease characteristics between younger and older adults. For example, the percentage of patients presenting with the activated B-cell like $(A B C)$ subtype increases with age, and this subtype is associated with a poorer prognosis compared to the germinal center B-cell like (GBC) subtype. ${ }^{4,5}$ Attempts to improve survival may focus on overcoming the poorer prognosis associated with the ABC subtype of DLBCL. Indeed, studies focused on improving survival in the elderly by intensifying treatment. However, dose-intensified R-CHOP or lenalidomide maintenance after R-CHOP, did not lead to improved OS. ${ }^{6-8}$ Therefore, it remains questionable whether intensification of treatment is the way to go in the elderly, since this also introduces additional toxicity. Another explanation for the poorer survival in elderly DLBCL patients is the lower application of standard immunochemotherapy. Therefore, instead of focusing 
on treatment intensification, a better strategy for improving OS in elderly lymphoma patients might be increasing the application rate of standard therapy. Populationbased studies, including our own study, observed that only $33-70 \%$ of elderly lymphoma patients received standard immunochemotherapy, creating a window of opportunity for improvement. ${ }^{9-11}$ An important focus is selecting those elderly patients in whom the benefits of treatment outweigh the disadvantages of treatment. Since we observed that DLBCL and its treatment have less impact on HRQOL for elderly compared to younger patients, aiming for curation can be worthwhile.

Treatment decision-making in elderly patients is complicated, since it concerns a very diverse patient population with varying degrees of impairment in functional and cognitive status and comorbidity. Therefore, biological age is more important than chronological age. There are, however, no guidelines or rules to guide hematologists to make treatment decisions in this patient population and in clinical practice decisions are made based on the individual hematologist's judgment.

In addition, most trials studying treatment in patients with a hematological malignancy use traditional outcome parameters such as progression-free and overall survival as primary endpoint. These endpoints focus on quantity of life as the primary goal of treatment. However, in addition to these traditional outcome parameters it is of great importance to evaluate the consequence of treatment on the quality of life of patients.

\section{Factors that influence treatment-decision making by hematologists}

In this thesis we observed that age, comorbid conditions and functional impairment all influence treatment-decision making by hematologists.

\section{Age}

With respect to age, in DLBCL patients advanced age (75 years or above) was associated with lower odds of receiving treatment with curative intent. Of patients aged $\geq 80$ years, only $50 \%$ received regimens containing rituximab and anthracyclines and up to $25 \%$ received no anti-lymphoma treatment.

A Canadian population-based study also observed that elderly patients frequently do not receive $\mathrm{R}-\mathrm{CHOP}$, which is considered standard immunochemotherapy in DLBCL. ${ }^{9}$ This was also observed in two population-based studies in the Netherlands, one including patients diagnosed between 1998 and 2004 and one including patients only in the Northern part of the Netherlands. ${ }^{10,11}$ Moreover, in this thesis we observed that age was independently associated with not receiving treatment with curative intent. This confirms the findings from previous studies, in which hematologists indicated that high age in itself, is a reason not to initiate curative treatment. ${ }^{9,10,12,13}$ Interestingly, in our survey only $2 \%$ of hematologists reported to frequently refrain from curative treatment, as opposed to $79 \%$ who responded to sometimes refrain 
from curative treatment in elderly patients. In addition, in the case vignette study more than $80 \%$ of hematologists reported to treat a patient of over 80 years with full dose chemotherapy with curative intent if the patient has no relevant medical history. The results from the survey and case vignette study are contradictory with the results from our population-based study, which indicated that high age is indeed independently associated with not receiving therapy with curative intent. This suggests that there is a discrepancy between what hematologists think they practice and what they actual practice. In routine clinical practice there indeed still appears to be a great reluctance to use the R-CHOP regimen in elderly patients, even though this regimen has proven to improve survival compared to suboptimal or no antilymphoma therapy, even in the very elderly. ${ }^{9-11,14-16}$ Moreover, in our study we also observed that overall survival did not differ between younger and older elderly patients treated intensively. It could be argued that these results merely indicate that hematologists are apparently well capable in selecting those elderly patients that are fit enough to receive R-CHOP. However, this does not imply that there were no patients in the non-R-CHOP group that would have benefitted from this treatment. The prejudices of hematologists towards treatment of the elderly with a hematological malignancy are of major concern. Increasing the awareness amongst hematologists of the role of under-treatment in the poorer prognosis of elderly patients could lead to more outweighed treatment decisions in which, for example, high age would not be adduced as sole reason for refrainment from treatment. Through this way the percentage of elderly patients treated with standard chemotherapy schedules could be increased, thereby improving overall survival. ${ }^{13,17}$ Although selecting elderly DLBCL patients for intensive treatment can be challenging, from the hematologists' perspective high age alone should not be a reason for refrainment of treatment with curative intent. Herewith, it is of importance to be aware of the life expectancy of elderly patients, which is longer than many doctors probably realize. For example, the life expectancy of an 80-year old male is more than eight years and of an 80-year old female is more than nine years and it is expected that the life expectancy will increase further in the next decades. ${ }^{18}$

\section{Comorbidities and functional impairment}

In our studies we found that the presence of comorbidities in elderly DLBCL patients influences treatment-decision making. More precisely, in patients with ischemic heart disease or heart failure, muscle, connective tissue and joint disease, genitourinary disease or CNS disease the likelihood of receiving curative treatment is decreased. The number of comorbidities was not related to the application of immunochemotherapy with curative intent.

Other population-based studies, performed in other countries or time periods than our study, also observed that in the presence of comorbidities intensive 
chemotherapy is less often initiated..$^{10,14,19,20}$ In our survey, but also in other studies it was observed that hematologists stated comorbidity as reason for refrainment from treatment and this is also what they practice. ${ }^{9,10,12}$ The negative influence of comorbidity on the application of immunochemotherapy with curative intent might be due to several mechanisms. First, hematologists may fear for increased risk of treatment-related toxicity in patients with comorbidity, although studies report conflicting results regarding the association between comorbidities and toxicity. ${ }^{21,22}$ Second, comorbidity is associated with an inferior survival in elderly DLBCL patient and this might discourage treatment initiation. ${ }^{14,19-25}$ However, it is not clear whether the decreased survival among patients with comorbidities is due to the comorbidity itself or treatment-related toxicity or that it is the results of suboptimal chemotherapy. Another explanation for the negative association between comorbidities and intensive chemotherapy might be that patients with comorbidities have worse performance status and this may lead to refrainment from treatment. $A$ study among elderly DLBCL patients reported an independent association between performance status and treatment with CHOP-like chemotherapy, but not between comorbidity and CHOP-like chemotherapy. ${ }^{10}$ However, in this study only a limited amount of comorbidities was evaluated. In another population-based study the influence of severity of comorbidity on choice of treatment was evaluated. ${ }^{21}$ Severity of comorbidity had no effect on the chance of receiving chemotherapy, except for patients with aggressive NHL and cardiovascular comorbidity. Performance status was not evaluated. Whether it is justified that patients with comorbidity receive less chemotherapy is obscure. Thus, the exact role that comorbidity should play in treatment of elderly patients as well as the appropriate way to evaluate the extent of comorbidity is unclear.

In this thesis we also observed that dementia, ADL and IADL are important factors that influence treatment decisions. Various studies observed an association between ADL, $I A D L$, cognition or frailty and survival or inability to complete chemotherapy, although this could not be confirmed in other studies. ${ }^{26-31}$ These contradictory results make it difficult to define the role these factors should play in treatment decision-making. Currently, these factors are not systematically evaluated in elderly patients with a hematological malignancy, since the therapeutic consequences are not clear and it is time consuming.

\section{HRQOL in elderly DLBCL and MM survivors}

\section{The impact of DLBCL and its treatment on HRQOL}

In this thesis we observed that younger DLBCL patients had better HRQOL than elderly DLBCL patients, except for financial problems, which occurred more often in younger patients. However, the differences between younger DLBCL survivors and the age- and 
sex-matched normative population were larger than the differences observed between elderly survivors and the normative population. It has been reported before that HRQOL in Non-Hodgkin lymphoma (NHL) survivors is inferior in several domains compared to HRQOL in a normative population. ${ }^{32-35}$ Two studies have focused specifically on the effect of treatment on HRQOL in elderly patients with aggressive NHL. It was observed that before start of treatment HRQOL was better in patients with a lower compared to patients with a higher (age adjusted) International Prognostic Index (IPI). ${ }^{36,37}$ During treatment HRQOL deteriorated in de lower age adjusted IPI group, but remained stable in de higher age adjusted IPI group. ${ }^{36}$ At the end of treatment, improvement in HRQOL was observed. ${ }^{36,37}$ Differences in HRQOL between younger versus elderly patients were addressed in three other studies. These studies showed that younger survivors experience better physical health, but worse mental health and overall quality of life in comparison to elderly survivors. ${ }^{38-40}$

The observation in this thesis that the differences in HRQOL between younger DLBCL survivors and their age -and sex- matched normative population are larger than the differences between elderly survivors and their normative counterparts may indicate that the impact of DLBCL and its treatment is greater for younger than for older survivors. These results are in line with two other studies in cancer survivors. ${ }^{41,42}$ Possible explanations might be that elderly patients have fewer work-, family- and social-related demands than younger patients or that elderly patients have better strategies to cope with stressful events through more life experience. Another explanation might be that age influences the importance that NHL patients assign to quality of life domains, however in one study investigating this issue this could not be confirmed. ${ }^{43}$ Of note, it cannot be excluded that HRQOL in elderly patients is less deteriorated due to less intensive treatment schedules compared to younger patients. The optimal treatment for DLBCL with respect to progression-free and overall survival consists of combination immunochemotherapy with rituximab, cyclophosphamide, doxorubicin, vincristine and prednisolone (R-CHOP). ${ }^{44,45}$ However, in clinical practice elderly patients are often not treated with R-CHOP, because of poor performance status or comorbidity, but also high age is adduced as sole reason for refraining from standard treatment. $9,10,12-14,17,46,47$ Concerns regarding the negative impact of treatment on the patient's HRQOL play a major role in the decision to refrain from standard treatment. The results shown in this thesis do not support this. Therefore, in elderly DLBCL-patients standard treatment with R-CHOP should always be seriously considered and the presumption that treatment will negatively influence HRQOL should not be a leading argument in treatment decision-making. 


\section{The impact of MM and its treatment on HRQOL}

We observed no major differences in HRQOL between younger versus older MM patients, except for financial problems, which, like in DLBCL patients, occurred more frequently in patients who were aged $\leq 65$ years.

The differences, however, in HRQOL between younger patients and the normative population were larger than the differences observed between patients older than 65 years and the normative population, comparable to the results found in DLBCL. This implies that the impact of MM and its treatment on HRQOL is larger for younger patients compared to older patients. An explanation for this observation might be that younger patients more often receive intensive treatment with high dose chemotherapy followed by autologous stem cell transplantation. Also, elderly patients are in general faced with lower work-, family- and social related demands and they might have better coping strategies through more life experience.

In two other studies HRQOL in MM patients compared to that in a normative population was investigated. These studies, of which one study contains partially the same data as the data used in this thesis, also found a deteriorated HRQOL in MM patients compared to a normative population. ${ }^{48,49}$

Several studies investigating the effect of treatment with melphalan and prednisone in combination with bortezomib, lenalidomide or thalidomide in elderly patients found improvement of HRQOL during treatment. ${ }^{50-55}$ Nevertheless, although HRQOL improved during treatment, it was still markedly reduced in comparison to the normative population. ${ }^{49}$ Also in this thesis we observed that MM patients of both age categories experienced a high symptom burden. Especially pain, which is caused by skeletal destruction, and tingling hands and feet, a known side effect of treatment with bortezomib and thalidomide, were frequently reported and these symptoms are associated with worse HRQOL.

$\mathrm{MM}$ is an incurable illness with a high burden of disease due to bone lesions, renal impairment and anemia. HRQOL is markedly impaired for younger patients and to a lesser extent also for elderly patients. Therefore, next to prolongation of survival, also preservation or improvement of HRQOL should be in important goal of treatment. Important causes for deterioration in HRQOL are pain and tingling hands or feet and attention should be paid to alleviating these symptoms.

\section{Methodological considerations}

In this thesis two topics were studied that have not been studied extensively before: treatment-decision making by hematologists in elderly patients and HRQOL in elderly DLBCL and MM survivors, compared to younger patients and compared to a normative population. 
In general, randomized controlled phase 3 trials (RCTs) are considered the gold standard for providing evidence. To be included in an RCTs, patients must meet to strict inclusion criteria. This results in a homogeneous, but highly selected patient population. Therefore, the results of RCTs are not generalizable for patients not meeting the inclusion criteria. Patients are frequently excluded from RCTs because of high age, comorbidity or performance status and consequently this often involves elderly patients. Population-based studies give the opportunity to study these patient populations that are not represented in RCTs. Therefore, the results of our population-based studies as described in chapters 4, 5 and 6 are representative of real-world elderly lymphoma and MM patients. This is one of the major strengths of this thesis.

In chapter 4 we evaluated the impact of comorbidity on primary treatment with curative intent in elderly DLBCL patients. The association between comorbidity and its relationship to treatment among lymphoma patients has been studied before in a population-based setting. ${ }^{19-21}$ However, as opposed to these studies, in our population-based study patients were diagnosed in a more recent time period and only patients with DLBCL were included and not patients with other histological features. Further, we exclusively studied elderly patients ( $\geq 65$ years) instead of patients of all ages and the impact of specific comorbidities on treatment was evaluated instead of merely the impact of the presence or absence of comorbidities.

In chapter 5 and 6 we evaluated the impact of HRQOL on DLBCL survivors and MM patients. HRQOL in DLBCL and MM patients has been studied before. However, these studies did not focus specifically on elderly patients. In addition, the HRQOL assessment in previous studies often was part of a randomized trial, creating a selection bias, as opposed to our population-based studies. Another strength in our HRQOL studies is the use of a normative population, making it possible to evaluate the influence of cancer on HRQOL beyond the influence of 'natural' ageing and impact of comorbid diseases on HRQOL. Further, when comparing HRQOL scores, not only statistical significance was evaluated, but also clinical relevance. Many previous studies only relied on statistical significance to determine the impact on HRQOL. However, for the clinical interpretation of HRQOL differences, the clinical relevance of HRQOL differences should be determined and this contributes to influencing clinical practice based on HRQOL results.

Another strength is that the response rates of patients to our questionnaires in chapter 5 and 6 were high; 73\% of MM patients and $85 \%$ of DLBCL survivors receiving a questionnaire responded. In a meta-analysis an average response rate of $40-70 \%$ was reported, so in our studies this was higher. ${ }^{56}$ To evaluate representativeness of our data, we compared differences in demographic and clinical characteristics between respondents, non-respondents, and patients with unverifiable addresses in both chapter 5 and 6 . Although in general these groups were comparable, we did observe differences in sex, primary treatment or age. It is possible that non- 
responders did not respond because of poor health or because of absence of symptoms. To gain more insight into this, more information about the non-responders and patients with unverifiable addresses should be collected, such as response to primary treatment. For the studies in this thesis, these data were not available.

In the HRQOL studies in chapter 5 and 6, the comorbidities evaluated were selfreported using the Self-Administered Comorbidity Questionnaire (SCQ). The SCQ is a validated instrument to assess comorbid conditions. Another approach to evaluate comorbidities is using a medical record-based comorbidity measure, however, a limitation of this method is that it largely depends on a good quality of documentation.

The European organization for Research and Treatment of Cancer Quality of Life Questionnaire Core 30 (EORTC QLQ-C30), and the EORTC QLQ-MY20 disease specific module, were used to assess HRQOL. The EORTC QLQ-C30 is a generic cancer questionnaire, while the EORTC QLQ-MY20 module explores HRQOL issues more specific for MM. These questionnaires are widely used and validated to evaluate $\mathrm{HRQOL}$ in cancer patients. Using these questionnaires in this thesis provided insightful information on HRQOL in elderly patients. However, they might not meet all the needs of HRQOL assessment in elderly cancer patients. ${ }^{57}$ Therefore, an additional questionnaire was developed, the EORTC QLQ-ELD15, which can be used in conjunction with the EORTC QLQ-C30. ${ }^{58}$ The EORTC QLQ-ELD15 focuses more on psychosocial issues and comprises five scales (mobility, worries about others, future worries, maintaining purpose and burden of illness) and two single items (joint stiffness, and family support). For the studies in this thesis, this questionnaire has not been used. For future studies it would be useful to use the EORTC QLQ-ELD15, since the QLQ-C30 does not meet all the needs of HRQOL assessment in older cancer patients. However, since the EORTC QLQ-ELD15 is specifically validated for elderly patients, it cannot be used for comparison of HRQOL in younger patients as evaluated in our studies.

A limitation of this thesis is that for the studies described in chapter 2 and 3 the response rate of hematologists was low, namely 34-37\%. On the other hand, in other surveys response rates of only 13-21\% were achieved among physicians and our response rate is much higher. ${ }^{59,60}$ Strategies to improve the response rate may be shortening the length of the questionnaire or using incentives. In our questionnaire, we offered a handbook of hematology in the elderly as incentive. This incentive as well as a reminder e-mail sent to non-responders might have helped to achieve a higher response rate than observed in other surveys among physicians. In our survey, there were no clear indications that especially hematologists with a special interest in elderly patients responded or the contrary. In addition, it was a multicenter study including hematologist working in different types of hospitals. Therefore, it can be assumed that the results are generalizable. Nevertheless, it cannot be excluded and may also be likely that the opinions as expressed by hematologists in the survey differ 
from the actual clinical practice. Therefore we aimed to compare these results using population-based data in chapter 4 . A limitation of chapter 4 is that the impact of performance status on primary treatment could not be analyzed, since performance status was undetermined in a large proportion of patients.

There are several limitations in our HRQOL studies. First, selection bias cannot be excluded, due to death of patients or due to non-participation because of poor health or absence of symptoms. However, although a direct comparison is not possible, the prevalence of comorbidities observed among respondents in our HRQOL studies seems comparable to the prevalence at time of cancer diagnosis as registered in the Southeast region of the Netherlands Cancer Registry. ${ }^{61}$ This suggests that the patients in our studies were representative of the population as a whole. Second, detailed information on primary treatment and response were unavailable. It is unknown whether elderly patients might have had less aggressive treatments compared to younger patients and this could have influenced HRQOL. In addition, due to inclusion of patients at different times since diagnosis, the survival time differed between patients and this might have influenced HRQOL.

\section{Future directions: improving care for elderly patients with a hematological malignancy}

The management of hematological malignancies in elderly patients is challenging, while hematologists will increasingly be faced with this patient population due to expansion of the elderly population. It is important to improve care for this growing group of elderly patients with a hematological malignancy. Future directions will be discussed in this section.

\section{Inclusion of elderly patients in clinical trials}

Elderly patients are underrepresented in clinical trials due to direct age-based exclusion or due to other selective in -and exclusion criteria. As a result there is a lack of evidence on the optimal treatment for elderly patients, which contributes to the complexity of their treatment. ${ }^{62,63}$ Therefore, it is of importance that future studies focus more on treatment of elderly patients with hematological malignancies. This can be achieved by introducing less restrictive in -and exclusion criteria so that in clinical trials the whole population for whom the treatment will be used is represented. Another option is stratification based on for elderly relevant criteria or designing trials that solely include elderly patients.

In addition, traditional endpoints such as disease-free, progression-free and overall survival are not the only appropriate endpoints in elderly patients. Disease-related symptoms, but also the psychosocial impact of a disease and its treatment may be of 
equal importance for this patient category. Therefore, evaluation of other clinical relevant endpoints, such as HRQOL and effect of treatment on functional status and on cognitive function is of increasing importance. ${ }^{64}$ These outcomes can be evaluated through patient-reported outcome (PRO) instruments, through which treatment effects that are only known to patient and the patient's perspective about the effectiveness of a treatment can be evaluated. ${ }^{65,66}$

\section{Evaluating treatment preferences from a patients' perspective}

In the current thesis we focused on factors that influence treatment-decision making by hematologists. However, little is known about the patients' perspective regarding treatment-decision making and treatment preferences. It is unknown for what reasons patients choose to refrain from treatment or what the role is off the social network on treatment-decision making by the patient. In addition, very little is known about to what extent a patient is willing to accept toxicities in order to achieve a certain treatment goal. Treatment goals could be life extension, alleviating pain, improving other symptoms than pain or maintaining independency. Information is lacking on which of these treatment goals are the most important to elderly patients and whether this differs in case of a potentially curable versus an incurable disease. A study among multiple myeloma patients observed that longer life expectancy and further treatment options had the greatest influence on treatment-decision making by patients, whereas emotional and physical quality of life were considered less important. ${ }^{67}$ This seems to indicate that quantity of life might be more important to patients than quality of life. However, studies evaluating treatment preferences in gastric and prostate cancer patients observed the opposite. ${ }^{68,69}$ Further, several studies among patients with different malignancies suggest that risk tolerance depends on the expected benefits of a treatment. ${ }^{70,71}$ In addition, age seems to influence the trade-offs patients make. ${ }^{72}$

Expanding our knowledge on this topic is important, since this could lead to improved information provision and shared decision-making.

\section{Pre-treatment evaluation}

Treatment decision-making in the elderly is difficult, as the population of elderly patients is very heterogeneous. It is a great challenge to select those elderly patients in whom the benefits of treatment outweigh the disadvantages.

The prevalence of comorbid conditions in elderly patients is high and increases to over $70 \%$ in patients of 75 years and older. ${ }^{61}$ Especially cardiovascular diseases have a high prevalence of $31-52 \%$, but also hypertension, prior malignancies, pulmonary diseases and diabetes mellitus are common comorbidities. We observed that elderly patients with comorbidities receive less standard chemotherapy. To expand our understanding 
of the influence of comorbidities on treatment of elderly patients, future trials should focus more on specific comorbidities. For example, cardiovascular diseases are associated with a lower odd of receiving R-CHOP in elderly patients with DLBCL. This is explained by the dose-dependent cardiotoxicity of anthracyclines. Due to this risk of cardiotoxicity, there is a reluctance to give anthracyclines to patients with a known diminished cardiac reserve. Early diagnostics of patients prone to develop cardiotoxicity would allow timely adjustment of treatment before the loss of cardiac function.

In addition, a closer collaboration with geriatric specialists might be of added value, because of their extensive clinical experience with elderly patients. Geriatric specialists could play an important role in optimizing the general health status of a patient in order to reduce the chances of premature treatment discontinuation. Examples are recognition of malnutrition, dependency in ADL or IADL and polypharmacy in the elderly, with subsequent interventions leading to improvement. These interventions could indirectly influence cancer treatment, by increasing compliance or reducing the risk for adverse events. For example, the prevalence of polypharmacy and use of inappropriate medication is over $40 \%$ in the geriatric oncology population. ${ }^{73}$ This increases the risk of adverse drugs reactions, interactions and non-adherence and can therefore negatively affect cancer treatment. Indeed, a study evaluating health-care-related adverse events leading to hospital admission in elderly individuals (including patients with a hematological malignancy) observed that the most common adverse event was medication-related. ${ }^{74}$ The number of medications used and dependency in IADL were predictive factors of admission. Whether interventions regarding malnutrition, $A D L$ and IADL dependency and polypharmacy are efficacious with respect to treatment in elderly patients with a hematological malignancy is unknown and therefore this could be a focus for future research.

\section{Concluding remarks}

It became evident in this thesis that comorbidities and age impact treatment-decision making by hematologists in elderly patients. In addition, we observed that there is a discrepancy between what hematologists think they practice and what they actually practice: High patient age was associated with lower odds of receiving intensive treatment, while hematologists did not specify patients' age as a reason for forgoing treatment. Furthermore, the impact of DLBCL and MM and its treatment has less impact on HRQOL of elderly patients than younger patients compared to a normative population. 
Treatment decisions in elderly are very difficult. However, based on quality of life and lifetime to gain, treating elderly patients can be very worthwhile. Therefore, appropriate, balanced shared decision-making, based on disease, patient and social characteristics, is very rewarding. 


\section{References}

1. Giri U, Martin GM. Survival outcomes in the very elderly with DLBCL prior to and after the introduction of rituximab: a US populaton-based study. Blood Advances 2017;1:615-8.

2. Issa DE, van de Schans SA, Chamuleau ME, et al. Trends in incidence, treatment and survival of aggressive B-cell lymphoma in the Netherlands 1989-2010. Haematologica 2015;100:525-33.

3. Dinmohamed AG, Issa DE, van der Poel MWM, et al. Treatment and relative survival in very elderly patients with DLBCL in The Netherlands: a population-based study, 1989 to 2015 Blood Advances 2017;1:1839-41.

4. Rosenwald A, Wright G, Chan WC, et al. The use of molecular profiling to predict survival after chemotherapy for diffuse large-B-cell lymphoma. N Engl J Med 2002;346:1937-47.

5. Mareschal S, Lanic H, Ruminy P, Bastard C, Tilly H, Jardin F. The proportion of activated B-cell like subtype among de novo diffuse large B-cell lymphoma increases with age. Haematologica 2011;96:1888-90.

6. Delarue $\mathrm{R}$, Tilly $\mathrm{H}$, Mounier $\mathrm{N}$, et al. Dose-dense rituximab-CHOP compared with standard rituximabCHOP in elderly patients with diffuse large B-cell lymphoma (the LNH03-6B study): a randomised phase 3 trial. Lancet Oncol 2013;14:525-33.

7. Thieblemont $\mathrm{C}$, Tilly H, Gomes da Silva M, et al. Lenalidomide Maintenance Compared With Placebo in Responding Elderly Patients With Diffuse Large B-Cell Lymphoma Treated With First-Line Rituximab Plus Cyclophosphamide, Doxorubicin, Vincristine, and Prednisone. J Clin Oncol 2017;35:2473-81.

8. Kuhnl A, Cunningham D, Counsell N, et al. Outcome of Elderly Patients with Diffuse Large B-cell Lymphoma Treated with R-CHOP: Results from the UK NCRI R-CHOP14v21 trial with combined analysis of molecular characteristics with the DSHNHL RICOVER-60 trial. Ann Oncol 2017;28(7): 1540-6.

9. Varga C, Holcroft C, Kezouh A, et al. Comparison of outcomes among patients aged 80 and over and younger patients with diffuse large B-cell lymphoma: a population based study. Leuk Lymphoma 2014;55:533-7.

10. van de Schans SA, Wymenga AN, van Spronsen DJ, Schouten HC, Coebergh JW, Janssen-Heijnen ML. Two sides of the medallion: poor treatment tolerance but better survival by standard chemotherapy in elderly patients with advanced-stage diffuse large B-cell lymphoma. Ann Oncol 2012;23:1280-6.

11. Boslooper K, Kibbelaar R, Storm H, et al. Treatment with rituximab, cyclophosphamide, doxorubicin, vincristine and prednisolone is beneficial but toxic in very elderly patients with diffuse large B-cell lymphoma: a population-based cohort study on treatment, toxicity and outcome. Leuk Lymphoma 2014;55:526-32.

12. Hasselblom S, Stenson M, Werlenius O, et al. Improved outcome for very elderly patients with diffuse large B-cell lymphoma in the immunochemotherapy era. Leuk Lymphoma 2012;53:394-9.

13. Peters FP, Lalisang RI, Fickers MM, et al. Treatment of elderly patients with intermediate- and highgrade non-Hodgkin's lymphoma: a retrospective population-based study. Ann Hematol 2001;80:1559.

14. Tien YY, Link BK, Brooks JM, Wright K, Chrischilles E. Treatment of diffuse large B-cell lymphoma in the elderly: regimens without anthracyclines are common and not futile. Leuk Lymphoma 2015;56:65-71.

15. Bairey O, Benjamini O, Blickstein D, Elis A, Ruchlemer R. Non-Hodgkin's lymphoma in patients 80 years of age or older. Ann Oncol 2006;17:928-34.

16. Chihara D, Westin JR, Oki Y, et al. Management strategies and outcomes for very elderly patients with diffuse large B-cell lymphoma. Cancer 2016;122:3145-51.

17. Peters FP, Fickers MM, Erdkamp FL, Wals J, Wils JA, Schouten HC. The effect of optimal treatment on elderly patients with aggressive non-Hodgkin's lymphoma: more patients treated with unaffected response rates. Ann Hematol 2001;80:406-10.

18. Centraal Bureau voor de Statistiek. http://statline.cbs.nl.

19. van Spronsen DJ, Janssen-Heijnen ML, Lemmens VE, Peters WG, Coebergh JW. Independent prognostic effect of co-morbidity in lymphoma patients: results of the population-based Eindhoven Cancer Registry. Eur J Cancer 2005;41:1051-7. 
20. van Spronsen DJ, Janssen-Heijnen ML, Breed WP, Coebergh JW. Prevalence of co-morbidity and its relationship to treatment among unselected patients with Hodgkin's disease and non-Hodgkin's lymphoma, 1993-1996. Ann Hematol 1999;78:315-9.

21. Janssen-Heijnen ML, van Spronsen DJ, Lemmens VE, Houterman S, Verheij KD, Coebergh JW. A population-based study of severity of comorbidity among patients with non-Hodgkin's lymphoma: prognostic impact independent of International Prognostic Index. Br J Haematol 2005;129:597-606.

22. Wieringa A, Boslooper $\mathrm{K}$, Hoogendoorn $\mathrm{M}$, et al. Comorbidity is an independent prognostic factor in patients with advanced-stage diffuse large B-cell lymphoma treated with R-CHOP: a population-based cohort study. Br J Haematol 2014;165:489-96.

23. Kobayashi Y, Miura K, Hojo A, et al. Charlson Comorbidity Index is an independent prognostic factor among elderly patients with diffuse large B-cell lymphoma. J Cancer Res Clin Oncol 2011;137:1079-84.

24. Lin TL, Kuo MC, Shih LY, et al. The impact of age, Charlson comorbidity index, and performance status on treatment of elderly patients with diffuse large B cell lymphoma. Ann Hematol 2012;91:1383-91.

25. Merli F, Luminari S, Rossi G, et al. Outcome of frail elderly patients with diffuse large B-cell lymphoma prospectively identified by Comprehensive Geriatric Assessment: results from a study of the Fondazione Italiana Linfomi. Leuk Lymphoma 2014;55:38-43.

26. Winkelmann N, Petersen I, Kiehntopf M, Fricke HJ, Hochhaus A, Wedding U. Results of comprehensive geriatric assessment effect survival in patients with malignant lymphoma. J Cancer Res Clin Oncol 2011;137:733-8.

27. Spina M, Balzarotti M, Uziel L, et al. Modulated chemotherapy according to modified comprehensive geriatric assessment in 100 consecutive elderly patients with diffuse large B-cell lymphoma. Oncologist 2012;17:838-46.

28. Soubeyran P, Fonck M, Blanc-Bisson C, et al. Predictors of early death risk in older patients treated with first-line chemotherapy for cancer. J Clin Oncol 2012;30:1829-34.

29. Aaldriks AA, Maartense $E$, le Cessie $S$, et al. Predictive value of geriatric assessment for patients older than 70 years, treated with chemotherapy. Crit Rev Oncol Hematol 2011;79:205-12.

30. Nabhan C, Smith SM, Helenowski I, et al. Analysis of very elderly $(>/=80$ years) non-hodgkin lymphoma: impact of functional status and co-morbidities on outcome. Br J Haematol 2012;156:196204.

31. Aaldriks AA, Giltay EJ, Nortier JW, et al. Prognostic significance of geriatric assessment in combination with laboratory parameters in elderly patients with aggressive non-Hodgkin lymphoma. Leuk Lymphoma 2015;56:927-35.

32. Mols F, Aaronson NK, Vingerhoets AJ, et al. Quality of life among long-term non-Hodgkin lymphoma survivors: a population-based study. Cancer 2007;109:1659-67.

33. Jerkeman M, Kaasa S, Hjermstad M, Kvaloy S, Cavallin-Stahl E. Health-related quality of life and its potential prognostic implications in patients with aggressive lymphoma: a Nordic Lymphoma Group Trial. Med Oncol 2001;18:85-94.

34. Smith SK, Zimmerman S, Williams CS, Zebrack BJ. Health status and quality of life among non-Hodgkin lymphoma survivors. Cancer 2009;115:3312-23.

35. Smith SK, Mayer DK, Zimmerman S, et al. Quality of life among long-term survivors of non-Hodgkin lymphoma: a follow-up study. J Clin Oncol 2013;31:272-9.

36. Doorduijn J, Buijt I, Holt B, Steijaert M, Uyl-de Groot C, Sonneveld P. Self-reported quality of life in elderly patients with aggressive non-Hodgkin's lymphoma treated with CHOP chemotherapy. Eur J Haematol 2005;75:116-23.

37. Merli F, Bertini M, Luminari S, et al. Quality of life assessment in elderly patients with aggressive nonHodgkin's Lymphoma treated with anthracycline-containing regimens. Report of a prospective study by the Intergruppo Italiano Linfomi. Haematologica 2004;89:973-8.

38. Zebrack BJ, Yi J, Petersen L, Ganz PA. The impact of cancer and quality of life for long-term survivors. Psychooncology 2008;17:891-900.

39. Smith SK, Crespi CM, Petersen L, Zimmerman S, Ganz PA. The impact of cancer and quality of life for post-treatment non-Hodgkin lymphoma survivors. Psychooncology 2010;19:1259-67.

40. Jensen RE, Arora NK, Bellizzi KM, et al. Health-related quality of life among survivors of aggressive non-Hodgkin lymphoma. Cancer 2013;119:672-80. 
41. Bifulco G, De Rosa N, Tornesello ML, et al. Quality of life, lifestyle behavior and employment experience: a comparison between young and midlife survivors of gynecology early stage cancers. Gynecol Oncol 2012;124:444-51.

42. Hall AE, Boyes AW, Bowman J, Walsh RA, James EL, Girgis A. Young adult cancer survivors' psychosocial well-being: a cross-sectional study assessing quality of life, unmet needs, and health behaviors. Support Care Cancer 2012;20:1333-41.

43. Kouroukis T, Meyer R, Benger A, Marcellus D, Foley R, Browman G. An evaluation of age-related differences in quality of life preferences in patients with non-Hodgkin's lymphoma. Leuk Lymphoma 2004;45:2471-6.

44. Coiffier B, Lepage E, Briere J, et al. CHOP chemotherapy plus rituximab compared with CHOP alone in elderly patients with diffuse large-B-cell lymphoma. N Engl J Med 2002;346:235-42.

45. Feugier P, Van Hoof A, Sebban C, et al. Long-term results of the R-CHOP study in the treatment of elderly patients with diffuse large B-cell lymphoma: a study by the Groupe d'Etude des Lymphomes de I'Adulte. J Clin Oncol 2005;23:4117-26.

46. Thieblemont C, Grossoeuvre A, Houot R, et al. Non-Hodgkin's lymphoma in very elderly patients over 80 years. A descriptive analysis of clinical presentation and outcome. Ann Oncol 2008;19:774-9.

47. Diem S, Ess S, Cerny T, Fruh M, Hitz F. Diffuse large B-cell lymphoma in elderly patients: a retrospective analysis. Eur J Intern Med 2014;25:577-82.

48. Mols F, Oerlemans S, Vos AH, et al. Health-related quality of life and disease-specific complaints among multiple myeloma patients up to $10 \mathrm{yr}$ after diagnosis: results from a population-based study using the PROFILES registry. Eur J Haematol 2012;89:311-9.

49. Gulbrandsen N, Hjermstad MJ, Wisloff F, Nordic Myeloma Study G. Interpretation of quality of life scores in multiple myeloma by comparison with a reference population and assessment of the clinical importance of score differences. Eur J Haematol 2004;72:172-80.

50. Delforge $M$, Dhawan R, Robinson $D$, Jr., et al. Health-related quality of life in elderly, newly diagnosed multiple myeloma patients treated with VMP vs. MP: results from the VISTA trial. Eur J Haematol 2012;89:16-27.

51. Dimopoulos MA, Delforge M, Hajek R, et al. Lenalidomide, melphalan, and prednisone, followed by lenalidomide maintenance, improves health-related quality of life in newly diagnosed multiple myeloma patients aged 65 years or older: results of a randomized phase III trial. Haematologica 2013;98:784-8.

52. Dimopoulos MA, Palumbo A, Hajek R, et al. Factors that influence health-related quality of life in newly diagnosed patients with multiple myeloma aged $>/=65$ years treated with melphalan, prednisone and lenalidomide followed by lenalidomide maintenance: results of a randomized trial. Leuk Lymphoma 2014;55:1489-97.

53. Alegre A, Oriol-Rocafiguera A, Garcia-Larana J, et al. Efficacy, safety and quality-of-life associated with lenalidomide plus dexamethasone for the treatment of relapsed or refractory multiple myeloma: the Spanish experience. Leuk Lymphoma 2012;53:1714-21.

54. Verelst SG, Termorshuizen F, Uyl-de Groot CA, et al. Effect of thalidomide with melphalan and prednisone on health-related quality of life (HRQoL) in elderly patients with newly diagnosed multiple myeloma: a prospective analysis in a randomized trial. Ann Hematol 2011;90:1427-39.

55. Niesvizky R, Flinn IW, Rifkin R, et al. Community-Based Phase IIIB Trial of Three UPFRONT BortezomibBased Myeloma Regimens. J Clin Oncol 2015;33(33):3921-9.

56. Cook C, Heath F, Thompson RL. A meta-analysis of response rates in web -or internet-based surveys. Educational and Psychological Measurement 2000;60:821-36.

57. Wheelwright S, Darlington AS, Fitzsimmons D, et al. International validation of the EORTC QLQ-ELD14 questionnaire for assessment of health-related quality of life elderly patients with cancer. $\mathrm{Br} \mathrm{J}$ Cancer 2013;109:852-8.

58. Johnson C, Fitzsimmons D, Gilbert J, et al. Development of the European Organisation for Research and Treatment of Cancer quality of life questionnaire module for older people with cancer: The EORTC QLQ-ELD15. Eur J Cancer 2010;46:2242-52. 
59. Scott $\mathrm{A}$, Jeon $\mathrm{SH}$, Joyce $\mathrm{CM}$, et al. A randomised trial and economic evaluation of the effect of response mode on response rate, response bias, and item non-response in a survey of doctors. BMC Med Res Methodol 2011;11:126.

60. Viera AJ, Edwards T. Does an offer for a free on-line continuing medical education (CME) activity increase physician survey response rate? A randomized trial. BMC Res Notes 2012;5:129.

61. Lowenberg B, Ossenkoppele GJ, Blijlevens NMA, Leebeek FWG, Zweegman S. Klinische epidemiologie van bloed -en lymfeklierkanker in Nederland. Leerboek Hematologie (in Dutch) 2015;Chapter 22: 368-9.

62. Talarico L, Chen G, Pazdur R. Enrollment of elderly patients in clinical trials for cancer drug registration: a 7-year experience by the US Food and Drug Administration. J Clin Oncol 2004;22:462631.

63. Bellera C, Praud D, Petit-Moneger A, McKelvie-Sebileau P, Soubeyran P, Mathoulin-Pelissier S. Barriers to inclusion of older adults in randomised controlled clinical trials on Non-Hodgkin's lymphoma: a systematic review. Cancer Treat Rev 2013;39:812-7.

64. Wildiers $\mathrm{H}$, Mauer $\mathrm{M}$, Pallis $\mathrm{A}$, et al. End points and trial design in geriatric oncology research: a joint European organisation for research and treatment of cancer--Alliance for Clinical Trials in Oncology-International Society Of Geriatric Oncology position article. J Clin Oncol 2013;31:3711-8.

65. Health USDo, Human Services FDACfDE, Research, et al. Guidance for industry: patient-reported outcome measures: use in medical product development to support labeling claims: draft guidance. Health Qual Life Outcomes 2006;4:79.

66. Kvam AK, Waage A. Health-related quality of life in patients with multiple myeloma - does it matter? Haematologica 2015;100:704-5.

67. Muhlbacher AC, Lincke HJ, Nubling M. Evaluating patients' preferences for multiple myeloma therapy, a Discrete-Choice-Experiment. Psycho-Social Medicine 2008;5:Doc10.

68. Hofheinz R, Clouth J, Borchardt-Wagner J, et al. Patient preferences for palliative treatment of locally advanced or metastatic gastric cancer and adenocarcinoma of the gastroesophageal junction: a choice-based conjoint analysis study from Germany. BMC Cancer 2016;16:937.

69. Uemura H, Matsubara N, Kimura G, et al. Patient preferences for treatment of castration-resistant prostate cancer in Japan: a discrete-choice experiment. BMC Urol 2016;16:63.

70. Shafey M, Lupichuk SM, Do T, Owen C, Stewart DA. Preferences of patients and physicians concerning treatment options for relapsed follicular lymphoma: a discrete choice experiment. Bone Marrow Transplant 2011;46:962-9.

71. Gonzalez JM, Ogale S, Morlock R, et al. Patient and physician preferences for anticancer drugs for the treatment of metastatic colorectal cancer: a discrete-choice experiment. Cancer Manag Res 2017;9:149-58.

72. Fu AZ, Graves KD, Jensen RE, Marshall JL, Formoso M, Potosky AL. Patient preference and decisionmaking for initiating metastatic colorectal cancer medical treatment. J Cancer Res Clin Oncol 2016;142:699-706.

73. Nightingale G, Hajjar E, Swartz K, Andrel-Sendecki J, Chapman A. Evaluation of a pharmacist-led medication assessment used to identify prevalence of and associations with polypharmacy and potentially inappropriate medication use among ambulatory senior adults with cancer. J Clin Oncol 2015;33:1453-9.

74. Magdelijns FJ, van Avesaath RE, Pijpers E, Stehouwer CD, Stassen PM. Health-care-related adverse events leading to admission in older individuals: incidence, predictive factors and consequences. Eur J Public Health 2016;26:743-8. 


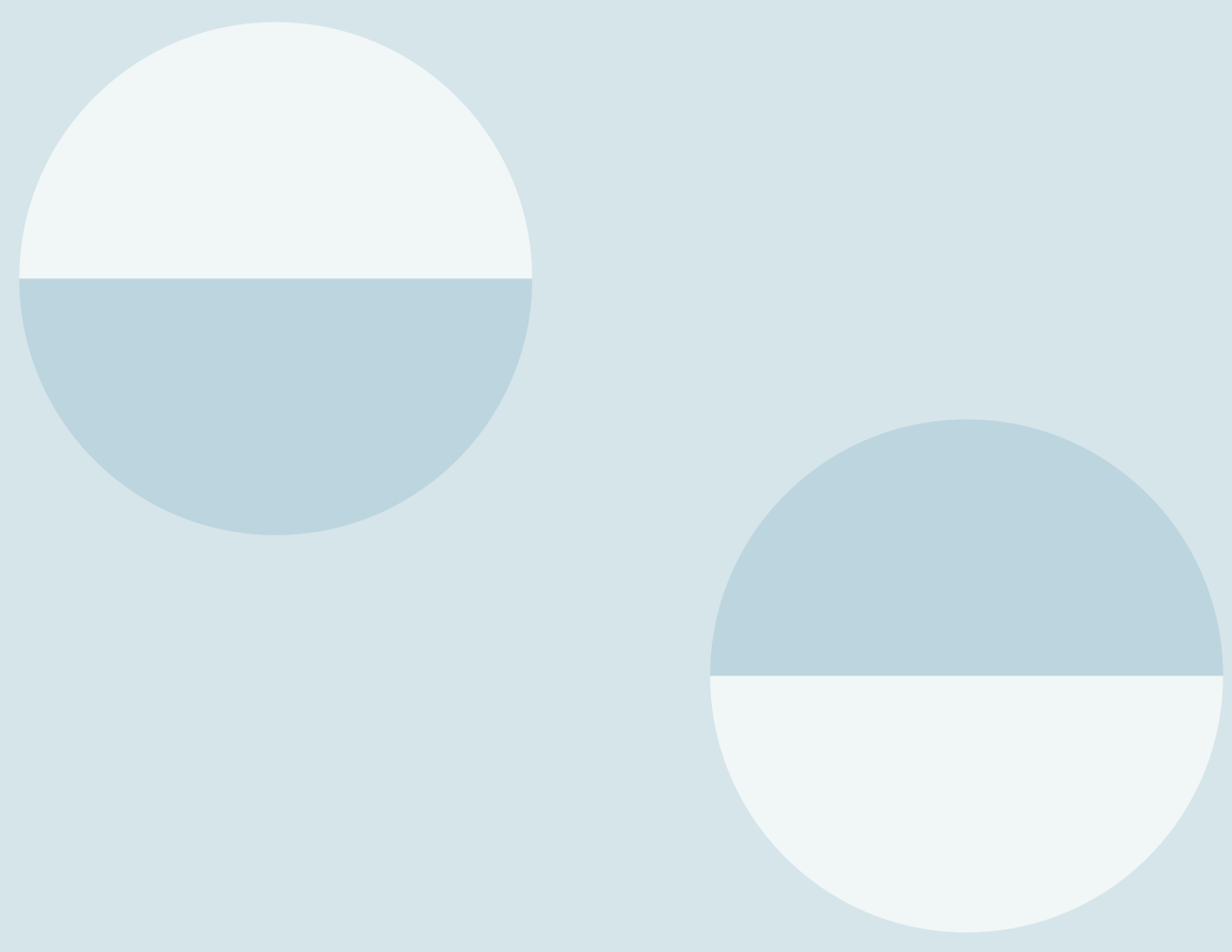
NEDERLANDSE SAMENVATTING 



\section{Nederlandse samenvatting}

In Nederland kregen in 2016 ruim 80.000 mensen van 60 jaar en ouder de diagnose kanker. Bij meer dan 6.500 van deze patiënten betrof het een hematologische maligniteit, zoals lymfeklierklierkanker of leukemie. De meeste hematologische maligniteiten komen vaker voor op hogere leeftijd. Er wordt dan ook verwacht dat het aantal ouderen met een hematologische maligniteit de komende jaren zal stijgen ten gevolge van de vergrijzing van de samenleving.

De twee hematologische maligniteiten die het meeste voorkomen zijn Diffuus Grootcellig B-cel lymfoom (DLBCL) en multipel myeloom (MM). DLBCL is een vorm van lymfeklierkanker, namelijk specifieke type agressief Non-Hodgkin lymfoom (NHL). De gemiddelde leeftijd waarop de diagnose NHL wordt gesteld is 67 jaar. Patiënten met DLBCL kunnen onder andere last krijgen van vergrote lymfeklieren of onbegrepen koorts, gewichtsverlies of nachtzweten. De diagnose wordt gesteld door een biopt (stuk weefsel) te nemen uit een lymfeklier en dit onder de microscoop te onderzoeken. De standaard behandeling van DLBCL bestaat uit zogenaamde immunochemotherapie middels R-CHOP kuren. Hierbij staat iedere letter van de kuur voor een ander geneesmiddel. Het doel van deze behandeling is om mensen te genezen, helaas lukt dit niet altijd.

Bij multipel myeloom is er een kwaadaardige woekering van plasmacellen. Dit kan leiden tot bloedarmoede, een te hoog calcium gehalte, achteruitgang van de nierfunctie of spontane botbreuken. Als de diagnose wordt vermoed kan middels bloedonderzoek worden bekeken of er aanwijzingen zijn voor de ziekte. Uiteindelijk wordt de diagnose bevestigd met beenmergonderzoek. De gemiddelde leeftijd waarop de diagnose wordt gesteld is 69 jaar. Multipel myeloom kan niet genezen worden. Daarom wordt er alleen maar gestart met een behandeling als patiënten negatieve gevolgen van de ziekte ondervinden. Behandeling kan dan bestaan uit (een combinatie van) bestraling, chemotherapie, corticosteroïden, eiwitafbraakremmers, bloedvatgroeiremmers of antilichamen.

DLBCL en MM zijn ziekten die met name op hogere leeftijd voorkomen. Het nemen van behandelbeslissingen bij ouderen met een hematologische maligniteit is complex en bij iedere patiënt moeten de mogelijke voor -en nadelen van een behandeling tegen elkaar afgewogen worden. Deze complexiteit van het nemen van een behandelbeslissing heeft een aantal oorzaken. Ten eerste zijn er weinig klinische studies verricht waar oudere patiënten aan mochten deelnemen, waardoor er relatief weinig wetenschappelijk bewijs is voor de behandeling van deze patiënten. Verder zijn ouderen een heterogene groep, waarbij de algehele conditie varieert van kwetsbaar tot zeer fit. Ook hebben oudere patiënten vaak nog andere ziekten, ook wel comorbiditeiten genoemd.

Tot voor kort waren medische behandelingen met name gericht op verlenging van leven. De laatste jaren is er echter steeds meer aandacht gekomen voor kwaliteit van 
leven. Dit is ook bij ouderen zeer belangrijk, aangezien de balans tussen de voordelen en risico's van een behandeling delicaat is. Zo kan bij patiënten met een hematologische maligniteit de kwaliteit van leven beïnvloed worden door de ziekte zelf, alsook door de behandeling. Een behandeling kan enerzijds een negatieve invloed hebben op kwaliteit van leven, bijvoorbeeld ten gevolge van bijwerkingen. Anderzijds kan de kwaliteit van leven uiteindelijk ook verbeteren, doordat de ziekte wordt teruggedrongen.

Dit proefschrift is opgedeeld in twee delen. Het eerste deel beschrijft het nemen van behandelbeslissingen door hematologen bij oudere patiënten met een hematologische maligniteit. In het tweede deel wordt de kwaliteit van leven van oudere patiënten met DLBCL en MM beschreven.

Hoofdstuk 1 van het proefschrift beslaat een algemene introductie over ouderen met DLBCL en MM, de rol van geriatrische assessment in het nemen van behandel beslissingen en het belang van kwaliteit van leven als uitkomstmaat.

\section{Deel I - Behandelbeslissingen}

In hoofdstuk 2 hebben we onderzocht welke factoren van invloed zijn op het nemen van behandelbeslissingen door hematologen bij oudere patiënten met een hematologische maligniteit. Dit hebben we gedaan door een enquête te houden onder hematologen in Nederland. Wij vonden dat comorbiditeiten een belangrijke rol spelen in het nemen van een behandelbeslissing. Met name cognitieve stoornissen (bijvoorbeeld dementie) en hart -en vaataandoeningen speelden een grote rol. Verder werd er ook rekening gehouden met de mate waarin mensen de handelingen zelfstandig kunnen doen die dagelijks in het gewone leven verricht worden. Verder gaven hematologen aan dat ze bij ouderen regelmatig een lagere dosering chemotherapie geven uit angst voor bijwerkingen en dat de behandeling van ouderen bemoeilijkt wordt door gebrek aan wetenschappelijk bewijs.

In hoofdstuk 3 gingen we verder op dit onderwerp in door vignetten (casussen) voor te leggen aan hematologen over oudere patiënten met DLBCL. Hierbij gaven hematologen aan dat zij ouderen met DLBCL die verder helemaal gezond waren zouden behandelen met een volledige dosis chemotherapie, zoals dit ook bij jongeren gebeurd. In aanwezigheid van andere ziekten of indien er geen sociaal netwerk is, werden patiënten minder vaak behandeld en dit effect was meer uitgesproken op hogere leeftijd.

Om te bestuderen of de bevindingen uit bovenstaande enquête overeenkomen met wat er in de dagelijks praktijk gebeurd, onderzochten we in hoofdstuk $\mathbf{4}$ met behulp van gegevens van de Nederlandse Kanker Registratie wat het effect was van leeftijd en comorbiditeit op de behandeling van ouderen met DLBCL. Hierbij bleek dat de toediening van standaard immuno-chemotherapie (R-CHOP) daalde met het stijgen 
van de leeftijd van de patiënt en dat een aanzienlijk deel van de patiënten een verminderd aantal kuren kreeg. Leeftijd 75 jaar en ouder, hartziekten, spier/bindweefsel/gewrichtsziekten, urogenitale ziekten en ziekten van het centraal zenuwstelsel verlaagden de kans om een behandeling te krijgen die als doel heeft genezing van de ziekte.

Op basis van deze bevindingen hebben we geconcludeerd dat comorbiditeiten, maar ook hoge leeftijd op zichzelf, een grote invloed hebben op het maken van behandelbeslissingen, zoals het krijgen van een behandeling met als doel genezing bij DLBCL. Verder observeerden wij dat er een discrepantie is tussen wat hematologen aangeven in de enquête (namelijk dat zij een oudere patiënt zonder andere relevante ziekten een standaard behandeling zouden geven) en wat er in de dagelijkse praktijk gebeurt (waarbij hogere leeftijd de kans op het krijgen van een dergelijke behandeling kleiner maakt).

\section{Deel II - Kwaliteit van leven}

In dit deel wordt de invloed van de diagnose en behandeling van DLBCL en MM op kwaliteit van leven van ouderen beschreven. Hierbij maakten we gebruik van specifieke vragenlijsten. De kwaliteit van leven van oudere patiënten werd vergeleken met die van jongere patiënten en met een normpopulatie (een steekproef uit de Nederlands bevolking).

In hoofdstuk 5 werd kwaliteit van leven bij patiënten met DLBCL onderzocht in drie leeftijdscategorieën, namelijk 18-59 jaar, 60-75 jaar en ouder dan 75 jaar. Het bleek dat de oudste groep patiënten op een aantal domeinen van kwaliteit van leven slechter scoorde dan de jongeren. Financiële problemen kwamen minder vaak voor bij ouderen. Echter, de verschillen in kwaliteit van leven tussen patiënten en de normpopulatie, waren groter voor jongeren dan voor ouderen. Dit duidt erop dat de invloed van DLBCL op kwaliteit van leven groter is voor jongeren dan voor ouderen.

Kwaliteit van leven bij patiënten met MM werd onderzocht in hoofdstuk 6 . We vergeleken twee leeftijdsgroepen met elkaar, namelijk patiënten van 65 jaar en jonger versus patiënten ouder dan 65 jaar. Ook werden patiënten van deze twee leeftijdsgroepen weer vergeleken met een normpopulatie. Er werden geen grote verschillen gevonden in kwaliteit van leven tussen jongere en oudere patiënten, behalve financiële problemen, welke vaker voorkwamen bij jongeren. In vergelijking met de normpopulatie observeerden we dat de kwaliteit van leven van jongere MM patiënten meer verslechterd was dan van oudere MM patiënten. Echter, in beide leeftijdsgroepen gaven patiënten aan veel klachten te hebben.

Op basis van deze resultaten concludeerden wij dat angst voor verslechtering van kwaliteit van leven geen argument is om af te zien van een mogelijk genezende behandeling bij ouderen met DLBCL. Een dergelijke behandeling moet dan ook altijd overwogen worden, ongeacht de leeftijd. Verder concludeerden wij dat de ziektelast 
bij $\mathrm{MM}$ voor zowel jongeren als ouderen hoog is, en dat naast verlengen van leven ook verbeteren van kwaliteit van leven een belangrijk doel van de behandeling moet zijn.

Tot slot, worden in hoofdstuk 7 de belangrijkste bevindingen van dit proefschrift samengevat en bediscussieerd. Verder worden de tekortkomingen in de onderzoeksmethoden beschreven en worden aanbevelingen gedaan voor toekomstig onderzoek. 



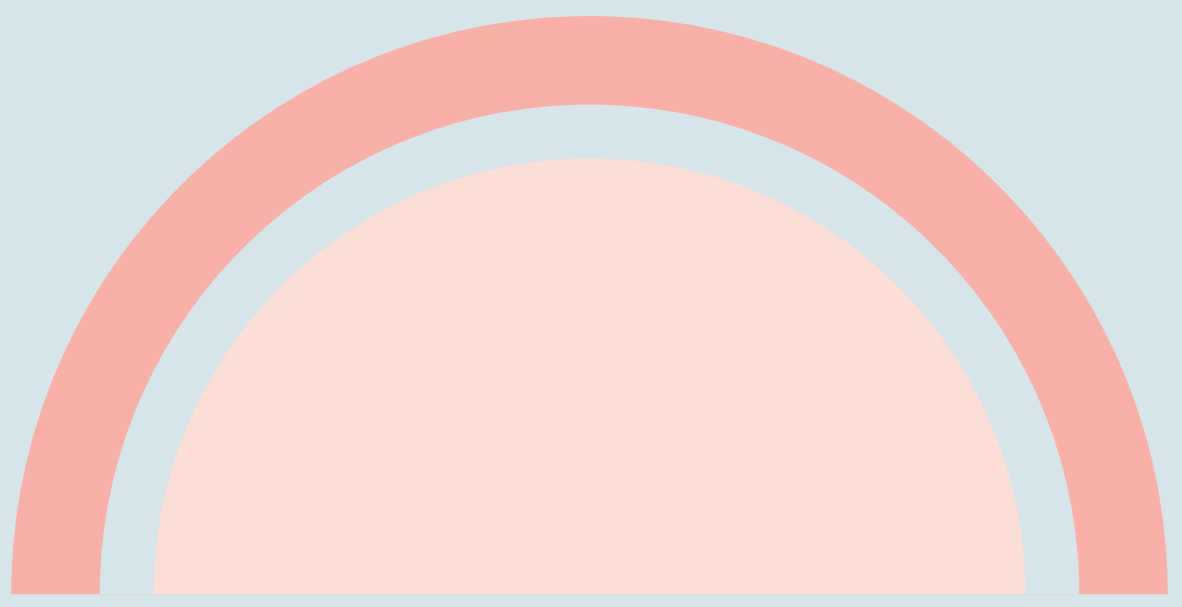




\section{VALORISATION ADDENDUM}





\section{Valorisation addendum}

Valorisation is defined as "the process of creating value from knowledge, by making knowledge suitable and/or available for social (and/or economic) use and by making knowledge suitable for translation into competitive products, services, processes and new commercial activities". In this addendum the relevance of the knowledge gained from the studies described in this thesis is addressed.

Most hematological malignancies occur at higher age. In the Netherlands, 3607 patients aged 60-74 years old and 2732 patients aged 75 years and older were diagnosed with a hematological malignancy in 2016..$^{1}$ Due to changes in population demographics and treatment results, the number of elderly patients with a hematological malignancy is expected to increase even further. Despite the high incidence of older adults with hematological malignancies, many questions are left unanswered in this patient category.

This thesis aimed to provide insight into treatment-decision making by hematologists in elderly patients. Aspects such as the influence of comorbidity, cognitive disorders and functional status on treatment-decision making were studied. Further, the association between socio-demographic and clinical variables, including specific comorbid conditions, and treatment with curative treatment was investigated. In addition, the impact of being diagnosed with and treated for Diffuse Large B-cell Lymphoma (DLBCL) or Multiple Myeloma (MM) on the health-related quality of life (HRQOL) of elderly patients was investigated.

In our opinion, this thesis is relevant for patients, hematologists and society.

\section{Relevance for patients}

Treatment-decision making involves in the first place our patients. Factors, such as comorbidities, that influence the process of treatment-decision making by hematologists have a major impact on the therapy proposed to the patient. Increasing the awareness among hematologists about the process of treatment-decision making in elderly patients, will lead to even more considerate treatment decisions. Hopefully, treatment with curative intent will be considered in all elderly patients regardless of age, ensuring that elderly patients receive the treatment that they will benefit from. Discussing all treatment options with patients will lead to improved shared-decision making and higher patient satisfaction.

Further, the results of our HRQOL studies are of major relevance to our patients. Insights into the effect of a disease and its treatment on HRQOL may also influence treatment-decision making by hematologists and patients. Our studies showed that a premise of declining HRQOL should not be dominant in the choice of treatment. 


\section{Relevance for hematologists}

It is important for hematologists to increase the awareness of the factors that influence treatment-decision making. We observed in this thesis that there is a discrepancy between what hematologists think they practice and what they actual practice. Being aware of this might be practice changing. An example is creating awareness among hematologists about the fact that there is a group of elderly patients receiving suboptimal therapy for reason of their high age.

Further, our HRQOL studies showed that the impact of DLBCL and MM and its treatment has less impact on HRQOL of elderly patients than younger patients. This knowledge may influence the way hematologists think about treatment in the elderly. In addition, this is of importance in informing our patients. It aids in making more informed, individualized treatment decisions in daily practice and therefore this can lead to improved shared-decision making.

Lastly, the studies presented in this thesis might inspire other researchers to focus their work on elderly patients with hematological malignancies. This is of importance, since hematologists feel that treatment-decision making in the elderly is complex due to a lack of scientific evidence.

\section{Relevance for society}

Increasing our knowledge on elderly patients with hematological malignancies is of relevance for our society, since the incidence of this patient category is high and due to demographic changes is expected to increase. As a consequence, older adults with hematological malignancies will increasingly claim our healthcare system.

In addition, studying patient reported outcomes (PRO's) is of importance to society. HRQOL, an example of a PRO, helps to better understand treatment effectiveness. Until recently, traditional outcome parameters such as progression-free survival and overall survival, were the most important when determining whether a treatment demonstrated benefit. However, PRO's are more and more embraced as important outcome measures to determine treatment effectiveness ${ }^{2}$. In the approval of novel drugs or drug combinations, PRO's will also influence health policy-makers since regulatory agencies such as the FDA (Unites states Food and Drug Administration) and EMA (European Medicines Agency) have endorsed assessment of PRO's in clinical trials.

Hopefully the studies presented in this thesis contribute to the awareness of the importance of PRO's. 


\section{References}

1. http://www.cijfersoverkanker.nl.

2. Efficace F, Gaidano G, Lo-Coco F. Patient-reported outcomes in hematology: is it time to focus more on them in clinical trials and hematology practice? Blood 2017;130:859-66. 


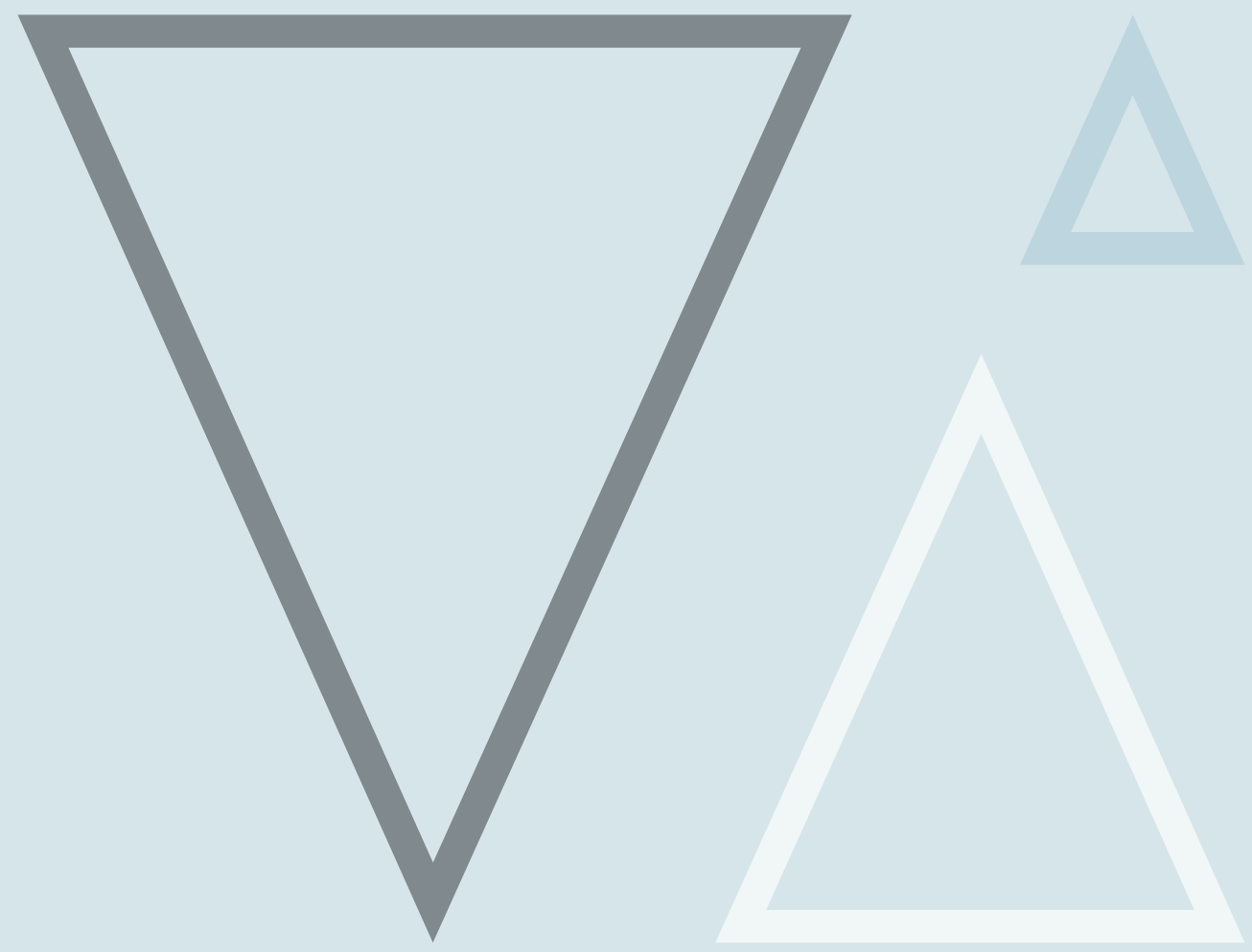




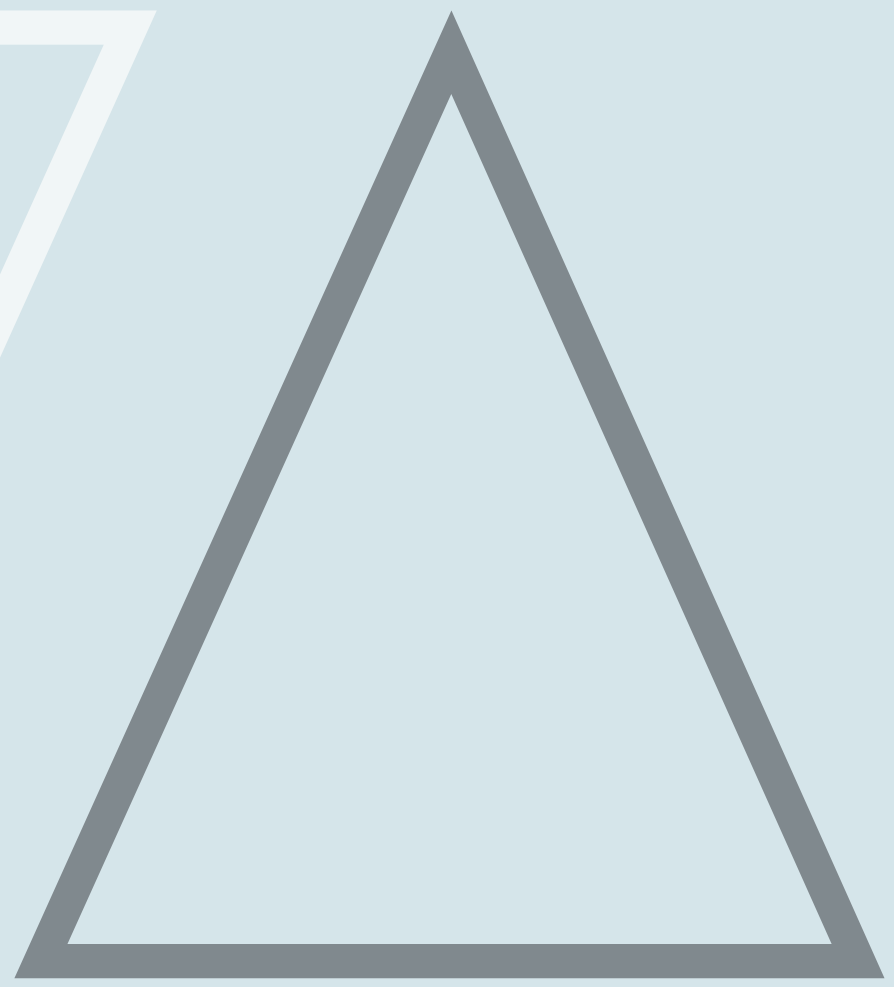

DANKWOORD 



\section{Dankwoord}

$\mathrm{Na}$ een aantal jaren werken aan dit proefschrift is het nu dan zo ver: het dankwoord kan geschreven worden. Er waren soms tegenslagen, maar er waren ook genoeg momenten om successen te kunnen vieren. Al deze momenten bij elkaar zijn samengebundeld met dit proefschrift als resultaat.

Zonder hulp van velen was het mij niet gelukt dit proefschrift te schrijven en deze mensen wil ik dan ook in het bijzonder bedanken.

Allereerst wil ik prof. dr. H.C. Schouten bedanken.

Beste Harry, het is al weer heel wat jaren geleden dat we elkaar hebben leren kennen tijdens mijn stage algemene interne geneeskunde op de afdeling hematologie. Ik was nog niet zo lang bezig met mijn opleiding tot internist en tijdens deze stage is mijn interesse voor de hematologie gewekt. Toen is ook het idee ontstaan om onderzoek te doen naar ouderen. Dankzij jouw begeleiding en contacten is dit proefschrift uiteindelijk tot stand gekomen. Het feit dat je deur altijd open stond (letterlijk) maakte dat ik laagdrempelig kon binnenlopen voor overleg. Niet alleen heb je me begeleid tijdens dit promotietraject, maar ook in mijn opleiding tot hematoloog. De manier waarop je patiënten benadert, empathisch, open, eerlijk en met respect, is zeker een voorbeeld voor mij. Dank ook dat ik de mogelijkheid heb gekregen om na het afronden van mijn opleiding in het MUMC te blijven werken en voor je begeleiding in mijn nog prille carrière als hematoloog. Ik ben blij dat ik de komende tijd nog met je mag samenwerken, zowel in de kliniek als tijdens congressen. Ik ga er dan ook vanuit dat de steak-afspraak bij Ruth's Chris steakhouse tijdens ASH 2018 nog altijd staat $;$.

Uiteraard wil ik ook prof. dr. L.V. van de Poll-Franse bedanken.

Beste Lonneke, jij bood mij de kans om gebruik te maken van de PROFILES data om onderzoek te kunnen doen naar kwaliteit van leven. Zonder jou hadden deze hoofdstukken in mijn proefschrift nooit tot stand kunnen komen. Ook heb je voor mij een belangrijke rol gespeeld in het laatste manuscript dat ik voor mijn proefschrift heb geschreven, waarbij jou contacten heel belangrijk bleken te zijn. Tot slot waren de opmerkingen en suggesties die je had bij de manuscripten altijd heel waardevol. Jouw kritische blik leidde zeker tot belangrijke verbeteringen.

Verder wil ik graag de leden van de beoordelingscommissie, Prof. dr. V.C.G. Tjan Heijnen, Prof. dr. J.W. Coebergh, Dr. J.K. Doorduijn en Prof. dr. C.D.A. Stehouwer, bedanken voor het kritisch doorlezen van mijn proefschrift.

Mijn dank gaat ook uit naar alle medeauteurs van de artikelen voor het kritisch meedenken. In het bijzonder wil ik Simone Oerlemans en Avinash Dinmohamed bedanken. 
Beste Simone, we hebben elkaar leren kennen via Lonneke en samengewerkt aan de kwaliteit van leven artikelen. Ik heb de samenwerking altijd prettig gevonden. Met name ook dank voor je hulp bij de statistiek en al je goede suggesties en opmerkingen bij het beoordelen van de manuscripten! Ik zou het ontzettend leuk vinden als we ook in de toekomst nog zouden kunnen samenwerken.

Beste Avinash, zonder jou had het laatste hoofdstuk dat ik wilde schrijven voor dit proefschrift nooit tot stand kunnen komen. Ik ben je enorm dankbaar voor al je inzet en hulp, zodat dit uiteindelijk gerealiseerd kon worden! We komen elkaar tegenwoordig regelmatig tegen op de verschillende HOVON werkgroep vergaderingen en ik hoop dat we in de toekomst nog vaak mogen samenwerken aan vele projecten.

Daarnaast wil ik graag een aantal collega's, Fabienne, Saskia en Floor, bedanken voor de fijne samenwerking en gezelligheid.

Lieve Fabienne, ik geloof dat er in onze carrières een aantal overeenkomsten zijn. We hebben elkaar alweer heel wat jaren geleden leren kennen in het Orbis Medisch Centrum. Jij was daar destijds als semi-arts, ik was net ANIOS. Ik geloof dat we aanvankelijk het liefst beiden in het Orbis onze opleiding tot internist hadden willen beginnen, maar we zouden terechtkomen in het MUMC. Beiden zijn we achteraf ook heel blij dat het zo gelopen is, want dit heeft ons gebracht waar we nu zijn. Jij hebt je promotie inmiddels al afgerond, ik nu bijna, we werken allebei nog in het MUMC en delen zelfs een kamer. Misschien dat deze overeenkomsten maakten dat we door anderen vaak met elkaar verwisseld werden, zeker toen we ook nog samen de roosters maakten! Dank voor al de gezellige praatjes en zeker ook voor al je bemoedigende woorden! Hopelijk kunnen we in de toekomst onze krachten bundelen voor onderzoek en zorg bij ouderen in de hematologie. Ik ben dan ook heel blij dat je mijn paranimf wil zijn!

Lieve Saskia, we hebben onze opleiding tot internist-hematoloog voor een groot deel samen doorlopen. We hebben elkaar leren kennen toen we samen onze algemene interne polikliniek stage deden en we konden het toen al goed met elkaar vinden. Ik kan me uit die periode ook nog goed een incident herinneren waarin we uitgerekend tijdens de ROIG hematologie op ons kop kregen omdat we teveel aan het kletsen waren! Ook tijdens het aandachtsgebied hematologie hebben we het leuk gehad: van het tripje naar Malaga samen met Floor, tot de labstage bloedtransfusie waarbij meteen een potje test-erytrocyten weggegooid kon worden nadat ze ons daar 1 minuut mee alleen hadden gelaten! Jij werkt inmiddels in het Radboud in Nijmegen, maar ik ben er van overtuigd dat wij contact houden. Dank voor de fijne samenwerking, de gezelligheid en de motiverende woorden. Ik vind het dan ook ontzettend leuk dat jij mijn paranimf wil zijn!

Lieve Floor, ook wij hebben ons aandachtsgebied hematologie grotendeels samen doorlopen en inmiddels zijn ook wij kamergenootjes in het MUMC. Jij bent momenteel ook bezig met je promotieonderzoek en ook jij combineert dit met je 
werk. Een keer bij elkaar kunnen klagen is dan ook heel fijn, maar nog fijner is natuurlijk het genieten als er een succes geboekt is!

Beste Tiny, uiteraard wil ik jou ook bedanken voor al je hulp bij dit proefschrift. Dank voor het klaarmaken van dit proefschrift voor de beoordelingscommissie, je snelle reacties op mails als ik weer met wijzigingen kwam, maar zeker ook voor je interesse over de voortgang van mijn promotie.

Zonder de steun van mijn familie was het mij niet gelukt om dit proefschrift te schrijven naast mijn (inmiddels afgeronde) opleiding.

Lieve papa en mama, dank jullie wel van al jullie hulp en gezelligheid. Jullie hebben me altijd gesteund in de keuzes die ik gemaakt heb en jullie bieden altijd jullie hulp aan voor zover mogelijk en geven goede adviezen. Dank jullie wel ook voor al de gezellige momenten die we samen beleven, zeker ook tijdens de lekkere dinertjes bij jullie thuis. En natuurlijk wil ik jullie ook bedanken voor alle oppasuurtjes die jullie inmiddels bij ons thuis doorbrengen als wij aan het werk zijn, waarbij jullie ook nog eens altijd bereid zijn extra in te springen als ik er door bijvoorbeeld een congres op mijn vrije dag niet ben voor Eline. Ik zou niet zo goed weten hoe ik het zonder al jullie hulp allemaal zou moeten doen. Ik hou van jullie!

Lieve Dennis, we zijn al weer heel wat jaren gelukkig samen en jij hebt dan ook alles meegekregen van mijn promotietraject. Ik heb in de weekenden heel wat uurtjes achter mijn computer doorgebracht en je hebt me daar altijd mijn gang in laten gaan. Jij bent heel belangrijk voor mij en jij hebt mij enorm geholpen om dit proefschrift te kunnen afronden. Van je relativerende woorden bij een tegenslag, waarin het je vaak lukte om me uiteindelijk om de situatie te laten lachen, tot de champagne bij de succesmomenten en je kookkunsten in de weekenden, het heeft me allemaal geholpen.

Lieve Eline, jij bent nog een beetje te klein om het allemaal mee te krijgen en het meeste van dit werk is gedaan voor jouw komst of terwijl je sliep. Toch heb je me zonder dat jij je daar bewust van bent ook geholpen, door de nodige afleiding en gezelligheid die je brengt; tenslotte gaan met duplo spelen en aan een proefschrift werken moeilijk tegelijkertijd! Je helpt me om alles te relativeren en ik geniet er altijd van om jou aan het einde van een werkdag weer lekker te kunnen knuffelen.

Lieve Dennis en Eline, we hebben het heel fijn met zijn drieën en ik hou heel veel van jullie! 

ABOUT THE AUTHOR 



\section{About the author}

Marjolein Wilhelmina Maria van der Poel was born on October $20^{\text {th }} 1983$ in Kerkrade, the Netherlands. In 2002 she graduated from pre-university education at College Rolduc in Kerkrade. She started medical school in 2003 at Maastricht University, Maastricht, the Netherlands and obtained her medical degree in 2009. Subsequently, Marjolein started working as a resident at the internal medicine department of Orbis Medical Centre in Sittard. She soon realized that she wanted to become a specialist in internal medicine and in 2010 she started her training to become an internist at Maastricht University Medical Centre, under the supervision of prof. dr. Coen Stehouwer (chair) and prof. dr. Richard Koopmans (acting trainer). During her internship at the department of hematology, Harry Schouten (professor of medicine and hematology) gave Marjolein the opportunity to conduct research in the field of elderly patients. The results of this research are presented in this thesis. In 2014 Marjolein started her fellowship hematology, which she finished in 2016. Currently, she is working as hematologist at Maastricht University Medical Centre. 




